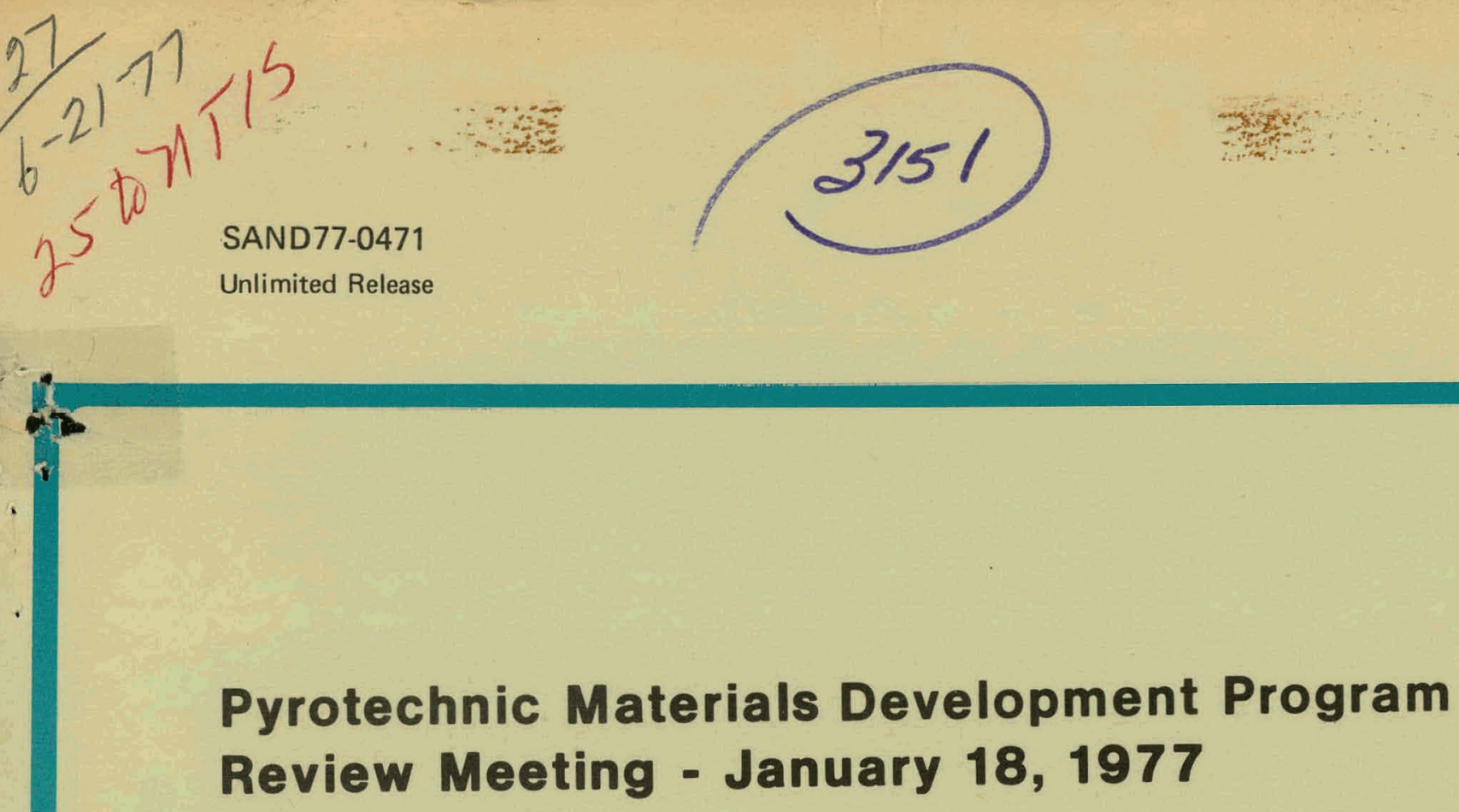

\title{
Pyrotechnic Materials Development Program Review Meeting - January 18, 1977
}

Rod K. Quinn, Editor

Prepared by Sandia Laboratories. Albuquerque New Mexico 87115 and Livermore, Californa 94550 for the United States Energy Research and Development Administration under Contract AT (29.1) 789 Printed April 1977 


\section{DISCLAIMER}

This report was prepared as an account of work sponsored by an agency of the United States Government. Neither the United States Government nor any agency Thereof, nor any of their employees, makes any warranty, express or implied, or assumes any legal liability or responsibility for the accuracy, completeness, or usefulness of any information, apparatus, product, or process disclosed, or represents that its use would not infringe privately owned rights. Reference herein to any specific commercial product, process, or service by trade name, trademark, manufacturer, or otherwise does not necessarily constitute or imply its endorsement, recommendation, or favoring by the United States Government or any agency thereof. The views and opinions of authors expressed herein do not necessarily state or reflect those of the United States Government or any agency thereof. 


\section{DISCLAIMER}

Portions of this document may be illegible in electronic image products. Images are produced from the best available original document. 
Issued by Sandia Laboratories, operated for the United States Energy Research \& Development Administration by Sandia Corporation.

\section{NOTICE}

This report was prepared as an account of work sponsored by the United States Government. Neither the United States nor the United States Energy Research \& Development Administration, nor any of their employees, nor any of their contractors, subcontractors, or their employees, makes any warranty, express or implied, or assumes any legal liability or responsibility for the accuracy, completeness or usefulness of any information, apparatus, product or process disclosed, or represents that its use would not intringe privately owned rights.

Printed in the United States of America

Available from

National Technical Information Service

U. S. Department of Commerce

5285 Port Royal Road

Springfield, VA 22161

Price: Printed Copy $\$ 5.00$; Microfiche $\$ 3.00$ 
SAND77-0471

Unlimited Release

Printed April 1977

PYROTECHNIC MATERIALS DEVELOPMENT PROGRAM REVIEW MEETING - JANUARY 18, 1977

Edited by Rod K. Quinn

Explosive Materials Division 2516

Sandia Laboratories

Albuquerque, New Mexico 87115

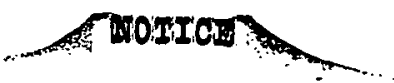

PORTIONS OF THIS REPORT ARE IILEGIBLE. It.

has been reproduced from the best available oopy t.o permit the broadest possible availo ability.

\section{ABSTRACT}

Ciurrent programs boing conducted at Sandia Laboralurles and Mound Laboratory in $\mathrm{Ti} / \mathrm{KClO}_{4}$ and $\mathrm{TiH}_{0.65} / \mathrm{KClO}_{4}$ pyrotechnic materials were reviewed. The subjects included chemlcal and mechanical properties of the starting materials and blends; e. g. , electrical resistivity, chemical and mechanical analysis, and compatibility/stability studies; special problems associated with surface analysis of these materials; and results on mathematical modeling of ignition. After the presentations, a panel discussion was held. Suggestions for future actlons in electrical and thermal conductivity, electrostatic pulse testing effects, ignition characteristics, pyrotechnic burn rate, compatibility. and communication of results were made.

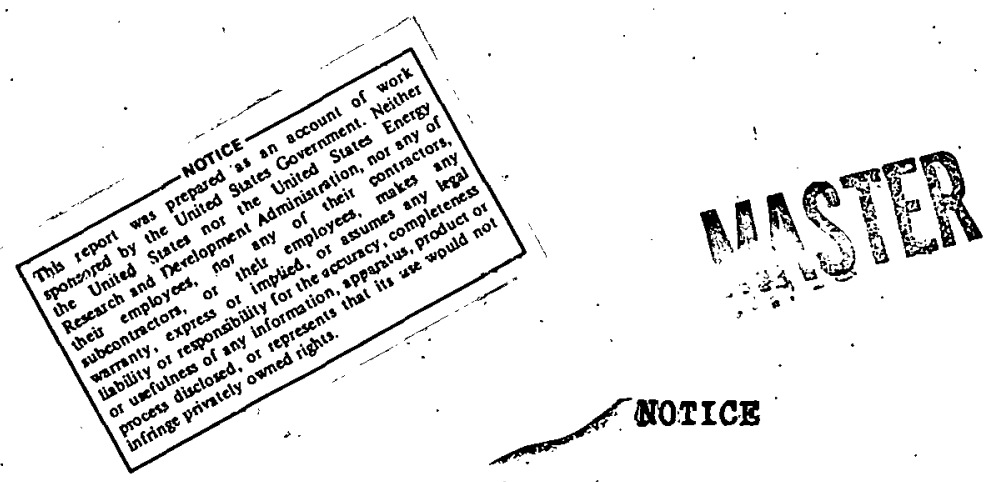

PORTIONS OF THIS REPORT ARE ILLEGIBLE. I Was been reproduced irom tre best avallable, copy to permit tho broadestpossible avail-i ability.

PISTRIBUTION OF THIS DOCUIMENT IS UNLIMITED 
Introduction

Properties of the Starting Materials

Titanium Subhydride Fuel Synthesis

7

Characterization of Adsorbed $\mathrm{H}_{2} \mathrm{O}$ on High-Surface Titanium . . . 8

Oxidation Studies of $\mathrm{Ti}$ and $\mathrm{TiH}_{\mathbf{x}}$ in Perchlorate Environment $\quad \therefore \quad 8$

Materials Properties of $\mathrm{Ti} / \mathrm{KClO}_{4}$ and $\mathrm{TiH}_{\mathrm{x}} / \mathrm{KClO}_{4}$ Blends $\quad \ldots$

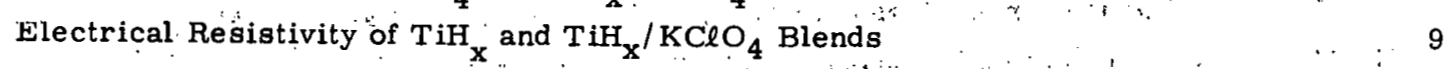

$\mathrm{X}$-Ray Diffraction Analyses of the $\mathrm{TiH}_{\mathbf{x}} / \mathrm{KClO}_{4}$ System $\ldots \ldots$

Thermal Analyses of the $\mathrm{TiH}_{\mathbf{x}} / \mathrm{KClO}_{4}$ System $\quad \ldots \quad 10$

Thermomechanical Analysis of $\mathrm{TiH}_{\mathbf{x}} / \mathrm{KClO}_{4}$ Blends $\ldots, \ldots$

Compatibility Studies $\quad \therefore \quad+\cdots:+\cdots+\cdots$

Compatibility/Stability of $\mathrm{TiH}_{\mathrm{x}} / \mathrm{KClO}_{4}$ Blends $\mathrm{Al} \cdots$

Compatibility Program of Pyrotechnic Materials at Mound 11

Additional Materials Studies $\quad$ - 12

Compaction Studies of Pyrotechnic Blends . $\quad 12$

Surface Studies of Pyrotechnic Materials Used in Thermal Batteries. 12

$\begin{array}{ll}\text { Mathematical Modeling } & 13\end{array}$

Modeling of Pyrotechnic Ignition $\quad 13$

Summary of Panel Discussion $\quad 13$

Electrical and Thermal Conductivity of Pyrotechnic Materials 13

Electrostatic Pulse Testing and Its Effect on Unit Resistance $\quad \cdot 14$

Ignition Characteristics $\quad$. 14

Burn Rate Studies $\quad 14$

Compatibility $\quad 15$

Communication $\quad 15$ 
1-9 Viewgraphs from Presentation by R. S. Carlson 18-23

10-17 Viewgraphs from Presentation by R. C. Bowman, Jr., et al.

$26-28$

18-34 Viewgraphs from Presentation by R. K. Quinn

30-35

35-42 Viewgraphs from Presentation by J. W. Reed (1), et al.

$38-41$

43-55 Viewgraphs from Pregentation by D. B. Sullenger

44-49

56-64 Viewgraphs from Presentation by J. W. Reed (2), et al.

$52-56$

65-76 Viewgraphs from Presentation by T. M. Massis-(1), et al.

58-63

77-87 Viewgraphs from Presentation by T. M. Massis (2), et. al.

66-71

88-101 Viewgraphs from Presentation by L. W. Collins, et al:

74-79

102-109. Viewgraphs from Presentation by A. C. Munger

$82-84$

110-115. Vlewgraphs from Presentation by W. E. Swartz

86-88

116- 122

Viewgraphs from Presentation by $A$.

A. Donaldson

$90-93$ 


\section{PYRÖTÉCHNIC MATERIALS DEVELOPMENTT PROGRAM REVIEW MEETING - JANUARY 18, 1977}

Introduction

This is the first report on advanced development programs on pyrotechnic materials at Mound Laboratory and Sandia Laboratories. The report consists primarily of summaries of presentations at the first semiannual meeting and is divided into six sections corresponding to the general categories into which the programs fall. A conclusion summarizes the panel discussion and emphasizes subjects that require special attention.

The purpose of these meetings is to review individual and group technical programs in pyrotechnic materials, especially as they relate to pyrotechnic component development. The development programs range from basic materials synthesis and properties to compatibility and mechanical data on pyrotechnic blends.

\section{Properties of the Starting Materials}

Titanium Subhydride Fuel Synthesis (R. S. Carlson).

Titanium subhydride $\left(\mathrm{TiH}_{0.65}\right.$ ) fuel, manufactured in $150-\mathrm{g}$ lots by Method $\mathrm{v}$ in a horizontal furnace and-reactor; was developed through several stages of lot size and preparation method. The current Method $V$ involves preparation from $\mathrm{TiH}_{2}$ by removing gas at constant temperatures $\left(438.5^{\circ} \mathrm{C}\right.$ ) for approximately 20 hours followed by cooling and passivating. A new horizontal rotating reactor capable of preparing a $1.5-\mathrm{kg}$ batch is in design. Thus, the samples will be heated in a more precisely: controlled furnace. Experiments in connection with the passivation step have shown that $\mathrm{O}_{2}$ takeup per square meter is relatively constant from batch to batch and accounts for 10 20 percent of the total $\mathrm{O}_{2}$ present in the subhydride: Composition vs. dehydriding temperature curves are related to the phase diagram, and a plot of final dynamic pressure at the end of the dehydriding step vs: composition at approximately $438.5^{\circ} \mathrm{C}$ can be used to halt accurately the process at any stoichiometry desired within closer tolerances than before. "Van't Hoff 'plots" of inverse temperature vs. log pressure for two samples of $\mathrm{TiH}, 0.67-0.69$ prepared from different starting materials and for $\mathrm{TiH}_{0.68}$ and $\mathrm{TiD}_{0.69}$ prepared from the same starting material show that there is no isotopic effect, verifying work by Haag and Shipko that the effect of differing impurity levels in the starting materials on the composition-pressure-temperature relationship is very important. Thermodynamic values for $\Delta H$ and $\Delta S$ are derived and are comparable to those of other workers. The plot also shows that the equilibrium pressure for $\mathrm{TiH}_{0.68}$ at. $35 \mathrm{n}^{\circ} \mathrm{C}$ is $0.05 \mathrm{~mm}$ or less, and that hysteresis is not present. Viewgraphs for this talk are shown in Figs. 1-9. 
Characterization of Adsorbed $\mathrm{H}_{2} \mathrm{O}$ on High-Surface Titanium (R. C. Bowman, Jr., A. Attalla, R. L. Yauger, C. M. Love, B. D. Craft)

The titanium metals being utilized in the pyrotechnic program are normally shipped and stored underwater. Although these materials undergo a drying procedure prior to blending with $\mathrm{KClO}_{4}$, questions have arisen on the concentration of adsorbed water on the surface and the possible detrimental effects on the initiation process and stability of the pyrotechnic blend.

In the present study, various analytical methods are applied to evaluate the effectiveness of two specific drying procedures on moisture removal from high surface $\mathrm{TiH}_{0.15}$ (QC-1779). The readsorption of water vapor was also investigated. Nuclear magnetic resonance (NMR) measurements lead to a determination of the adsorbed " $\mathrm{H}_{2} \mathrm{O}$ " concentrations. The proton.spin counts obtained by pulse NMR techniques have sufficient sensitivity to establish the following conclusions:

1. A significant amount of surface water is retained by high surface area Ti (i. e., $\sim 1.2$ weight percent for QC-1779 without drying at elevated temperature).

2. The conventional drying procedures are only partially effective in removing adsorbed $\mathrm{H}_{2} \mathrm{O}$.

3. Dried $\mathrm{TiH}_{\mathbf{x}}$ will readsorb water from the air during room-temperature exposure where humidity is an important parameter.

Viewgraphs for this talk are shown in Figs. 10-17.

Oxidation Studies of $\mathrm{Ti}$ and $\mathrm{TiH}_{\mathrm{x}}$ in Perchlorate Environment ( $\mathrm{R}, \mathrm{K}$, Quinn)

In order to determine the role of oxide layers in compatibility, passivity, and spark sensitivity, we are examining the surface and interfacial chemistry of certain pyrotechnic materials. Initial experiments involved electrochemical oxidation of $\mathrm{Ti}$ thin films in $\mathrm{KClO}_{4}$ solutions. The effects of the perchlorate medium on the oxidation of titanium metal are of interest, since these corrosive environments are extreme simulations of that potentially experienced by $\mathrm{Ti} / \mathrm{KClO} \mathrm{O}_{4}$ and $\mathrm{TiH}_{\mathbf{x}} / \mathrm{KClO}_{4}$ blends as they are loaded into explosive components. Also very porous films with large surface-to-volume ratios are obtained by manipulating evaporation parameters. These films are analogous to powders in their surface properties. Current/voltage curves show the onset of . current at $\sim+0.100 \mathrm{~V}$ vs. saturated calomel electrode (SCE), and steady-state currents are achieved at $>+0.400 \mathrm{~V}$. This process is consistent $w$ ith the initial dissolution of some fraction of the surface metal as $\mathrm{Ti}^{3+}$ and the subsequent oxidation to form oxides. Propagation of the oxide into the thin film proceeds as a linear function of applied voltage. Surface conductance measurements are possible on the $\mathrm{T} i$ thin films because the film thickness (200-250 $\AA$ ) approximates the inelastic mean free path (imfp) of the conduction electrons. Changes in surface composition are reflected in a change in conduction electron population and a subsequent change in surface conductance. With these films the absolute conductance drops as a function of applied voltage at a rate proportional to the rate of change of surface charge. Capacitance/potential data recorded simultaneously with a linear potential sweep experiment also indicated the irreversible 
formation of surface oxide. From the electrochemical data we propose a model for oxide growth into the metal by ionic conduction from the metal/oxide interface to the oxide/solution interface and subsequent oxidation of the mobile species at that interface. Ionic conduction appears to be the field-dependent, rate-limiting process.

Both electrochemically treated and untreated $\mathrm{T}$ i films were examined by Auger (AES) and $X$-ray photoelectron (ESCA) spectroscopy. Examination of the untreated and treated films indicated that the surfaces are not affected by electrochemical treatment, $O / T i \approx 1.6-1.7$ in all cases. The surface composition, as seen by ESCA, appears to be a combination of fully oxidized and fully reduced $\mathrm{T} i$ with possible intermediate states. Sputtering removes the higher oxidation states of $\mathrm{T} i$ leaving only $\mathrm{Ti}$ metal. The electrochemically oxidized films show oxide levels to greater depths, depending upon the extent of electrolytic treatment. The depth profiles were constructed by subtracting the depth profile for the blank film, and the resultant profiles are representative of the oxide produced electrochemicaliy. The total excess oxide correlates well with the charge passed during oxidation. One further observation; no chlorine is observed in the sputtering profiles, further substantiating our model for oxide growth.

Future experiments will involve (a) oxidation studies in more corrosive environments; e. g. , saturated $\mathrm{KClO}_{4}$, concentrated $\mathrm{HClO}_{4}$ and $\mathrm{HCl}$; (b) oxidation of titanium hydrides; (c) solid/solid interaction "studies; and (d) component hardware studies. Experiments are in progress to obtain comparative surface characterization of films, powders, and pressed pellets.

Viewgraphs for this talk are shown in Figs. 18-34.

Materials Properties of $\mathrm{Ti} / \mathrm{KClO}_{4}$ and $\mathrm{TiH}_{\mathrm{x}} / \mathrm{KClO}_{4}$. Blends

Electrical Resistivity of $\mathrm{TiH}_{\mathbf{x}}$ and $\mathrm{TiH}_{\mathbf{x}} / \mathrm{KClO}_{4}$ Blends (J. W. Reed, J. E. Glaub)

The electrical resistivities of pressed pellets of $\mathrm{TiH}_{\mathrm{K}}$ and $\mathrm{TiH} / \mathrm{KClO}_{1}$ blends were measured over a range of hydride stoichiometries and blend compositions. Measurements were carried out over a range of pressing loads from 5, 000 to 20,000 psi. Attempts were made to measure the resistivity of pressed pellets by applying electrodes to opposite faces. The resistivity measurements by this technique were highly sensitive to contact pressure. A four-point probe technique for measuring resistivity appeared to solve the problem associated with contact resistance. The problem of repeatability or, precision was not eliminated by this technique and appears to be characteristic of the pressed pellets. The precision of measurement at one point on the sample was good. When the position of the probe was changed, the measurement precision over the several positions became rather large. The precision was, however, sufficient to indicate trends and differences between blends, hydride composition and pressing densities. These differences in most cases were large compared to the measurement precision.

Viewgraphs for this talk are shown in Figs. 35-42. 
$\mathrm{X}$-Ray Diffraction Analyses of the $\mathrm{TiH}_{\mathrm{x}} / \mathrm{KClO}_{4}$ System (D. B. Sullenger)

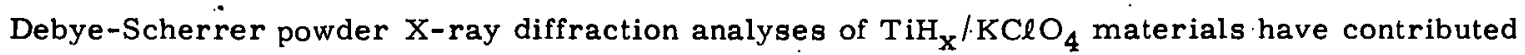
substantially to pyrotechnic development and production via characterization of baseline $\mathrm{Ti}, \mathrm{TiH}_{\mathbf{x}}$ and $\mathrm{KClO}_{4}$; assistance in finding a superior preparative method for $\mathrm{TiH}_{\mathbf{x}}$; support of other teams in a variety of ways; and development of fundamental data for $\mathrm{KClO}_{4}$ and for the $\mathrm{Ti}-\mathrm{H}$ system. A brief résumé of the experimental tèchnique employed, selection of standard patterns utilized and typical applications of the method during the Mound Pyrotechnic Project are presented. Planned future activities of diffraction analyses are indicated.

Viewgraphs for this talk are shown in Figs. 43-55.

Thermal Analyses of the $\mathrm{TiH}_{\mathrm{x}} / \mathrm{KClO}_{4}$ System (J. W. Reed, J. L. Ivey, C. L. Fread. R. H. Steinmeyer, R. L. Yauger, G. C. Abell)

A combined experimental and theorctical study of the system $\mathrm{TiH}_{\mathbf{x}} / \mathrm{KClO}_{4}$ was undertaken to investigate the thermodynamic and kinetic aspects of initiation of the $\mathrm{TiH}_{\mathrm{x}} / \mathrm{KClO}_{4}$ pyrotechnic system and to obtain parameters of interest in mathematical modeling of the initiation and propagation from a hot bridgewire source. Experimental results along with kinetic computations will be of interest in understanding the chemical processes involved. Initial computations from a limited number of experimental reaction exotherms obtained by use of a differential scanning calorimeter have yielded a reasonably consistent set of kinetic parameters over a range of heating rates.

Viewgraphs for this talk are shown in Figs. 56-64.

Thermomechanical Analysis of $\mathrm{TiH}_{\mathbf{x}} / \mathrm{KClO}_{1}$ Blends (T. M. Massis, P. K. Morenus)

A thermomechanical analysis (TMA) technique has been developed to simulate the decoupling or movement of the pyrotechnic away from the bridgewire in a loaded actuator configuration. By applying a force on the TMA probe assembly that rests against the pressed pyrotechnic in a loaded charge holder, the $\mathrm{TiH}_{0.65} / \mathrm{KClO}_{4}$ was observed to move or slip significantly in relation to the stationary charge holder material when thermally cycled from $-50^{\circ} \mathrm{C}$ to $+150^{\circ} \mathrm{C}$. A mismatch of greater than 2 to 1 in expansion coefficients of the $\mathrm{TiH}_{0.65} / \mathrm{KClO}{ }_{4}$ and charge holder materials exists. This test setup simulated the forces applied to the actuator during component environmental testing that resulted in movement of the pyrotechnic material away from the bridgewire.

A design change to alleviate this problem through the use of a one-way washer or spring has been incorporated. This TMA technique has been used to prove the design change. Repeated thermal cycles using the one-way washer concept on the TMA have shown no movement of the pressed $\mathrm{TiH}_{0.65} / \mathrm{KClO}_{4}$ in relation to the charge holder; whereas without the washer pellet slippage was observed during the first cooling cycle.

Viewgraphs for this talk are shown in Figs. 65-76. 
Compatíbility/Stability of $\mathrm{TiH}_{\mathrm{x}} / \mathrm{KClO}_{4}$ Blends (T. M. Massis, P. K. Morenus, R. M. Merrill)

Compatibility and stability testing at Sandia Laboratories, Albuquerque, of the structural and pyrotechnic materials in the MC2949 and MC3004 has shown no incompatibility between the various materials in question or significant instability of the pyrotechnics $\mathrm{Ti} / \mathrm{KClO}_{4}$ or $\mathrm{TiH}_{0.65} / \mathrm{KClO}_{4}$. The chemical reactivity test (CRT), coupon stacks and loaded components are currently being aged to prove both compatibility and stability of the various materials in question. All these programs are continuing, with many of them planned to run for 3 years.

The extent of reaction or degree of instability of the $\mathrm{Ti} / \mathrm{KClO}_{4}$ and $\mathrm{TiH}_{0.65} / \mathrm{KClO}_{4}$ has been found to be some 4 to 10 times lower than that previously found for $\mathrm{TiH}_{1.9} / \mathrm{KClO}_{4}$ through the temperatures tested. For example, less than 0.3 percent of the $\mathrm{Ti} / \mathrm{KClO}_{4}$ and less than 0.15 percent of the $\mathrm{TiH}_{0.65} / \mathrm{KClO}_{4}$ have reacted through 300 days at $100^{\circ} \mathrm{C}$ in the CRT sample configuration. Under the same condtions, about 1 -percent reactivity was measured for $\mathrm{TiH}_{1.9} / \mathrm{KClO}_{4}$.

Other observations include a surface area dependence on the amount of reactivity taking place (the greater the surface area of the fuel, the more reactive the material) and a greater reactivity in component geometry versus both the CRT and coupon configurations. Although a greater reactivity has: been shown to exist for loaded components than for other testing techniques, compatibility or. reliability has not been affected.

Viewgraphs for this talk are shown in Figs. 77-87.

Compatibility Program of Pyrotechnic. Materials at Mound (L. W. Collins, G. E. Kettling)

An experiment was performed to determine if pyrotechnic powders adsorbed enough moisture during production handling to exceed the moisture specification. The analytical results from.a 3month exposure of $\mathrm{Ti} / \mathrm{KClO}_{4}$ and $\mathrm{TiH}_{0.65} / \mathrm{KClO}_{4}$ to controlled humidities showed that no statistically significant quantities of water were adsorbed by either sample. In another experiment, the catalytic effect of metal oxides on decomposition of potassium perchlorate was determined quantitatively. It was shown that extremely minute quantities of certain oxides significantly reduce the apparent decomposition temperature of $\mathrm{KClO}_{4}-0.001$ percent of $\mathrm{Co}_{2} \mathrm{O}_{3}$ lowered the decomposition temperature by more than $25^{\circ} \mathrm{C}$. Isothermal weight loss measurements were used to compile a tabulation of the Arrhenius parameters for some common metal oxides with potassium perchlorate.

Current compatibility/stability studies at Mound Laboratory include chemical reactivity tests and chemiluminescence. Chemical reactivity tests for $\mathrm{TiH}_{0.65} / \mathrm{KClO}_{4}$ blends began in January and will extend through November. The feasibility of using chemiluminescence as an analytical tool for compatibility/stability studies is being investigated because of the unique advantages of fered by this method.

Viewgraphs for this talk are shown in Figs. 88-101. 


\section{Compaction Studies of Pyrotechnic Blends (A. C. Munger)}

An evaluation of compaction of pyrotechnic blends in charge holders was begun to investigate the variability in ETR data and firing times in various components.

It was discovered that the surface finish of the inner diameter of the charge holder greatly influenced the density achieved at the bridgewire. Force loss factors of up to 75 percent were discovered in some conditions.

The equipment was used to gelcet loading paraineler's for various charge holder designs. Data obtained show that. althnugh the fnrse ratiog oro about the saine fur llidnlum dnd titanium subhydride blends, the final densities achieved at the same compaction forces are quite different.

Viewgraphs of this talk are shown in Figs. 102-109.

\section{Surface Studies of Pyrotechnic Materials Used in Thermal Batteriess (W. F. Swrartz)}

Three samples of iron powder, each of unique origin, have been characterized with respect to the segregation of impurities to the surface as a function of temperature. Data taken show that for the three specimens, sulfur segregation is essentially the same. However, the segregation of carbon in the temperature range from $25^{\circ}-500^{\circ} \mathrm{C}$ is markedly different for each sample. It is vcry possible that the behavior of carbon could affect the performance of the various materials in pyrotechnic applications.

In an attempt to understand the carbon diffusinn meshanism, the lincties of lie prucess were studied for Lot 24 and Lot 16. The astivation encrgy of $6 \mathrm{kcal} /$ mule fur Lut 24 is cunsistent with a grain boundary diffusion phenomenon. Carbon diffusion in Lot 16 is markedly different, and the best estimate of an activation energy is approximately $24 \mathrm{kcal} / \mathrm{mole}$, which is more consistent with a bulk dlffusion process. Lot 16 has met specifications in thermal battery applications whereas Lot 24 has not with respect to burn rate.

Carbon in all lots thermally desorbs above $500^{\circ} \mathrm{C}$ in the form of gaseous carbon as determined by residual gas analyses (RGA) data.

With regard to sulfur segregation, Lots 11,16 and 24 behave identically. Kinetic data taken on Lot 16 yield an activation energy of $17.6 \mathrm{kcal} / \mathrm{mole}$, which is consistent with grain boundary diffusion in alpha-iron.

Since the sulfur behavior is essentially the same for all the iron powders studied, it is unlikely that the sulfur diffusion is the problem in pyrotechnic applications. It is felt that in these applications the carbon behavior is most critical.

Viewgraphs of this talk are shown in Figs 110-115. 


\section{Mathematical Modeling}

Modeling of Pyrotechnic Ignition (A. B. Donaldson)

The hot-wire ignition conditions for a pyrotechnic are considered using a mathematical model. The modej $\dot{i}$; based on the assumptions that the geometry is infinite in both the radial and axial directions, that the current passing through the bridgewire is constant, that all thermal and physical properties of both the bridgewire and pyrotechnic are constant, and that there is perfect thermal contact at the bridgewire-pyrotechnic interface.

The one-dimensional energy diffusion equation is employed to describe the pyrotechnic subject to bridgewire-pyrotechnic interface conditions that are specified by the current as well as by the system properties.

Based on either physical arguments or observation of analog or finite difference solutions, both the first and second spatial derivatives at the interface are found to change signs shortly before ignition. Hence, the occurrence of a null in these values is taken as the ignition criteria. By combining the remainder of the reactive diffusion equation with the interface conditions, an "ignition" temperature can be found. The time corresponding to the occurrence of this ignition temperature is then determined approximately from the inert (nonreactive) solution to the diffusion equation and interface conditions.

The results can then be matched to ignition data consisting of any two of the three variables ignition time, ignition temperature, or current level to deduce the reaction kinetics of the pyrotechnic. By this procedure, values for the preexponential factor have been estimated as $10^{4}$ to $10^{6} \mathrm{~s}^{-1}$ and the activation energy as 7 to $24 \mathrm{kcal} / \mathrm{mole}$ for $\mathrm{TiH}_{1.9} / \mathrm{KClO}_{4}(33 / 67)$.

Viewgraphs of this talk are shown in Figs. 116-122.

Summary of Panel Discussion

The summary section of this report contains a condensation of the panel discussion held at the end of the meeting. These items were taken from notes and a recording. The discussion has been organized into four different topical areas at the editor's discretion. Comments have been summarized, and suggested action has been indicated where appropriate.

\section{Electrical and Thermal Conductivity of Pyrotechnic Materials}

There was much discussion regarding the effects of parallel path resistance. It is not known whether changes in the measured bridgewire resistance ( $\$ 25$ percent) are material or mechanical. These changes and their variabilities cause serious design problems. Two questions should be immediately addressed: (1) Does the material resistivity change after blending? (2) Is there an 
experimentally significant variation in resistivity from sample lot to lot? These questions are being addressed at Mound by examining pellet conductivity as a function of several parameters.

Another key area of investigation is examination of the effect of oxide layers on the resistivity of powders. Currently, the effects of oxide layers on surface conductance of the metals and metal hydrides are being studied at Sandia. The effects of various oxide layer thicknesses on pyrotechnic properties will also be examined.

Another area in which studies are needed is that of possible physical and/or chemical changes in pressed blends as a function of testing, pressure, temperature, and time. Several possible techniques are being evaluated at Sandia by Divisions 2516 and 5822.

Electrostatic Pulse Testing and Its Effect on Unit Resistance

The measured bridgewire resistance in units can decrease by 15 percent upon testing with an electrostatic pulse $(20 \mathrm{kV}, 500 \Omega, 600 \mathrm{pF})$. For the MC2949 actuator this pulse is a field requirement and therefore must be addressed. To bring units back to the specified bridgewire resistance, thermal cycling is required. Component tests are being conducted by A. C. Munger, Mound, on 75 units to look at this effect and its magnitude. The suggestion was made to reconvene at least part of the attendees and present these data when available. B. R. Steele of SLA made the point that this resistance decrease has been observed for the MC2949 and the MC3004--two different configurations and two different materials $\left(\mathrm{TiH}_{0.65} / \mathrm{KClO}_{4}\right.$ and $\left.\mathrm{Ti} / \mathrm{KClO}_{4}\right)$.

\section{Ignition Characteristios}

Another area that was considered was that of ignition sensitivity. Although this is a key property for actuator function, little work has been done. No specific suggestions were made. However, subsequent conversations have indicated the possible use of laser-induced and minislapper ignition techniques.

\section{Burn Rate Studies}

Some attention in the overall advanced development. program should be given to burn rate. It was concluded that an experimental gap exists, and that techniques existing throughout the weapons laboratory system should be considered for this program. Two experimental apparatuses at Mound were mentioned--J. Mohler's optical technique for measuring the burn front and C. Chong's apparatus for looking àt reaction rate by mass spectrometrically examining products and measuring pressure and temperature excursions. Ray $\mathrm{Ng}$ of SLL also mentioned his experiments to measure pressure-time into zero volume. He has in addition looked at velocity as a function of time with a VISAR. The laser technique used at UMC for heat pellets was mentioned.

The major conclusion in this area is that development of a burn rate or reaction rate measuring capability at Mound should be a priority since data is required on actuators during and after firing. 


\section{Compatibility}

Two design engineers who are working on components using these pyrotechnic materials (A. K. Jacobson and B. R. Steele) expressed concern over the 24-year life requirement and materials compatibility. After considerable discussion, it was decided that through the work being done by T. M. Massis at SLA and Mound, much of this area was being covered. Subsequent to the meeting, a counterpart to Massis was named at Mound. L. W. Collins will coordinate Mound's compatibility studies, and the whole effort between the two laboratories will be coordinated through T. M. Massis.

The problem of what tests could be conducted to define an acceptable humidity range in the blending and loading areas was discussed. The electrical conductivity and NMR techniques were suggested as possibilities.

\section{Communication}

The final major area of discussion was that of communication of information between the individual staff members at the two laboratories. Two mechanisms were proposed. Review meetings will be held twice a year on an alternating basis between Mound Laboratory and Sandia Laboratories to discuss individual advanced development programs and exchange ideas on which programs should be implemented, altered and/or continued. The minutes and discussion contained in this report indicate this criterion was met for the first meeting. The second mechanism of information exchange should be a short (less than one page) written description of each individual's timely . contributions to specified program areas. These short reports should be made at least quarterly in an informal format, possibly in the component status reports. Details are being worked out at thils line.

The author apologizes to those individuals whose comments and/or suggestions may have been omitted. P. G. Neiswander and L. Cafferty are gratefully acknowledged for their help in compiling these minutes. 
FIGS. 1-9 - VIEWGRAPHS FROM PRESENTATION BY R. S. CARLSON 
Fig. 1 - Oxygen Absorption vs. Bet Surface Area of Titanium Subhydrides

\begin{tabular}{|c|c|c|c|c|c|c|}
\hline $\begin{array}{l}\text { Batch QC } \\
\text { Number } \\
\end{array}$ & $\begin{array}{r}\mathrm{H} / \mathrm{Ti} \\
\text { Ratio } \\
\end{array}$ & $\begin{array}{c}\text { Air } \\
\text { Fraction } \\
f a \\
\end{array}$ & $\begin{array}{c}\text { Air } \\
\text { Absorbed } \\
\left(\mathrm{n}_{\mathrm{A}} / \mathrm{m}^{2}\right. \\
\left.\times 10^{5}\right) \mathrm{b} \\
\end{array}$ & $\begin{array}{c}\text { QC of } \\
\text { Starting } \\
\text { Material }\end{array}$ & $\begin{array}{c}\text { Air } \\
\text { Absorbed } \\
\text { (wt \%) } \\
\end{array}$ & $\begin{array}{c}\text { Air Absorbed } \\
\text { Total } \mathrm{O}_{2} \\
\text { Content of } \\
\text { Subhydride } \\
\text { (wt \%) } \\
\end{array}$ \\
\hline 1711 & 0.64 & 0.239 & 5.51 & 1709 & & \\
\hline $1713 / 1714$ & 0.70 (av) & 0.205 & 5.97 & 1709 & & \\
\hline $1718 / 1719$ & 0.64 (av) & 0.189 & 4.60 & $\cdot 1709$ & & \\
\hline $1724 / 1725$ & 0.55 (av) & 0.209 & 5.78 & 1709 & & . \\
\hline $1730 / 1731$ & 0.64 (av) & 0.226 & 4. 57 & 1709 & & \\
\hline $1732 / 1733$ & 0,64 (av) & 0.209 & 5.71 & 1709 & & \\
\hline $1739 / 1740$ & 0.36 (av) & 0.243 & 7.37 & 1709 & & \\
\hline $1741 / 17 \pm 2$ & 0.04 (av) & 0.218 & 6.64 & 1623 & & \\
\hline 1743 & 1.44 & 0.235 & 6. 11 & 1709 & 0.263 & 15.4 \\
\hline 1744 & 1.52 & 0.234 & 5.47 & 1709 & 0.263 & 15.4 \\
\hline 1747 & 1.47 & 0.292 & 4.97 & $1709^{\mathrm{C}}$ & 1.16 & 18.5 \\
\hline 1749 & 1. 11 & 0.259 & 8.09 & 1709 & 0.261 & 15.1 \\
\hline 1761 & 0.63 & 0.238 & 8.58 & $1747^{d}$ & 1.64 & 18.4 \\
\hline $1782 / 1783$ & 0.67 (av) & 0.249 & 5.53 & 1709 & 0.176 & 10.6 \\
\hline $1784 / 1785$ & 0.66 (av) & & & 1623 & & \\
\hline $1^{\prime \prime \prime y 1 F}$. & U. b'r & & 5.66 & 1709 & 0.182 & 10.2 \\
\hline $1792 \mathrm{P}$ & 0.67 & 0.235 & 5.38 & 1709 & 0.174 & 10.3 \\
\hline
\end{tabular}

NOTES:

${ }^{a}=$ fraction of air admitted to reactor which is absorbed by titanium subhydride.

$$
=\frac{\mathrm{nF}_{\mathrm{I}}-\left(\mathrm{P}_{\mathrm{f} 1}+\mathrm{P}_{\mathrm{f} 2}+\cdots \mathrm{P}_{\mathrm{fn}}\right)}{n \mathrm{P}_{\mathrm{I}}}
$$

where $\mathrm{n}=$ number of gas additions

$P_{I}=$ initial pressure in chamber before absorption

$P_{f}=$ final pressure in chamber after absorption

$b_{n_{A}}=$ moles air absorbed

$\mathrm{m}^{2}=$ total surface area of subhydride in $\mathrm{m}^{2}$.

${ }^{C}$ Ballmilled QC1709. BET S. A. $=7.84 \mathrm{~m}^{2} / \mathrm{g}$.

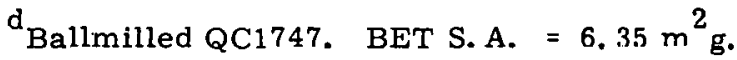


Fig. $2-$ Composition vs. Dehydriding Temperature at $20 \mathrm{hr}$.

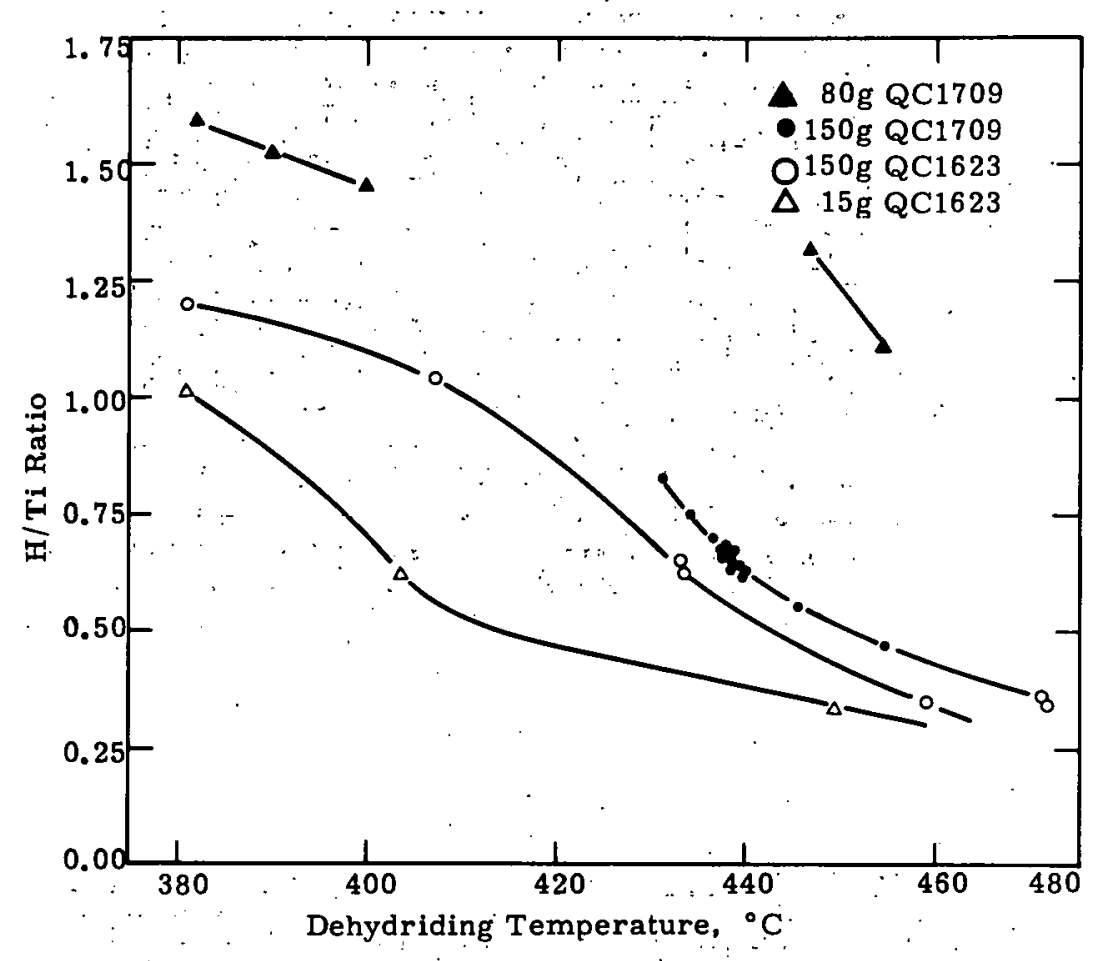

Fig. 3 -. Phase Diagram for Ti-H System

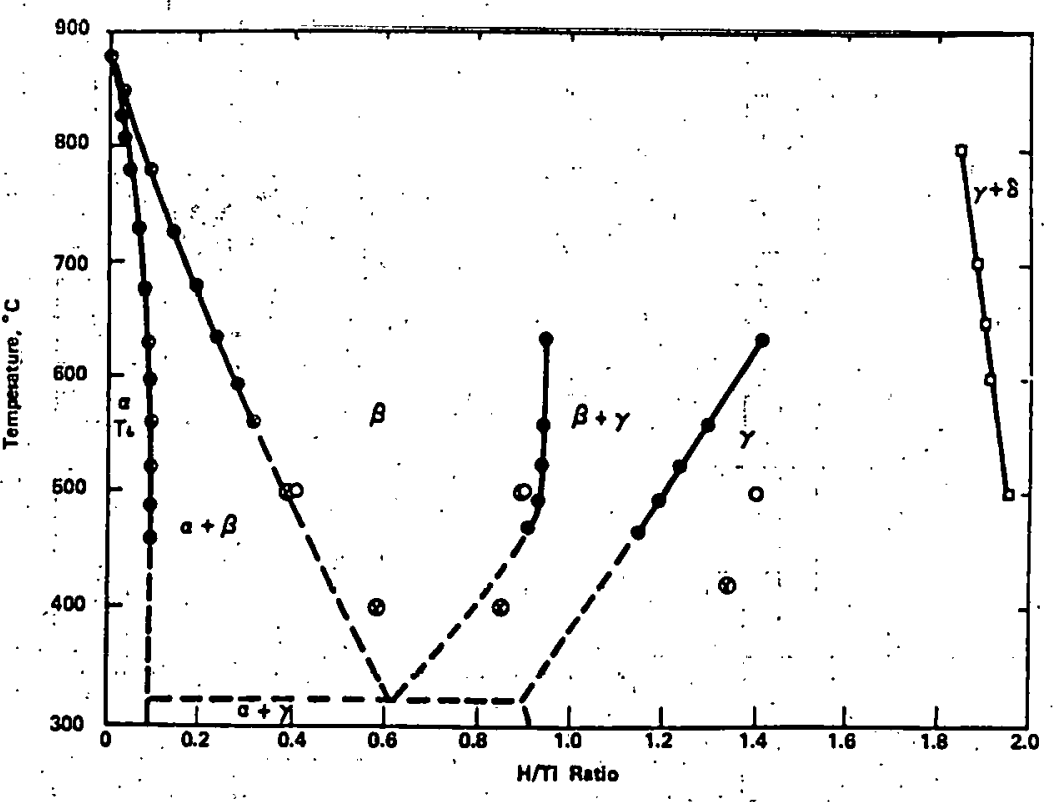


Fig. 4 - Final Dynamic Pressure v8. Composition

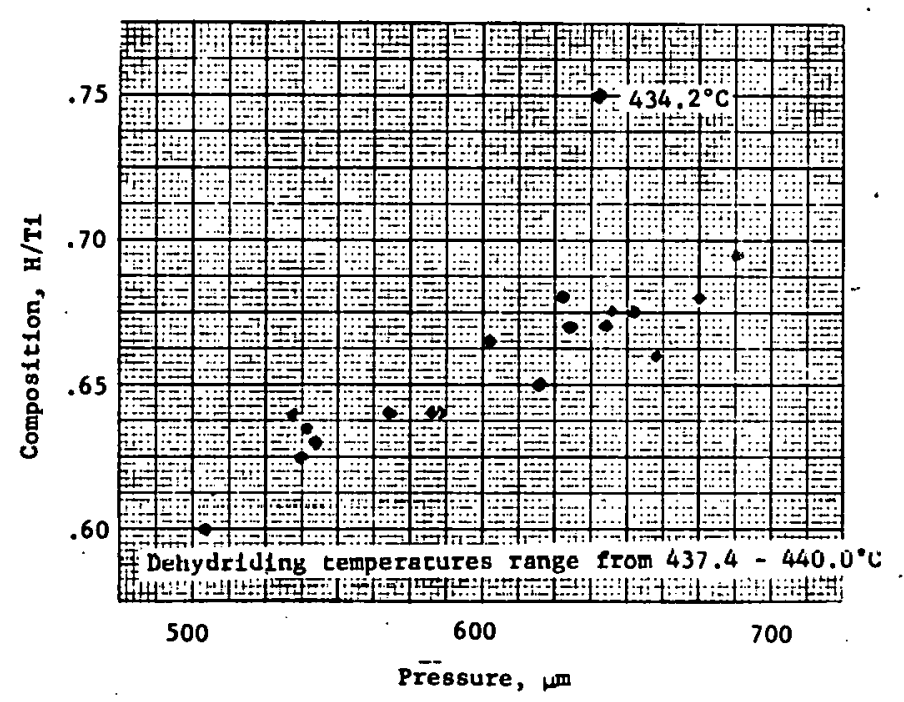

Fig. 5 -

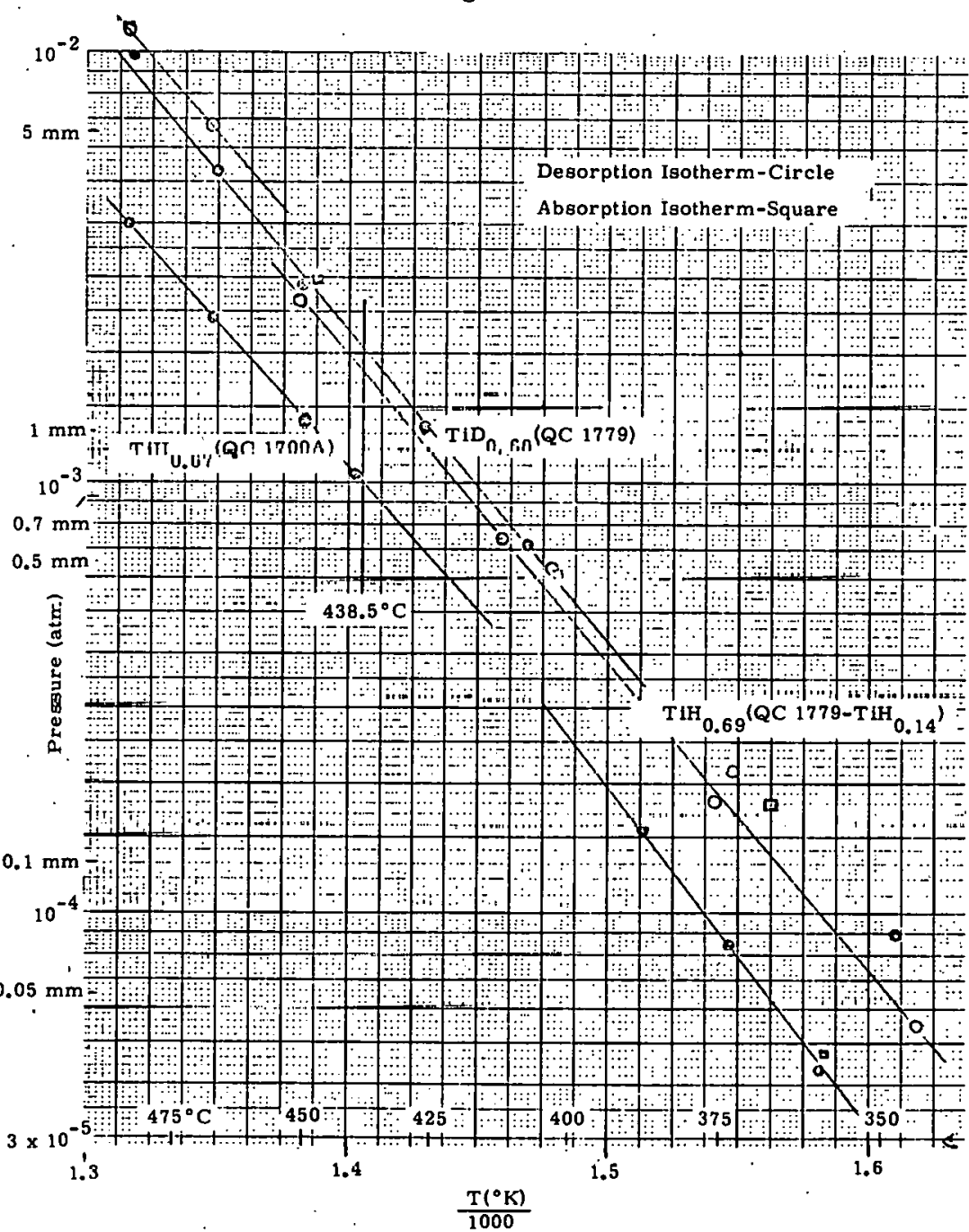


Fig. 6 - Analytical Results (W.t. \%) - Type 6

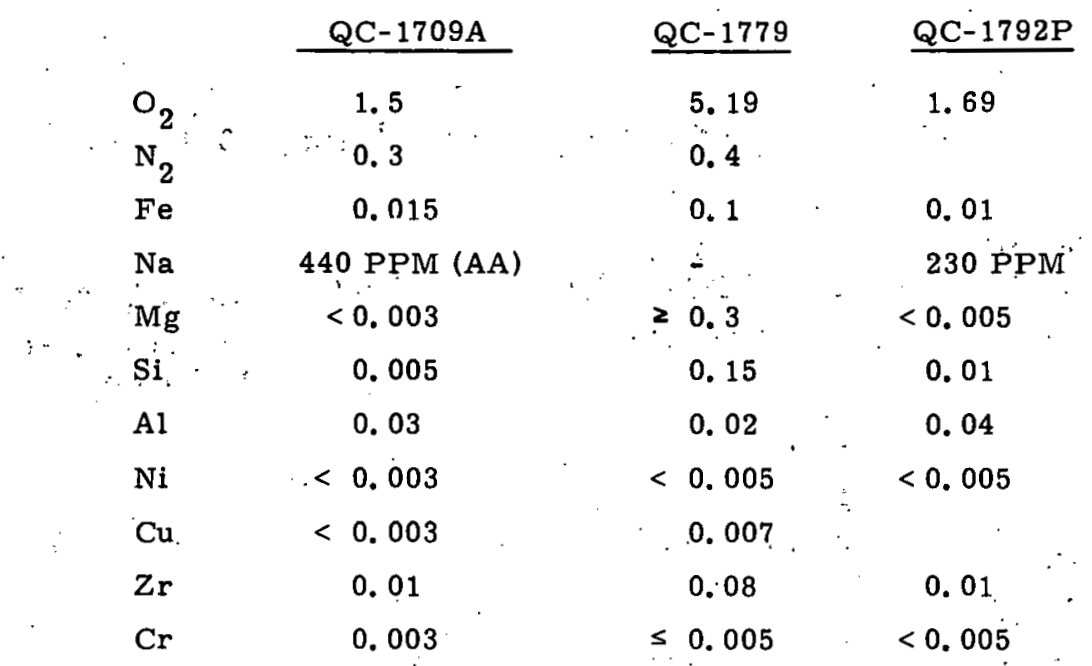

Fig. 7 - Thermodynamic Properties

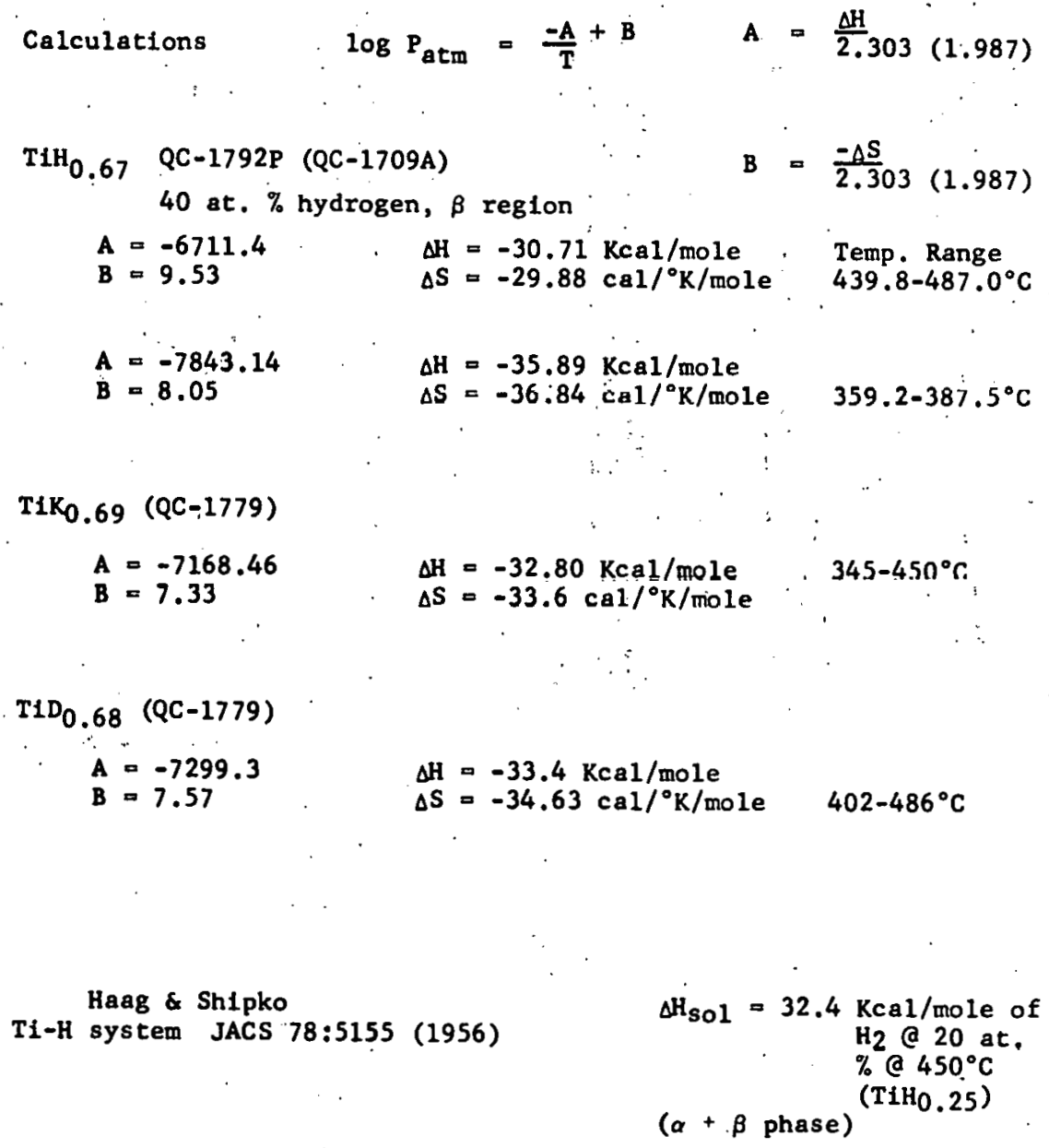

Haag \& Shipko

Ti-H system JACS 78:5155 (1956) 
SəYว7Eq 26 TE70J

"Llgt puB ' 6L9I 'TL9I-DO wOxJ popuola

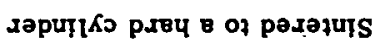

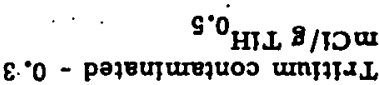

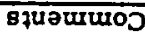

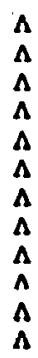

$\hat{\Lambda}$
$\Lambda$
$\Lambda$
$\Lambda$
$\Lambda$
$\Lambda$
$\Lambda$
$\Lambda$
$\hat{\Lambda}$
$\hat{\Lambda}$

$\Lambda$

$\hat{\Lambda}$

$\Lambda$

$\mathbf{\Lambda}$

$\mathbf{A}$
$\boldsymbol{\Lambda}$

$\boldsymbol{\Lambda}$

$\hat{\Lambda}$

$\Lambda$

$\Lambda I$

A

$\begin{array}{lll}\Lambda I & & \\ \Lambda I & \varepsilon 29 T\end{array}$

PIII

III

II

II

II

II

II

II

$I$
$I$
$I$

I

$7 \overline{\text { poy }}$

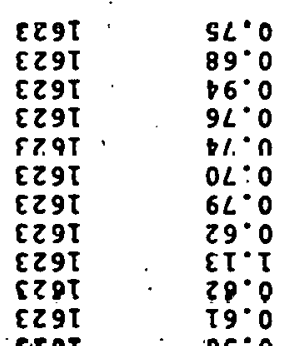

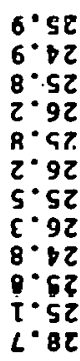

$50 \angle t$

TOLT

$00<T$

6691

R69T

S69

$669 \tau$

$\varepsilon 69 T$

$269 \tau$

169

$\angle 89 T$

EZ9T $\quad 65^{\circ} \mathrm{O} \quad 6^{\circ} 08.689$

c5ot

0.0
0.0

$\begin{array}{lll}\text { EZ9T } & \varepsilon L \cdot t \\ \text { T29T } & . & 65 \cdot T\end{array}$

นद2

Tदgा

โ 291

โ29T

โ 29 T

trgt

T29T

T29T
โ29T
T29

$\angle 6^{\circ} \mathrm{T}$

(75a) $\angle E \cdot 1$

$80^{\circ} \mathrm{T}$
$68^{\circ} 0$

$9 \cdot 22$

โ29

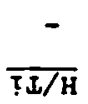

$\overline{(6)}$
$746+\partial_{M}$

J0 teT2078h
surq727s
81.0

IS.0

$\angle 5^{\circ} 0$

$89^{\circ} .0$

โ6.0

$95^{\circ} 0$

$60^{\circ} 0$

$09^{\circ} \mathrm{T}$

$68^{\circ} 0$

I $2 \cdot \mathrm{T}$

$\angle 6^{\circ} \mathrm{T}$

$\varepsilon L \cdot \tau$

2S. $\tau$

$18^{\circ} \mathrm{T}$

$16^{\circ} \mathrm{T}$

$\varepsilon L^{\circ} T$

T $9^{\circ} \mathrm{T}$

$55^{\circ} \cdot \mathrm{T}$

$5 E^{\circ} \mathrm{T}$

$\tau=L 2$

0.92

$\varepsilon \cdot \mathrm{s}$

$9 \cdot 52$

$9 \cdot 92$.

$\tau \cdot \varepsilon \tau$

$8 \cdot 52$

0.58

6.95

$\varepsilon \cdot 65$

$6^{\circ}$. 5

$9^{\circ} 05$

s:es

: 25

$5^{\circ} 25$

$5 \cdot 8 \varepsilon$

$\checkmark 6 \varepsilon$

L.PS

E. Eb

$5^{\circ} 8 \varepsilon$

$5^{\circ} 8 b$

Z. $\angle E$

c: $>9$

I 69

T. 49

T. 89

OS 0

हैร9

$6^{\circ} .96$

ON 20

T89T

$089 \mathrm{~T}$

$6<9$

$8 \angle 9 T$

LL9T

$9 \angle 9 T$

bL9T

$0<9$

$699 \mathrm{I}$

8991

L99T

999 T

599

$\checkmark 991$

E99र

0991

259

TS9T

0S9T

6b9T

४०9T.

Eb9t

LE9T

9E $9 T$

SE $9 T$

$\rightarrow$ E 9 T

EE 9T

$\bar{T} \overline{J / H}$ 
Fig. 9 - Titanium Subhydride Batches Produced in 2-1/2 In. O. D. Horizontal Tube Reactor

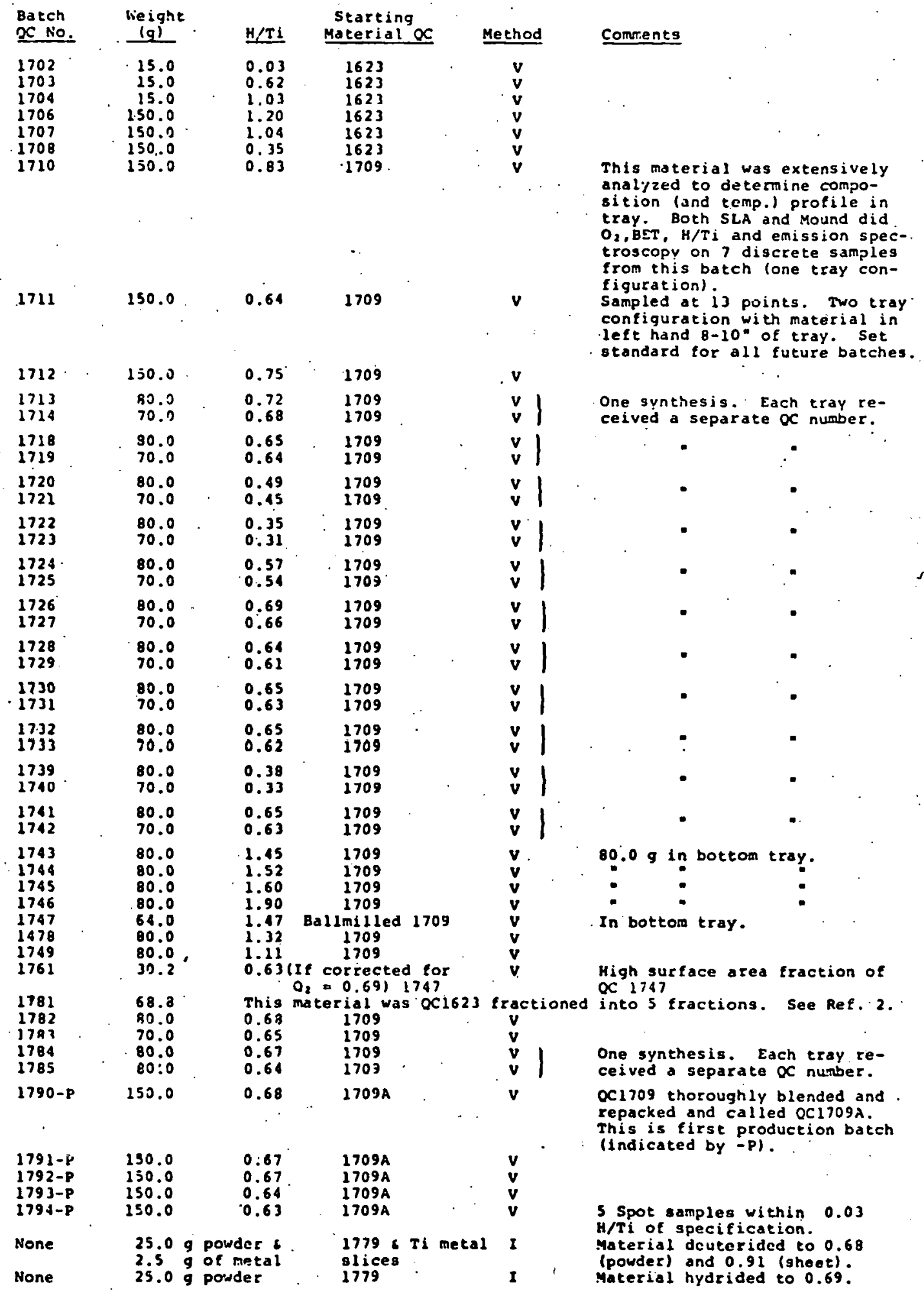




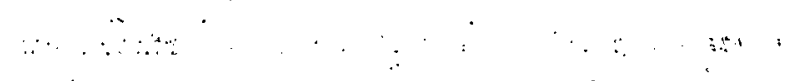

FIGS. 10-17 - VIEWGRAPHS FROM PRESENTATIÓN BY R. C. BOWMAN 
Fig. 10 - Characterization of Adsorbed $\mathrm{H}_{2} \mathrm{O}$ On High Surface Area Titanium

I. Objectives:

Determine Concentration of Adsorbed $\mathrm{H}_{2} \mathrm{O}$

Evaluate Effectiveness of Drying Procedures

Determine Readsorption of $\mathrm{H}_{2} \mathrm{O}$ After Drying

II. Primary Interest is High Surface Area Ti "Metal" - Shipped and Stored Under Water

Fig. 11 - Normal Components in Ti - "Metal"

$\alpha$ - Phase Ti Metal

$\gamma$ - Phase $\mathrm{TiH} \sim 1.5$

$\mathrm{TiO}_{2}$ (Surface Film of $\approx 20-30 \AA$ )

Adsorbed $\mathrm{H}_{2} \mathrm{O}$ and $\mathrm{OH}$ specics

Miscellaneous Impurities

Fig. 12 - NMR Spin Counting Techniques

I. Free Induction Decay (F'T)) - Pulse NMR

A. Decay Time Sensitive to Local Structure

- Short $(\leq 10 \mu \mathrm{s})$ - Rigid Atom in Bulk

- Long $(550$ o) - Mobile Species (surface)

B. Initial FID Minplitude - Concentration

II. Typical $\mathrm{FW}$ for $\mathrm{TiH}_{0.15}(\mathrm{QC}-1779)$

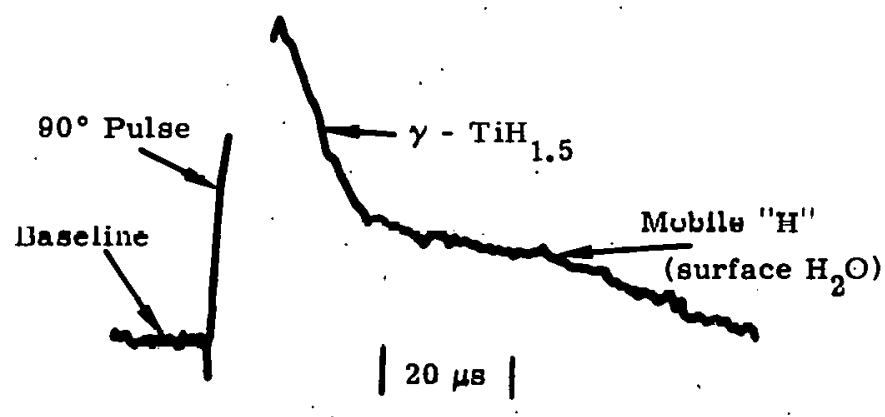


Fig. 13 - Sample Properties, and Analytical Data QC-1779 (Ventron Lot \#II-RS-14)

Nominal Stolchiometry: $\mathrm{TiH}_{0.15}$

Surface Area: $4.06 \mathrm{M}^{2} / \mathrm{G}$

Moisture (CEC Analyzer): 0.42 weight/percent

Elemental Analyses

Ti

$\mathrm{Ti}$

Weight/Percent

$\mathrm{H}$

94.48

N

$5.19 \pm 0.11$

0.31

$0.4 \pm 0.2$

$\mathrm{Si}$

20.3

C

0.15

0.10

Fig. 14 - Experimental Treatments

\begin{tabular}{|c|c|c|c|c|c|}
\hline & Treatment & $\begin{array}{c}\text { Pressure } \\
\text { (tor } r)\end{array}$ & $\begin{array}{c}\text { Temperature } \\
\left({ }^{\circ} \mathrm{C}\right)\end{array}$ & $\begin{array}{c}\text { Time } \\
\text { (hr) }\end{array}$ & Sample Handling \\
\hline I. & Air-Dried & Ambient & R. T. & $>72$ & Air \\
\hline II. & High-Vac. & $=10^{-5}$ & $190-5$ & 88 & Inert \& Vac. \\
\hline III. & Vac. Furnáce & $5 \times 10^{-2}$ & 105 & 24 & Inert \& Vac. \\
\hline IV. & III + Air & - & R. T. & 1 & Air \\
\hline V: & $\begin{array}{l}\text { IV + } 100 \% \text { Rel. } \\
\text { Humidity }\end{array}$ & - & R. T. & 45 & Air \\
\hline
\end{tabular}

Fig. 15 - Results for $\mathrm{QC}-1779$

NMR-Concentration (weight/percent)

\begin{aligned} Sample & \multicolumn{1}{c}{ Treatment } \\ I & Air-Dried \\ II & High Vacuum-Inert \\ III & Vacuum-Inert \\ IV & Vacuum-1 hr Air \\ V & Vacuum-45 hr \\ & $100 \%$ Relative Humidity \end{aligned}

" $\mathrm{H}$ "

(Mot. Nar. )*

" $\mathrm{H}_{2} \mathrm{O}$ "

$0.129 \pm 0.003$

1. $16 \pm 0.02$

$0.051 \pm 0.005$

$0.46 \pm 0.05$

$0.083 \pm 0.006$

$0.75 \pm 0.05$

$0.099 \pm 0.006$

0. $89 \pm 0.05$

0. $172+0,016$

1. $55 \pm 0.14$

*Motionally narrowed; refer to Fig. 12, Mobile "H". 
Fig. 16'- Summary

I. QC-1779 Assuming Only $\mathrm{H}_{2} \mathrm{O}$ for Proton $\mathrm{FID}$

A. Normal Drying Procedures Only Partially Effective

- CEC Moisture Analysis Represents Differences.

- Removes Weakly Bound $\mathrm{H}_{2} \mathrm{O}$ and $\mathrm{OH}$ Species.

B. Readily Readsorbs $\mathrm{H}_{2} \mathrm{O}$ From Water Vapor.

C. These Findings Probably Valid for $\mathrm{All}_{\mathrm{TiH}}$

Fig. 1.7 - Comparison With Infrared Studies of $\mathrm{TiO}_{2}$ Surfaces

A. Several Forms for Adsorbed $\mathrm{H}_{2} \mathrm{O}$ and $\mathrm{OH}$ Species.

- Chemisorption - Various $\mathrm{OH}$

- Strong Molecular Adsorṕtion

- Weak Molecular Adsorption

B. $\mathrm{H}_{2} \mathrm{O}$ Removal Incomplete Below $300^{\circ} \mathrm{C}$

(.) Reversible Reactions With Water Vapor at Room Temperature 
FIGS. 18-34 - VIEWGRAPHS FROM PRESENTATION BY R. K. QUINN 
Fig. 18 - Interfacial Electrochemiatry

PAR 173 Potentiostat with auxiliary equipment permits measure of:

(a) Current - voltage

(b) Charge - voltage

(c) Capacitance

(d) Surface conductance*

Thin Film Electrodes:

200-600. A Ti

deposited at $25 \mathrm{C}$ to $500 \mathrm{C}$

on $\mathrm{SiO}_{2}$ or $\mathrm{Al}_{2} \mathrm{O}_{3}$ substrates

SURFACL' ANALYSIS

AES/ESCA - PHI-548 Spectrometer

Fig. 19 - Current (i). charge (Q) and surface resistance $(\Delta \mathrm{H})$ as a function of applied potential for a $200 \mathrm{~A}$ Ti electrode in IN $\mathrm{KClO}_{4}$

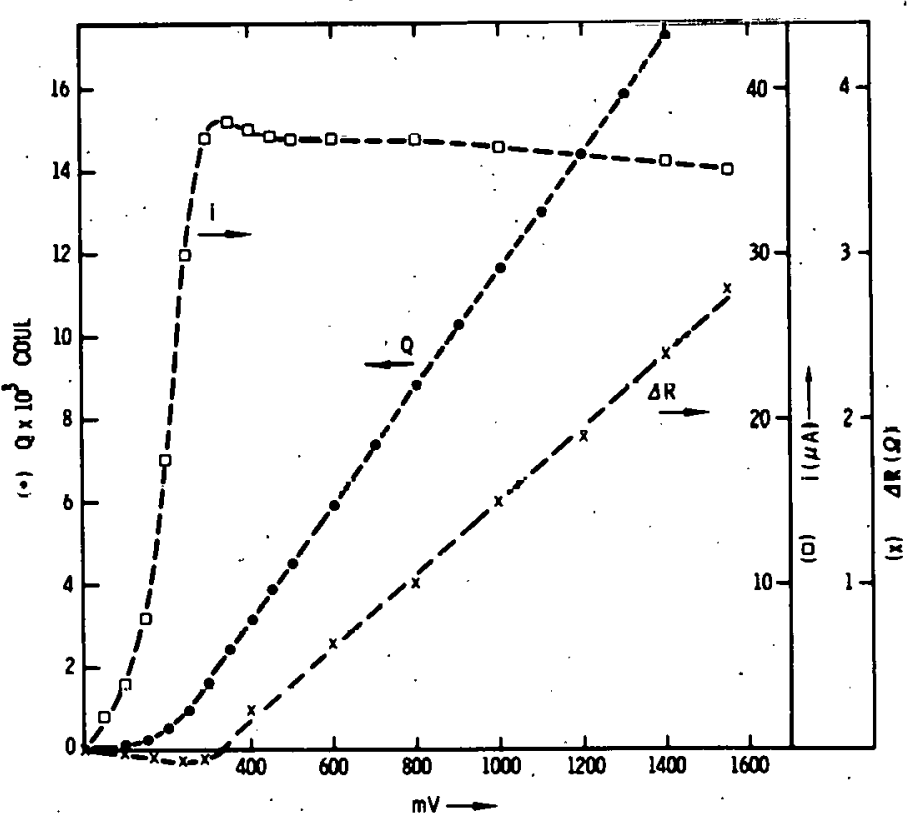


Fig. 20 - AES spectrum of Ti blank surface

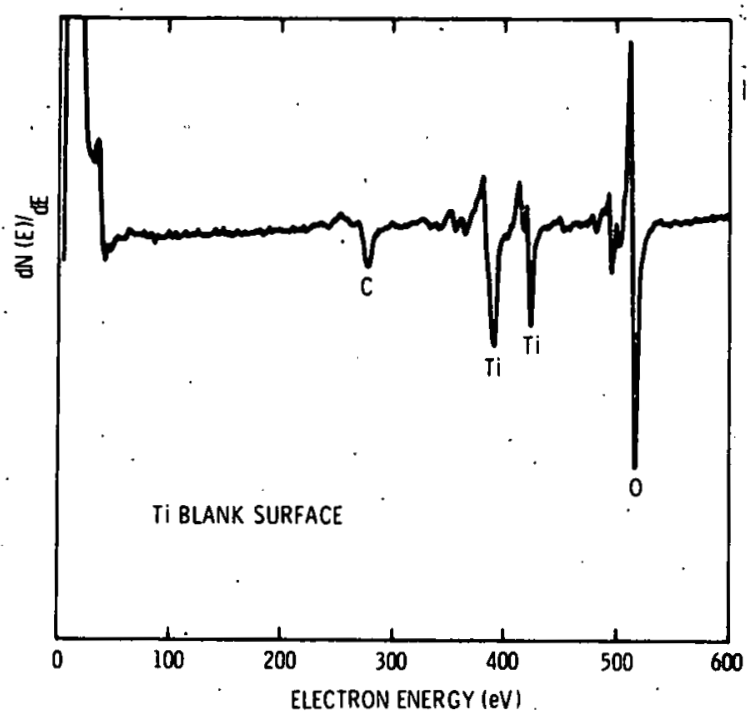

Fig. 22 - AES spectrum of Ti blank surface in pig. 20 aftei 0 ininules of argun lun etching.

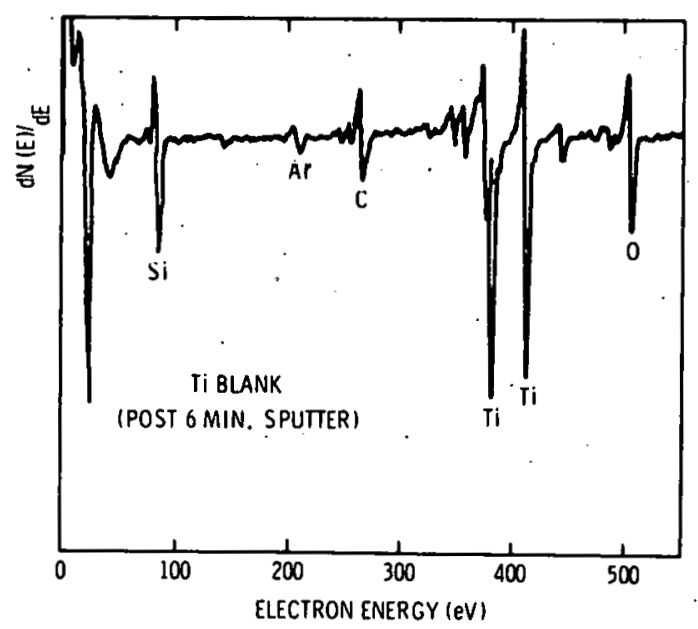

Fig. 21- $d N(E) / d E$ and $N(E)$ for Ti (LMM) AES peaks. Note structure of $\mathrm{N}(\mathrm{E})$ for high-energy $\mathrm{Ti}$ peak.

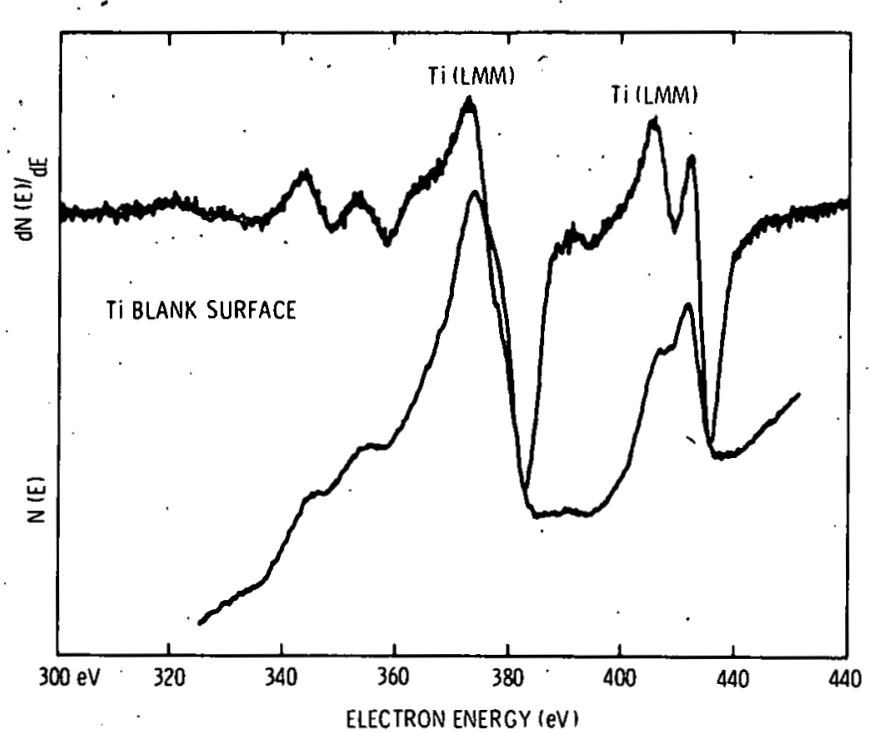

Fig. 23 - AES spectrum of Ti blank surface of Fig. 22 with $\mathrm{N}(\mathrm{E})$ of $\mathrm{Ti}(\mathrm{LMM})$ peaks. Compare IN(E) of high energy peak to that of Fig. 21.

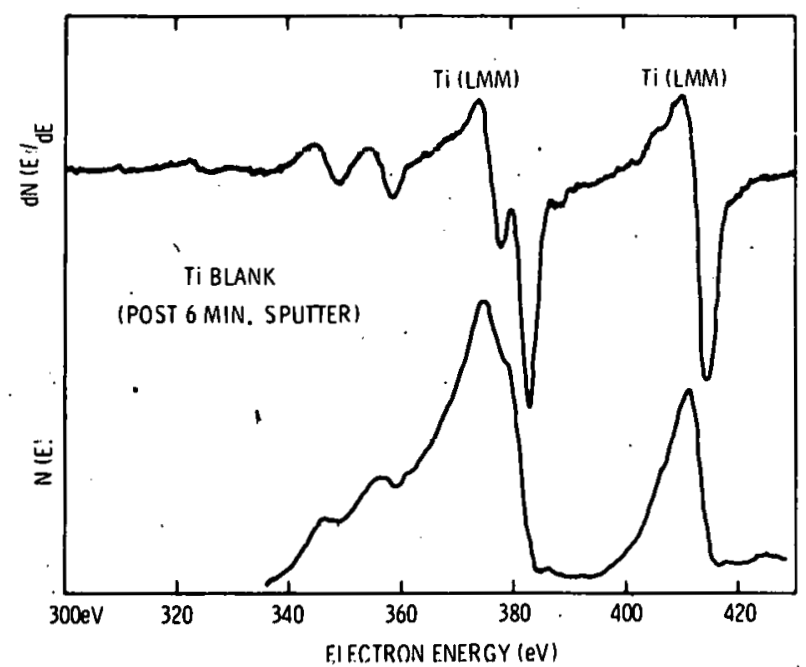


Fig. 24 - Table of ESCA peaks for several $\mathrm{T} i$ thin film electrodes.

The $\triangle B E$ terms are defined at bottom of figure.

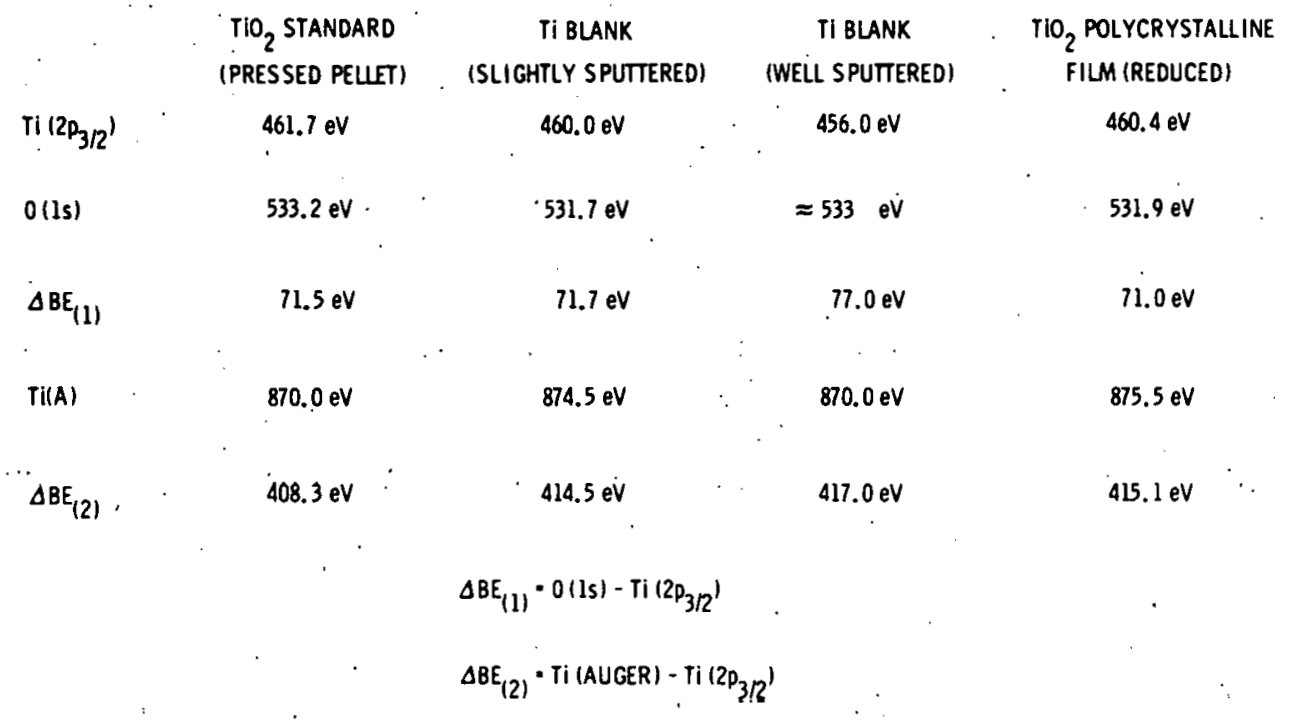

Fig. 25 - ESCA spectrum of Ti blank film. The principal peak is the ' 1 'i( $\left.\angle \mathrm{p}_{3 / 2}\right)$ with a higher energy shoulder for $\mathrm{Ti}$. $\left(\mathrm{zp}_{1 / 2}\right)$.

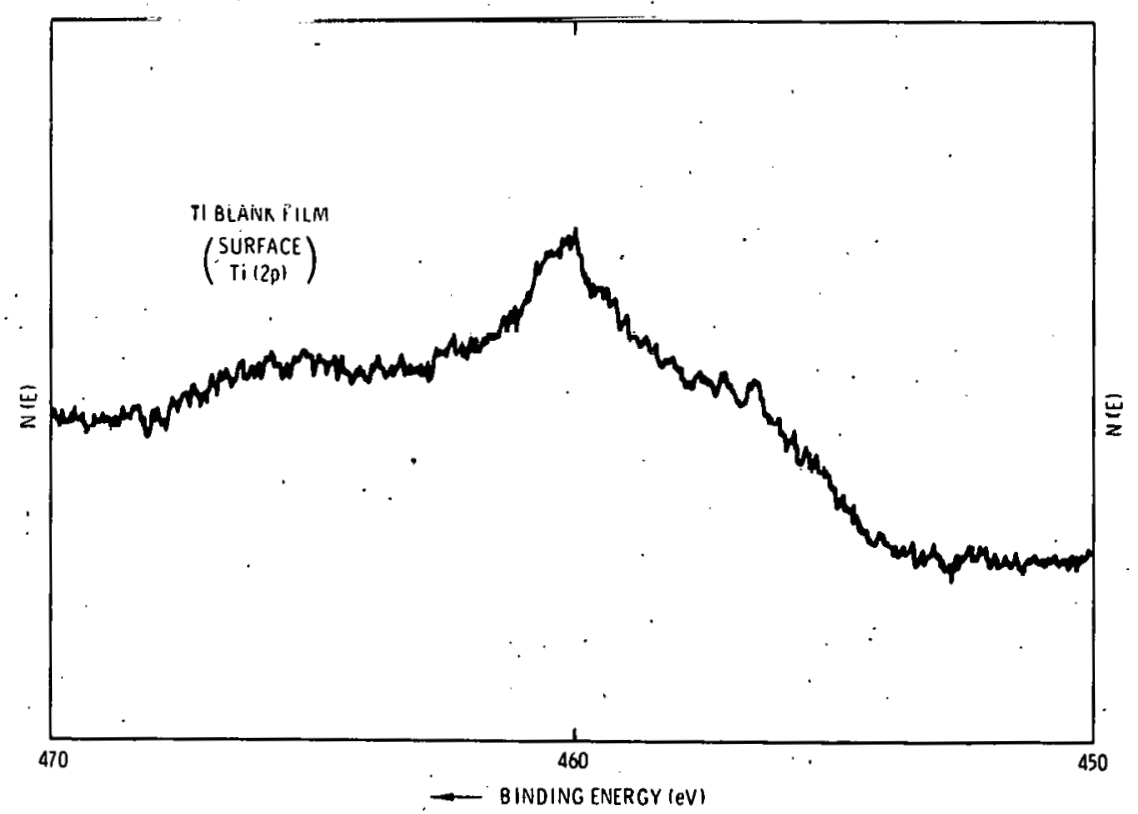


Fig. 26 - ESCA spectrum of Ti $\left(2 p_{3 / 2} \& 2 p_{1 / 2}\right)$ peaks for a $\mathrm{TiO}_{2}$ standard.

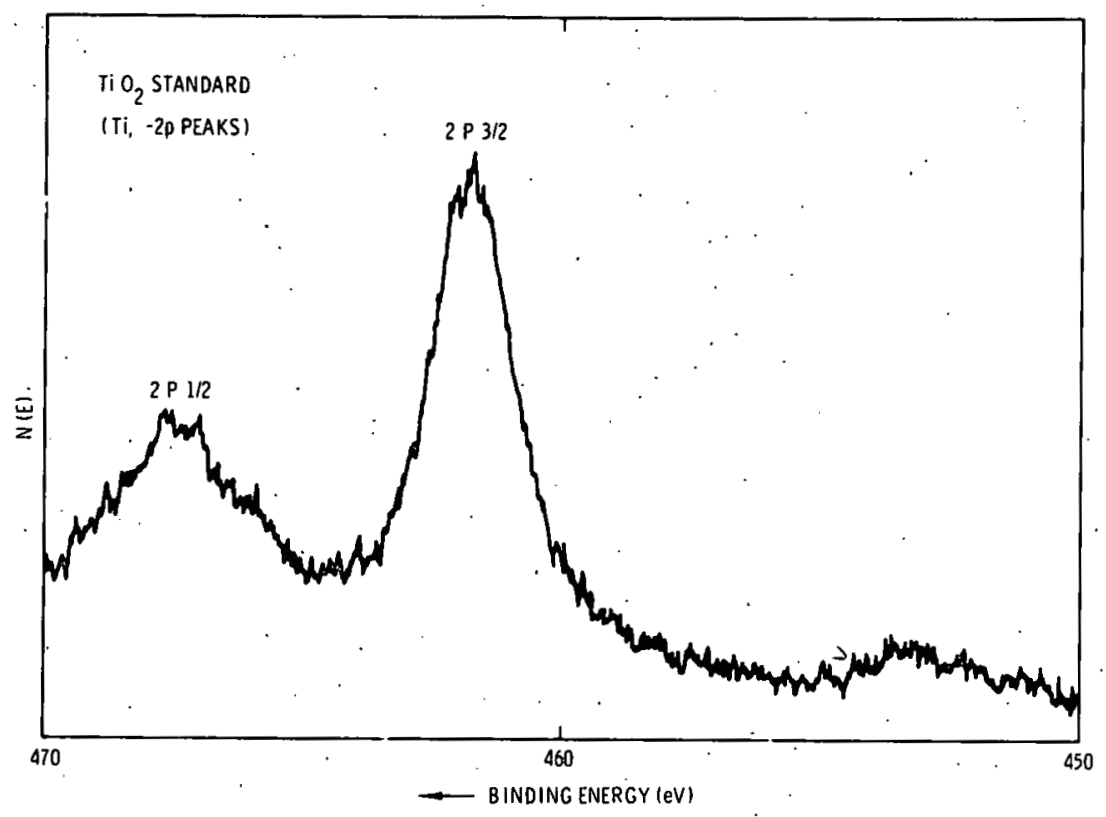

Fig. 27 - AES spectrum of Ti thin-film electrode after $4 \mathrm{mC}$ of oxidative change. Note similarity to $\mathrm{T} I$ blank in Fig. 20.

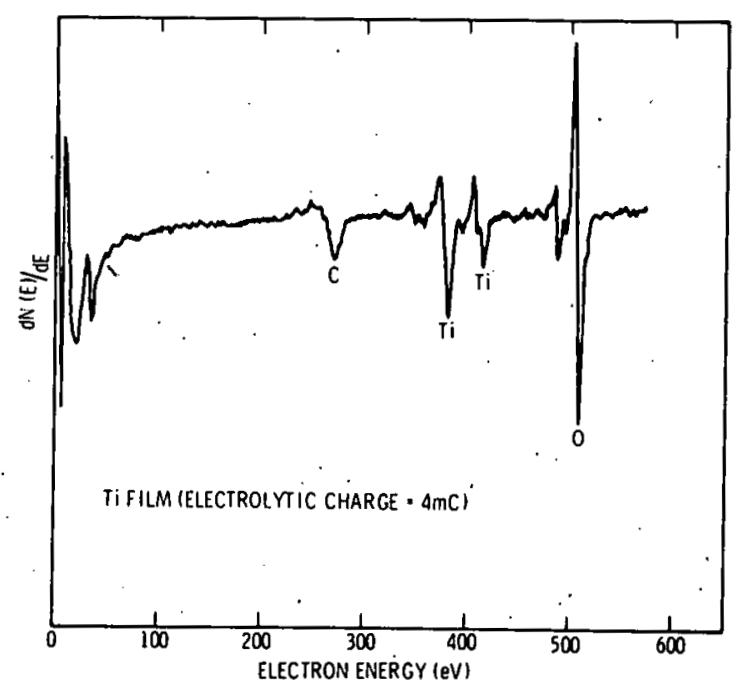

Fig. $28-\mathrm{dN}(\mathrm{E}) / \mathrm{dE}$ and $\mathrm{N}(\mathrm{E})$ as a function $\mathrm{E}$ for the electrode of Fig. 27. Compare this spectrum to that of Flg. 21

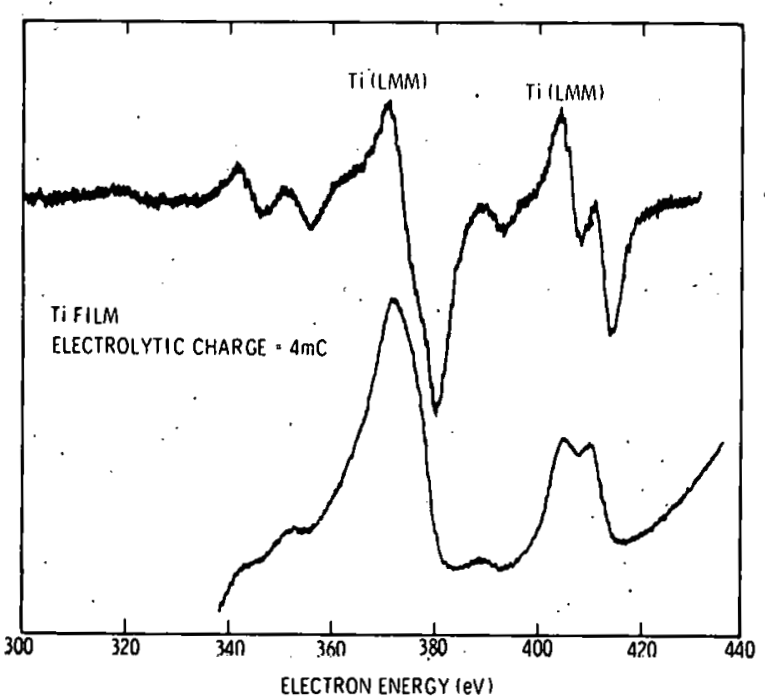


Fig. $29-d N(E) / d E$ and $N(E)$ as a function of $E$ for the electrode of Figs. 27 and 28 after 3 minutes of ion etching. Note $N(E)$ spectrum is similar to that of the blank shown in Fig. 23.

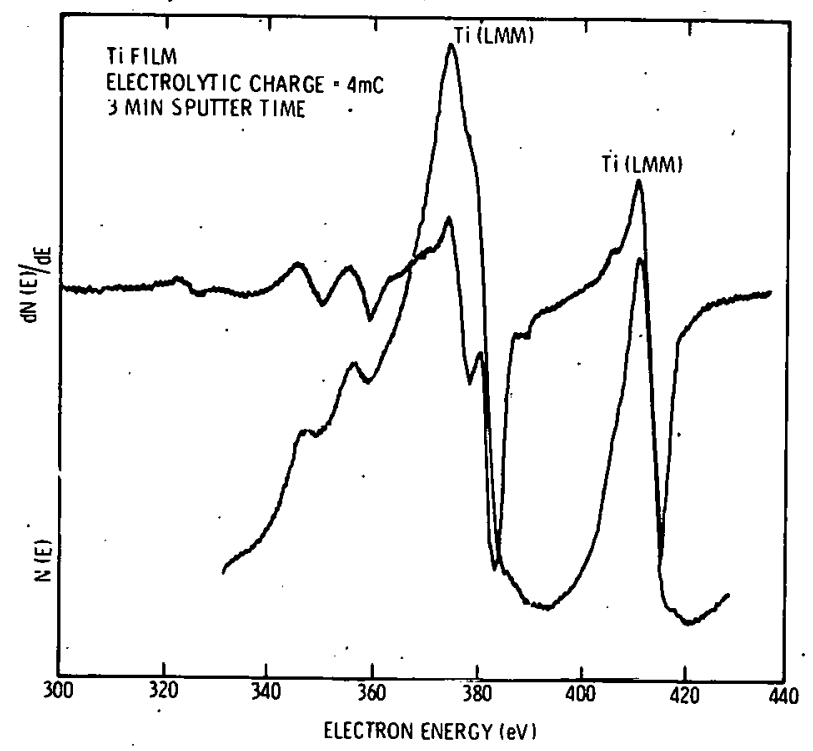

FIg. 31 - Corrected depth profile of Ti film electrode after $4 \mathrm{mC}$ of oxidative change. Normalized curve is that obtained after corrections for the blank profile (Fig. 30),

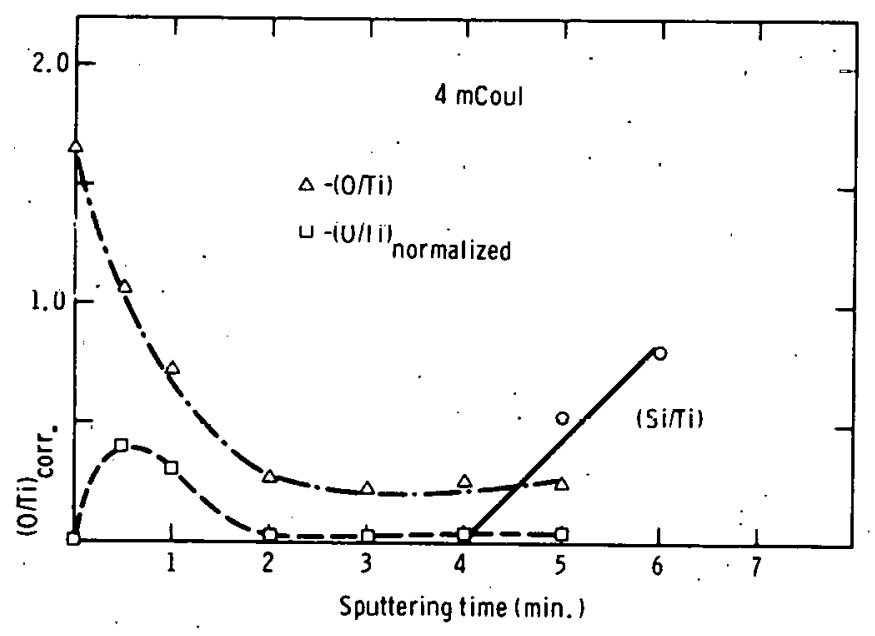

Fig. 30 - Corrected depth profile of oxygen to titanium for a blank Ti film electrode.

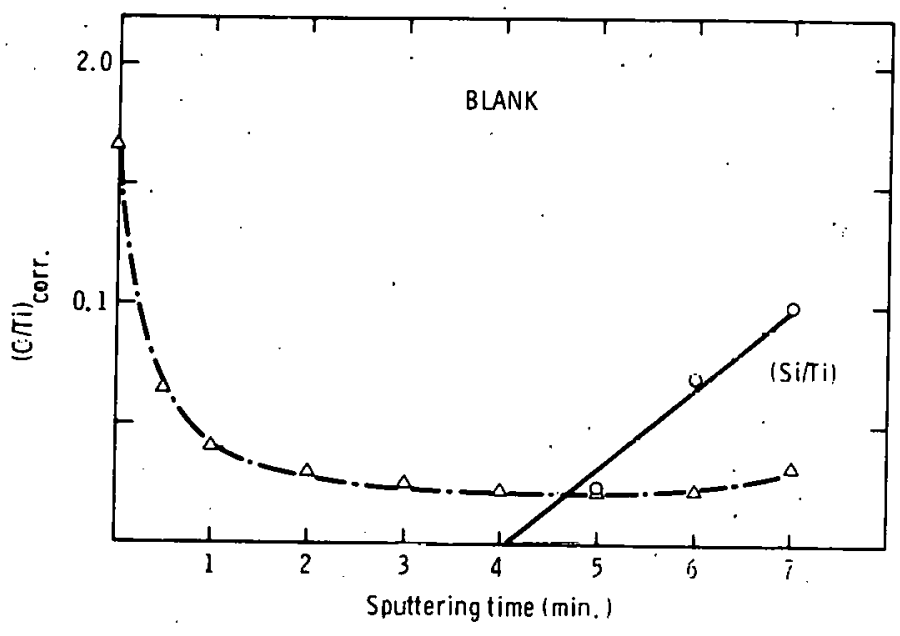

Fig. 32 - Corrected depth profile for $\mathrm{T} i$ thin film electrode after $13 \mathrm{mC}$ of oxidativo changc.

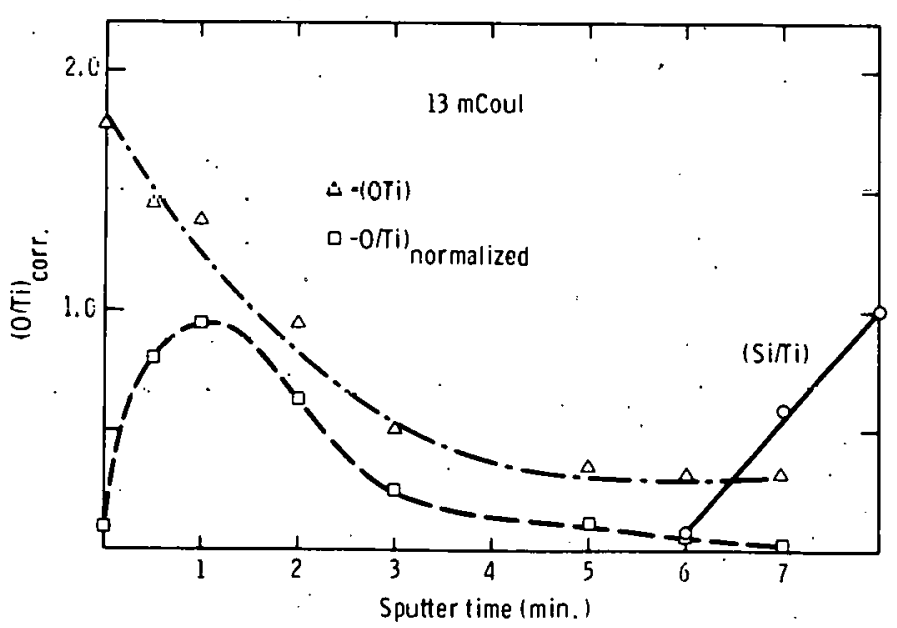


Fig. 33 - Correlation of relative excess oxide thickness from the normalized profile to the amount of oxidative change passed.

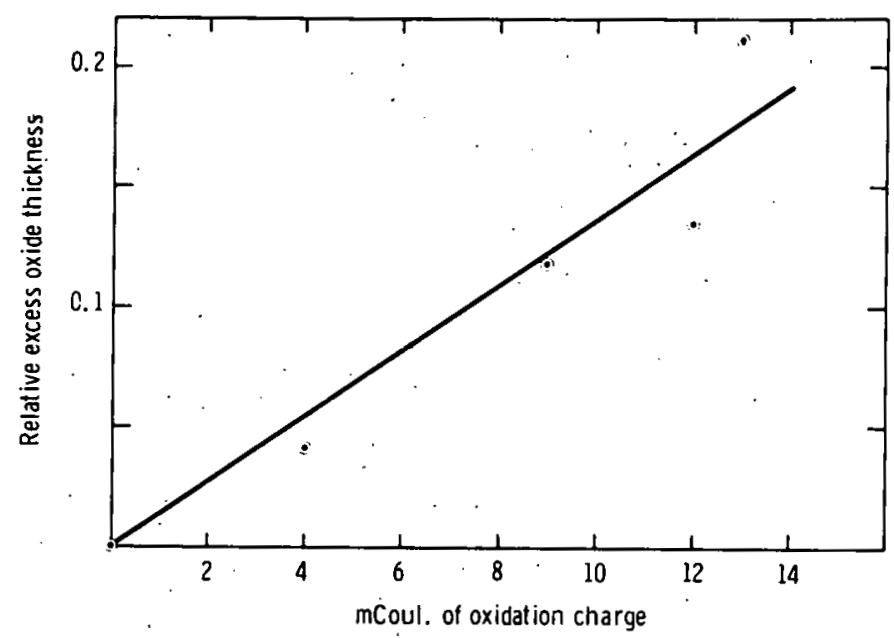

Fig. 34 - Proposed Future Work in this Area

(a) Increase Corrosive Environment

-Sacurated $\mathrm{KClO}_{4}$

- Concentrated $\mathrm{HClO}_{4}$

- Concentrated $\mathrm{HCl}$

(b) Titanium llydrides

(c) Solid/Solid Interaction

(d) Other Component Hardware Parts

e.8. Kovar, Nichrome

(e) Comparative Surface Characterization of

-Powders

-Pellets

-Films 
FIGS. 35-42 - VIEWGRAPHS FROM PRESENTATION BY J. W. REED 
Fig. 35 - Resistivity as a Function of $\mathrm{TiH}_{\mathrm{x}}$ Stoichiometry

10 Kpsi Pressing Load

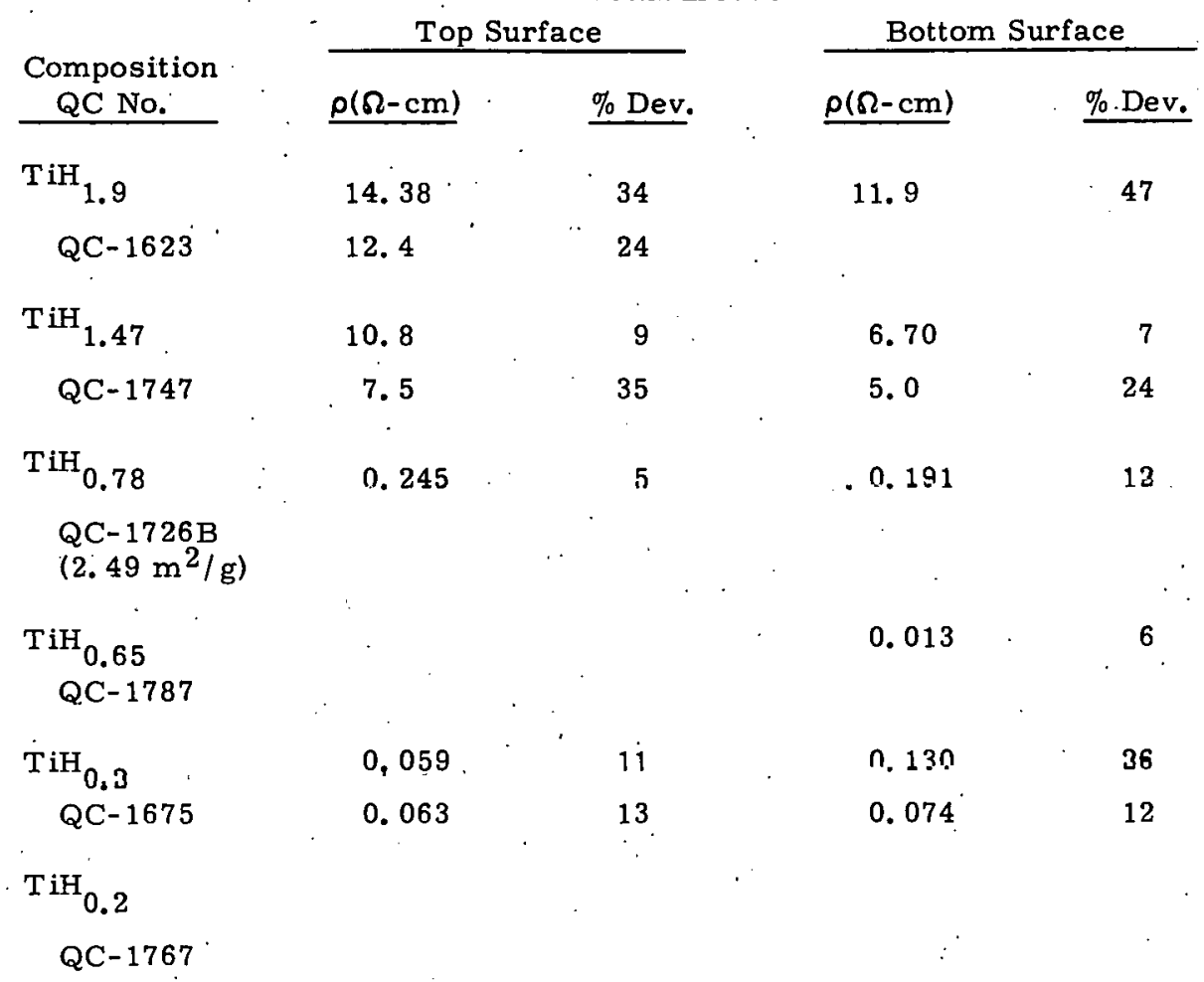

H'ig. 36 - Resistivity as a Function of $\mathrm{TiH}_{\mathrm{x}}$ Stoichiometry

30 Fpøi Fressing Luad

\begin{tabular}{|c|c|c|c|c|}
\hline \multirow[b]{2}{*}{$\begin{array}{l}\text { Composition } \\
\text { QC No. }\end{array}$} & \multicolumn{2}{|c|}{ Top Surfare } & \multicolumn{2}{|c|}{ Rott.nm Surface } \\
\hline & $\rho(\Omega-\mathrm{cm})$ & $\%$ Dev. & $\rho(\Omega-\mathrm{cm})$ & \% Dev: \\
\hline $\mathrm{TiH}_{1.8}$ & .2 .09 & . 12 & 3. ก? & 21 \\
\hline$Q C-1623$ & 1.75 & 12 & 4.67 & 24 \\
\hline $\begin{array}{l}\mathrm{TiH}_{1.47} \\
Q \mathrm{Q}-1747\end{array}$ & 0.44 & 24 & 0.68 & 11 \\
\hline $\begin{array}{l}\mathrm{I}^{\prime} \mathrm{iH} \\
0.78 \\
\mathrm{QC}-1726 \mathrm{~B} \\
\left(2.49 \mathrm{~m}^{2} / \mathrm{g}\right)\end{array}$ & 0.066 & 8 & 0.066 & 2 \\
\hline $\begin{array}{l}\mathrm{TiH}_{0.65} \\
\quad \mathrm{QC}-1787\end{array}$ & 0.007 & 36 & $\begin{array}{c}0.028 \\
.\end{array}$ & 33 \\
\hline $\begin{array}{l}\mathrm{TiH}_{0.2} \\
\quad \mathrm{QC}-1675\end{array}$ & 0.036 & 5 & 0.029 & 3 \\
\hline $\begin{array}{l}\mathrm{TiH}_{0.2} \\
\mathrm{QC}-1767\end{array}$ & 0.262 & 7 & 0.256 & 14 \\
\hline
\end{tabular}


Fig. 37 - Resistivity of $\mathrm{TiH}_{\mathrm{x}}$ as a Function of Hydride Stoichiometry

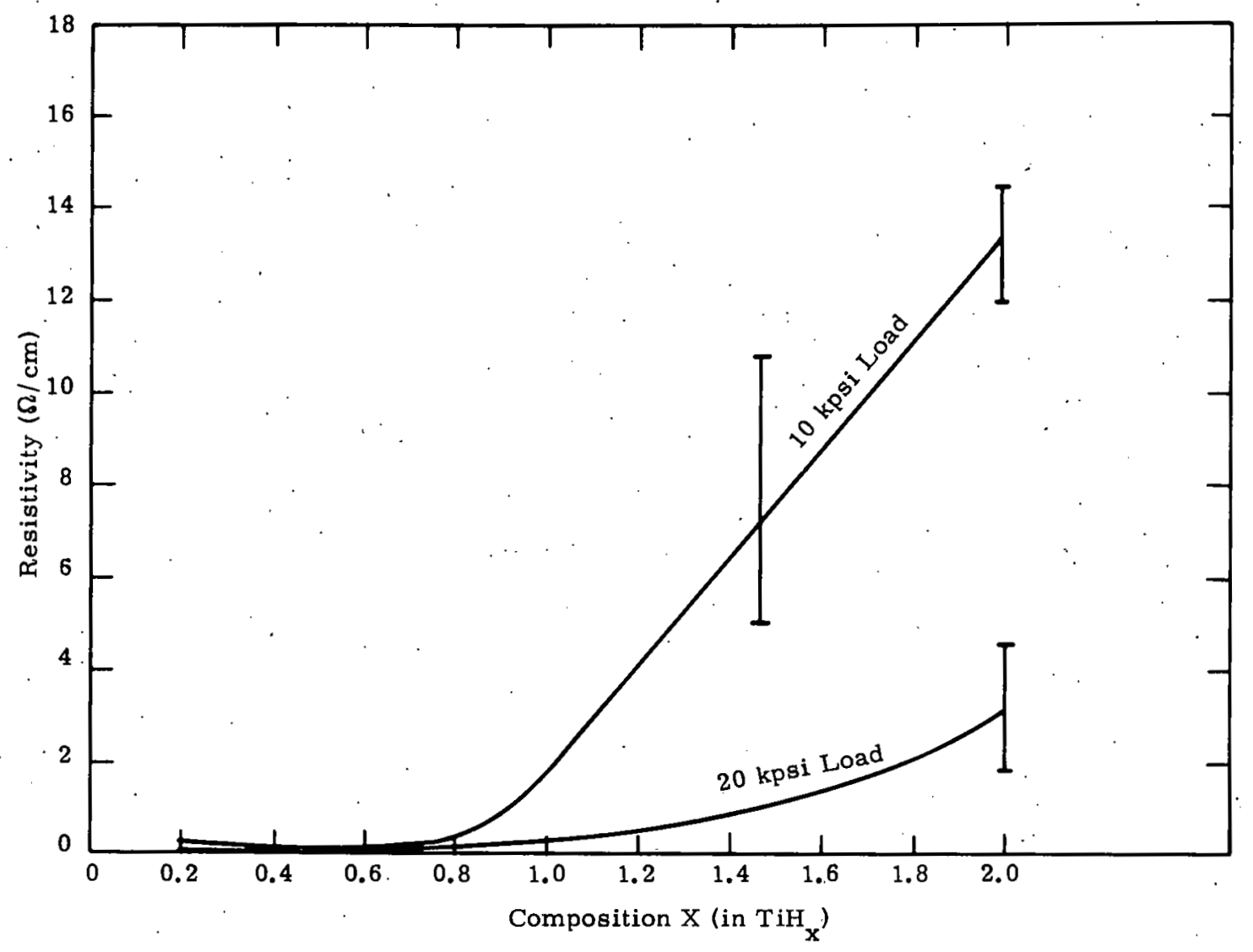

Fig. 38 - Resistivity of Several $\mathrm{TiH}_{\mathrm{x}} \mathrm{KClO}_{4}$ Blends

\begin{tabular}{|c|c|c|c|c|c|c|c|}
\hline \multicolumn{2}{|c|}{$\mathrm{PO}-3088$} & \multicolumn{2}{|c|}{$P O-3089$} & \multicolumn{2}{|c|}{$\mathrm{PO}-3087$} & \multicolumn{2}{|c|}{$P O-2040$} \\
\hline $\mathrm{TiH}_{0 .}$ & $\mathrm{KClO}_{4}$ & $\mathrm{TiH}_{0 .}$ & $\mathrm{KClO}_{4}$ & $\mathrm{TiH}_{1 .}$ & $\mathrm{ClO}_{4}$ & $\mathrm{TiH}_{0 .}$ & $\mathrm{KClO}_{4}$ \\
\hline $10 \mathrm{kpsi}$ & $20 \mathrm{kpsi}$ & $10 \mathrm{kpsi}$ & $20 \mathrm{kpsi}$ & $10 \mathrm{kpsi}$ & $20 \mathrm{kpsi}$ & $10 \mathrm{kpsi}$ & $20 \mathrm{kpsi}$ \\
\hline$\Omega-\operatorname{com}$ & $\Omega-\mathrm{rm}$ & $\Omega-\mathrm{cm}$ & $\Omega-\mathrm{cm}$ & $\Omega-\mathrm{cm}$ & $\Omega-\mathrm{cm}$ & $8 \div \mathrm{cm}$ & $\Omega-\mathrm{cm}$ \\
\hline 472 & 1.21 & 28.2 & 0.88 & 1172 & 4.31 & 3.08 & 0.44 \\
\hline 150 & 1.43 & 30.6 & 0.96 & - & 7.36 & 3.75 & 0.51 \\
\hline
\end{tabular}


Fig. 39 - Resistivity of Pressed Pellets of Sample QC-1823P $\left(\mathrm{TiH}_{0.65}\right)$ as a Function of Time

\begin{tabular}{|c|c|c|c|c|c|c|c|c|}
\hline \multirow{3}{*}{$\begin{array}{c}\text { Elapsed } \\
\text { Time } \\
\text { (Days) }\end{array}$} & \multicolumn{4}{|c|}{$10 \mathrm{kpsi}$ Load } & \multicolumn{4}{|c|}{20 kpsi Load } \\
\hline & \multicolumn{2}{|c|}{ FACE 1} & \multicolumn{2}{|c|}{ FACE 2} & \multicolumn{2}{|c|}{ FACE 1} & \multicolumn{2}{|c|}{ FACE 2} \\
\hline & $\rho(\Omega-\mathrm{cm})$ & \% Dev & $\rho(\Omega-\mathrm{cm}$ & $\%$ Dev & $\rho(\Omega-\mathrm{cm})$ & $\%$ Dev & $\rho(\Omega-\mathrm{cm}$ & $\%$ Dev \\
\hline 0.02 & 0.00392 & 6.7 & 0.00356 & 5.8 & 0.00175 & 2.6 & 0.00179 & 1.4 \\
\hline 0.75 & 0.00358 & 6.7 & 0.00326 & 0.6 & .' & & & \\
\hline 3 & 0.00347 & 6.7 & 0.00358 & 3.7 & & & & \\
\hline 7 & 0.00371 & 8 & .0 .00367 & 2.3 & 0.00186 & 3.4 & 0.00180 & 1 \\
\hline
\end{tabular}

Fig. 40 - Resistivity of $\mathrm{TiH}_{0.65}$ From Time of Preparation

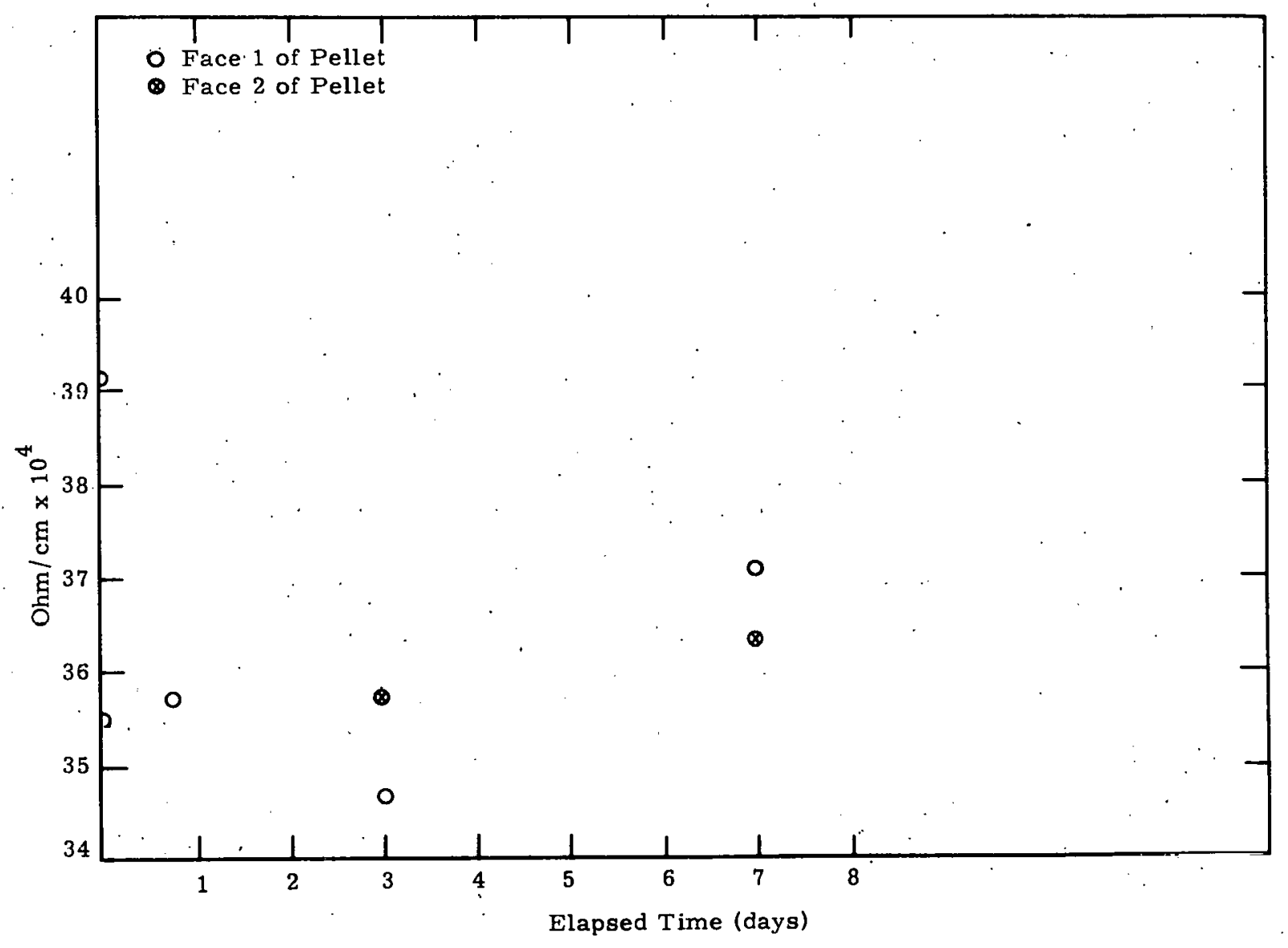


Fig. 41 - Resistivity of Sample PO-3086 With Pressure

\begin{tabular}{|c|c|c|c|c|c|}
\hline \multicolumn{2}{|c|}{$5 \mathrm{kpsi}$} & \multicolumn{2}{|c|}{$10 \mathrm{kpsi}$} & \multicolumn{2}{|c|}{$20 \mathrm{kpsi}$} \\
\hline $\begin{array}{c}\text { Resistivity } \\
(\Omega / \mathrm{cm}) \\
\end{array}$ & $\begin{array}{c}\text { Std. Dev. } \\
\% \\
\end{array}$ & $\begin{array}{l}\text { Resistivity } \\
(\Omega / \mathrm{cm}) \\
\end{array}$ & $\begin{array}{c}\text { Std. Dev. } \\
\% \\
\end{array}$ & $\begin{array}{c}\text { Resistivity } \\
(\Omega / \mathrm{cm}) \\
\end{array}$ & $\begin{array}{c}\text { Std. Dev. } \\
\% \\
\end{array}$ \\
\hline 58 & 43 & 2.1 & 22 & 0.44 & 9 \\
\hline 511 & 111 & 2.0 & 15 & 0.53 & 0.7 \\
\hline 103 & 42 & 2.53 & 1. 2 & 0.46 & 6.0 \\
\hline 103 & 19 & 4.30 & 0.3 & 0.55 & 0.2 \\
\hline
\end{tabular}

Fig. 42 -

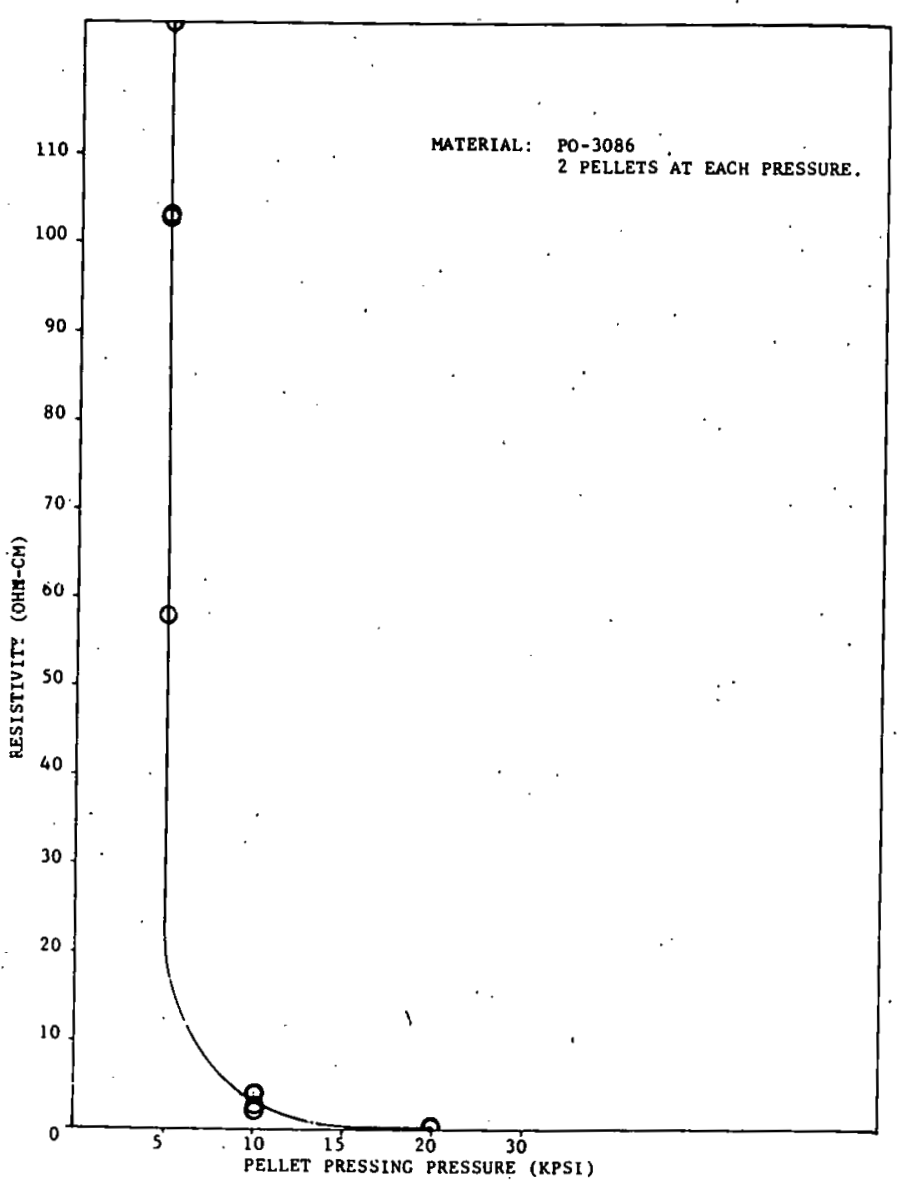


FIGS. 43-55 - VIEWGRAPHS FROM PRESENTATION BY D. B. SULLENGER 
DEBYE-SCHERRER POWDER X-RAY DIFFRACTION ANALYSES

OF $\mathrm{TiH}_{X}-\mathrm{KCIO}_{4}$ MATERIALS HAVE CONTRIBUTED SUBSTANTIALLY TO PYROTECHNIC DEVELOPMENT AND PRODUCTION VIA:

1. ChARACTERIZING BASELINE Ti, $\mathrm{TiH}_{\mathbf{X}}$ AND $\mathrm{KCIO}_{4}$;

2. ASSISTING IN FINOING A SUPERIOR PREPARATIVE METHOD FOR $\mathrm{TiH}_{\mathbf{x}}$ :

- 3. SUPPORTING OTHER TEAMS IN A VARIETY OF WAYS:

4. DEVELOPING FUNDAMENTAL DATA FOR $\mathrm{KCIO}_{4}$ AND FUR THE TI-H SYSTEMM

AS THE PROJECT CONTINUES POWDEH X-RAY DIFFRACTION WILL REMAIN A KEY METHOD OF ANALYSIS.

Fig. $44-$

STANDARD REFERENCE POWDER DIFFRACTION

PATTERNS SELECTED FOR THIS WORK

\begin{tabular}{|c|c|}
\hline SUBSTANCE & PATTERN AND SOURCE \\
\hline$u-T I$ & JCPDS 15.682 \\
\hline$\gamma-\mathrm{TiH}_{2 \cdot y}$ & $\begin{array}{l}\text { EXPERIMENTALLY DETERMINED } \\
\text { PATTERN FROM PROJECT BASE. }\end{array}$ \\
\hline- & IINE MATERIAL \\
\hline $\mathrm{KC1O}_{4}$ & $\begin{array}{l}\text { EXPERIMENTALLY DETEAMINED } \\
\text { PATTERN FROM PROJECT BASE. } \\
\text { LINE MATERIAL }\end{array}$ \\
\hline kra & JCPDS I 4.587 \\
\hline $\mathrm{TiO}_{2}$ (rutile) & JCPDS \ 21-1276 \\
\hline
\end{tabular}


Fig. 45 - Experimentally Obtained Patterns Compared to Standard Patterns (top and bottom), Each With $\mathrm{CuK}_{\alpha}$ Radiation (Ni foil $\mathrm{K}_{\beta}$ filters)
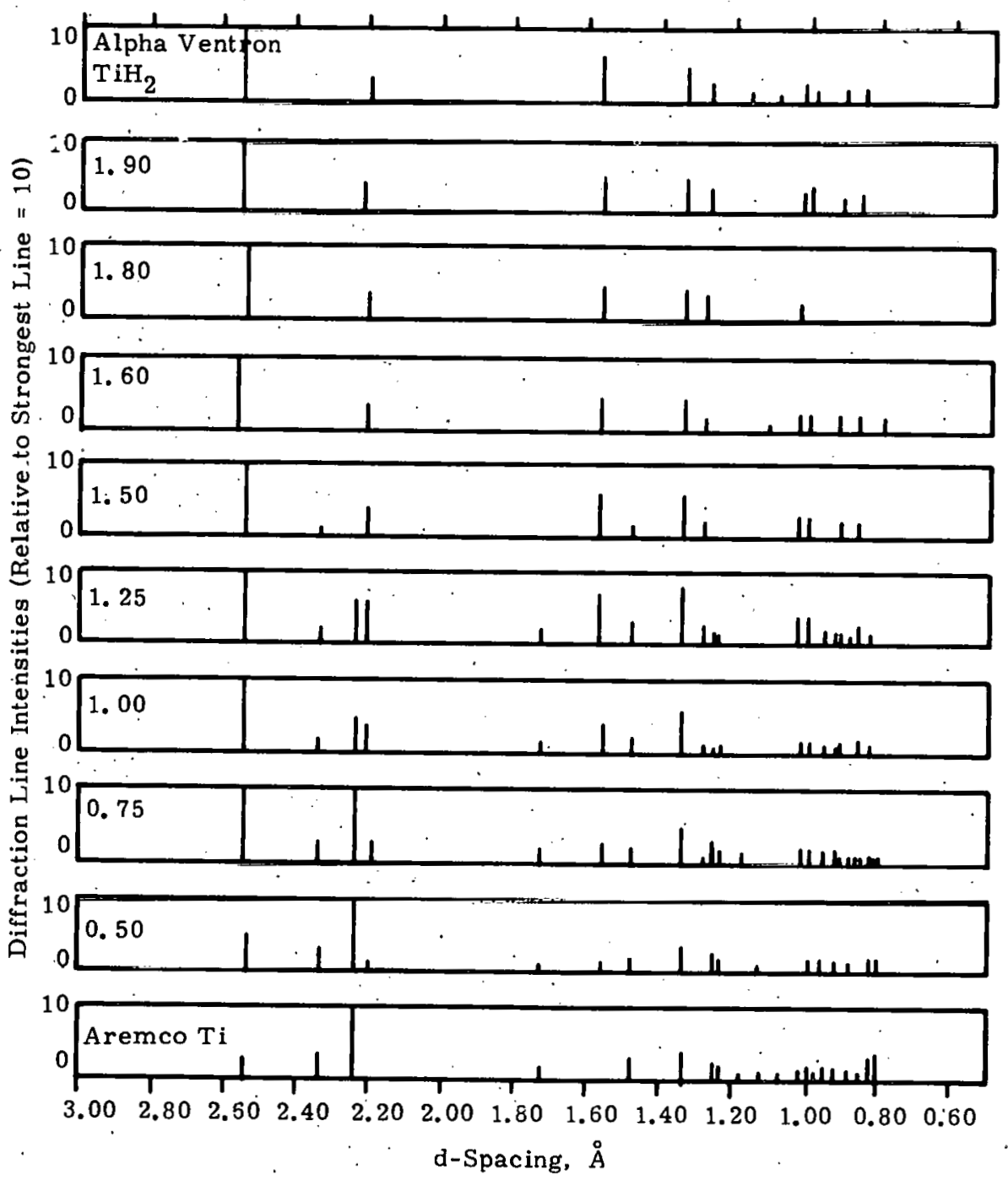
LABORATORY TITANIUM INTERNAL REFERENCE SAMPLE ANALYSES

\section{DESCRIPTION OF MATERIAL}

ALFA VENTRON TI POWOER: < 325 MESH: 99\% PURE

AREMCO $T_{1}:<200$ MESH: $99.7 \%$ PURE

AREMCO Ti: $1-5 \mu \mathrm{m} ; 99.7 \%$ PURE

AREMCO Ti: $<325$ MESH; $99.7 \%$ PURE
ANALYSIS: LATTICE PARAMETERS

$$
\begin{array}{ll}
a-T i & a_{0}=2.9476 \mathrm{~g} \lambda \\
& c_{0}=4.6872 \\
a-T i & \partial_{0}=2.950_{3} \\
& c_{0}=4.6799 \\
a-T i & a_{0}=2.95048 \\
& c_{0}=4.681_{1} \\
a-T i & a_{0}=2.951_{1} \\
& c_{0}=4.685_{3}
\end{array}
$$

Fig. $47-$

LABORATORY "Ti H ${ }_{2}$ " INTERNAL REFERENCE SAMPLE ANALYSES '

\section{DESCRIPTION OF MATERIAL}

ALFA VENTRON $\mathrm{TiH}_{2}$ FROM SLA.: "2 $\mu \mathrm{m} " ; 3.30 \mathrm{wt} \% \mathrm{H}$ ALFA VENTRON $\mathrm{TiH}_{2}$ FROM SLA: "7.2 $\mu \mathrm{m} ": 3.79 w \mathrm{wt} \%$ ALFA VENTRON $\mathrm{TiH}_{2}$ (LOT NO. J4805 A) ALFA VENTRON $\mathrm{TiH}_{2}$ (LOT NO. 4713A)

\begin{tabular}{|c|c|c|c|}
\hline \multirow[b]{2}{*}{ SAMPLE } & \multirow{2}{*}{\multicolumn{2}{|c|}{ a $(A) \quad b(A)$}} & \multirow[b]{2}{*}{$c(A)$} \\
\hline & & & \\
\hline ACS-GRAOE $\mathrm{KClO}_{4}$ & 8.861 & 5.6677 & $7.253 \mathrm{~g}$ \\
\hline $\operatorname{ACS~} \mathrm{KClO}_{4}-1 \mathrm{x}$ & $8.84_{2}$ & $5.667 \mathrm{~g}$ & 7.26 \\
\hline $\operatorname{ACS~} \mathrm{KClO}_{4}-2 x$ & 8.842 & $5.67_{1}$ & $7.254_{8}$ \\
\hline
\end{tabular}
ALFA.VENTRON $\mathrm{TiH}_{2} 1.88 \mu \mathrm{m}$ ALFA VENTRON $\mathrm{TiH}_{2} 1.88 \mu \mathrm{m}$

\section{ANALYSIS; LATTICE PARAMETERS}

$$
\begin{aligned}
\gamma-T i H_{2}: a_{0} & =4.459_{6} \\
\gamma-\mathrm{TiH}_{2}: a_{0} & =4.450_{2} \\
\gamma-\mathrm{TiH}_{2}: a_{0} & =4.448_{2} \\
\gamma-\mathrm{TiH}_{2}: a_{0} & =4.453_{3} \\
\gamma-\mathrm{TiH}_{2}: \mathrm{a}_{0} & =4.453_{3} \\
\gamma-\mathrm{TiH}_{2}: \mathrm{a}_{0} & =4.430_{5}
\end{aligned}
$$

Fig. 48 -

COMPARATIVE LATTIJCE PARAMETERS FOR ACS-GRADE $\cdot \mathrm{KCIO}_{4}$ VS RECRYSTALLIZED SAMPLES 
Fig. 49 -

RESULTS FROM AN X-RAY ANALYSIS OF SIEVE FRACTIONS OF $\mathrm{TiH}_{1.00}$

\begin{tabular}{|c|c|c|c|c|c|}
\hline \multirow{2}{*}{$\begin{array}{l}\text { PARTICLE } \\
\text { SIZE } \\
\end{array}$} & \multirow{2}{*}{$\begin{array}{l}\text { PRESENCE OF } \\
a-T i \text { PHASE }\end{array}$} & \multirow{2}{*}{$\begin{array}{l}\text { PRESENCE OF } \\
\text { TiH }_{2 \cdot y} \text { PHASE } \\
\end{array}$} & \multirow{2}{*}{$\begin{array}{l}\mathrm{TiH}_{2-Y} \text { LATTICE } \\
\text { PARAMETER (A) } \\
\end{array}$} & \multicolumn{2}{|c|}{$\begin{array}{l}\text { a-Ti LATTICE } \\
\text { PARAME TERS (A) }\end{array}$} \\
\hline & & & & $a_{0}$ & $\infty_{0}$ \\
\hline$>105 \mu \mathrm{m}$ & & $\checkmark$ & $a_{0}=4.418_{4}$ & -- & $\ldots$. \\
\hline $105 \cdot 74$ & & $\checkmark$ & $4.419_{4}$ & -- & -- \\
\hline $74-63$ & QUESTIONABLE & $\sqrt{ }$ & 4.4232 & $2.947_{1}$ & 4.692 \\
\hline $63 \cdot 53$ & $\checkmark$ & $\checkmark$ & $.4 .420_{8}$ & $2.947_{1}$ & 4.6825 \\
\hline $53-44$ & $\checkmark$ & $\checkmark$ & 4.4253 & 2.9507 & 4.683 \\
\hline $44 \cdot 37$ & $\checkmark$ & $\checkmark$ & 1.4246 & 2.9526 & $4.69_{3}$ \\
\hline$>105$ & . & $\checkmark$ & $4.420_{2}$ & & \\
\hline
\end{tabular}

Fig. 50 -

$\mathrm{TiH}_{2 \cdot y}$ LATTICE PARAMETERS OF $\mathrm{TiH}_{1.60}$ SIEVE FRACTIONS

\begin{tabular}{cc}
$\begin{array}{c}\text { PARTICLE } \\
\text { SIZE } \\
(\mu \mathrm{m})\end{array}$ & $\begin{array}{c}\mathrm{TiH}_{2-y} \text { LATTICE } \\
\text { PARAMETER } \\
(\hat{\mathrm{i}})\end{array}$ \\
\hline$<37$ & $4.409_{2}$ \\
$37-44$ & $4.408_{1}$ \\
$44-63$ & $4.410_{1}$ \\
$63-74$ & $4.409_{2}$ \\
$74-105$ & $4.408_{2}$ \\
$105-250$ & $4.410_{1}$
\end{tabular}

Fig. $51-$

LATTICE PARAMETERS OF CONSTITUENTS OF PARTICLE SIZED FRACTIONS OF $\mathrm{Ti} \mathrm{H}_{0.19}$

\begin{tabular}{|c|c|c|c|c|}
\hline \multirow[b]{3}{*}{ CUT } & \multirow[b]{3}{*}{ CONSTITUENT(S) } & \multicolumn{3}{|c|}{$\begin{array}{l}\text { LATTICE PARAMETERS } \\
\text { OF CONSTITUENTS (A) }\end{array}$} \\
\hline & & \multicolumn{2}{|c|}{$a-T i$} & \multirow{2}{*}{$\frac{\gamma-\mathrm{TiH}_{2 \cdot \mathrm{y}}}{\mathrm{a}}$} \\
\hline & & a & c & \\
\hline 1 & $\begin{array}{l}a-\mathrm{Ti} \text { (MAJOR): } \\
\gamma-\mathrm{TiH}_{2-y} \text { (MINOR) }\end{array}$ & $2.952_{2}$ & $4.704_{6}$ & $4.38_{6}$ \\
\hline 2 & $\begin{array}{l}a-T i \text { (MAJOR); } \\
y-T_{i H} \cdot y \text { (MINOFi) }\end{array}$ & $2.9531_{8}$ & $4.706_{2}$ & $4: 37_{6}$ \\
\hline 3 & $\begin{array}{l}a-T i \text { (MAJOR): } \\
\gamma-\mathrm{TiH}_{2-y} \text { (MINOR) }\end{array}$ & $2.9 \mathrm{B3}_{1}$ & $4.706_{4}$ & 4.378 \\
\hline 4 & $\begin{array}{l}a-\mathrm{Ti} \text { (MAJOR): } \\
\gamma-\mathrm{TiH}_{3 . \mathrm{V}} \text { (MINOR) }\end{array}$ & 2.953, & $4.707_{4}$ & 4.36 .6 \\
\hline 5 & $\begin{array}{l}a-T i(M A J O R) ; \\
\gamma-\mathrm{TiH}_{2 \cdot Y}\end{array}$ & $\begin{array}{r}2.952_{1} \\
.\end{array}$ & $4.706_{2}$ & $4.38_{6}$ \\
\hline RESIDUE & $\begin{array}{l}a-T i \text { (MAJOR): } \\
y-\mathrm{THH}_{2-Y} \text { (MINOR) }\end{array}$ & $2.854_{1}$ & $4.710_{3}$ & $4.38_{2}$ \\
\hline
\end{tabular}


Fig. 52 - Plot of Lattice Parameters of the Cubic $\mathrm{TiH}_{2-\mathrm{y}}$ Phase va. the Over-
all Composition of $\mathrm{TiH}$ Samples all Composition of $\mathrm{TiH}_{\mathrm{x}}$ Samples

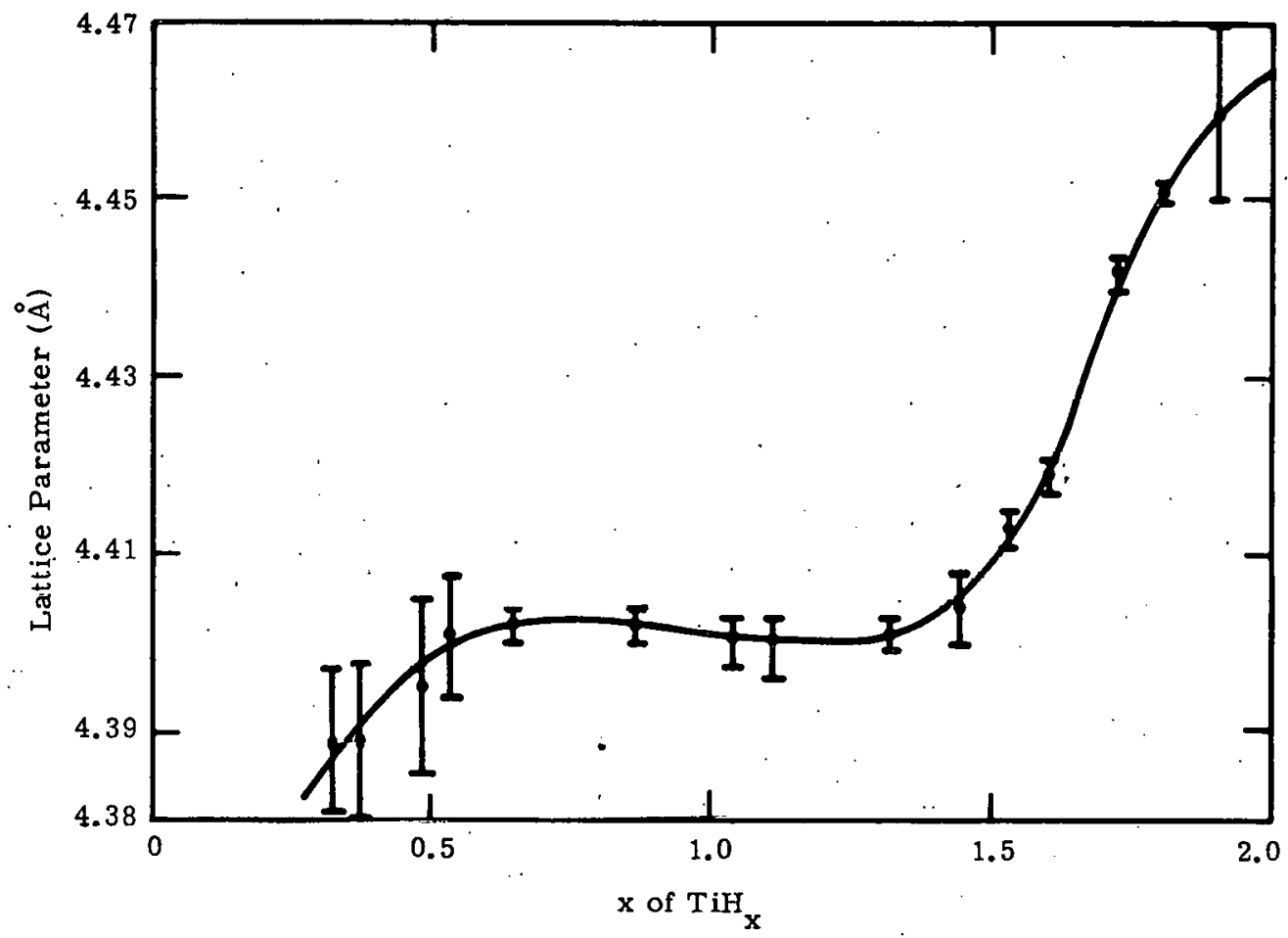

Fig. 5.3 - Lattice Parametcr for Ti-Al Alluy Sarnples

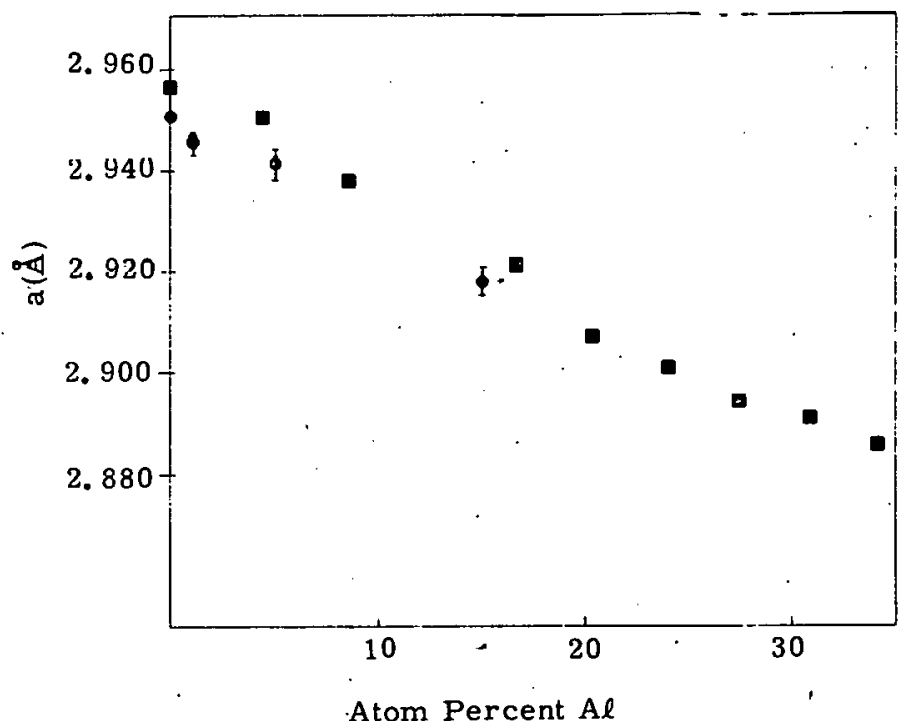


Fig. 54 - Lattice Parameter for Ti-Al Alloy Samples

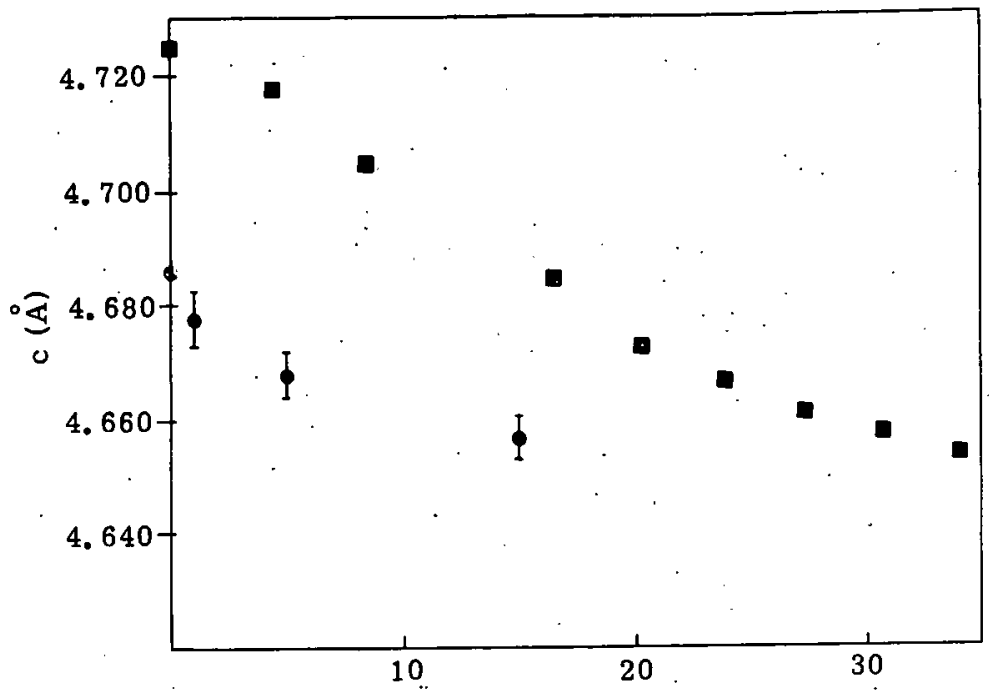

Atom Percent Al

Fig. 55 -

FURTHER PLANNED X-RAY DIFFRACTION SUPPORT OF PYROTECHNIC PRODUCTION AND DEVELOPMENT:

- CONTINUEd ROUTINE ANALYSES IN SUPPORT OF OTHER TEAMS

- elevated temperature studies of $\mathrm{TiH}_{x}$ AND $\mathrm{KClO}_{4}$

- decomposition effect or X-radiation on $\mathrm{KClO}_{4}$

- DEBYE-SCHERRER LIMITS FOR MINOR CONSTITUENTS

- quantitative diffRActometric ANALYSIS OF TITANIUM-HYDROGEN SYSTEM 
FIGS. 56-64 - VIEWGRAPHS FROM PRESENTATION BY J. W. REED 
Fig. 56 -

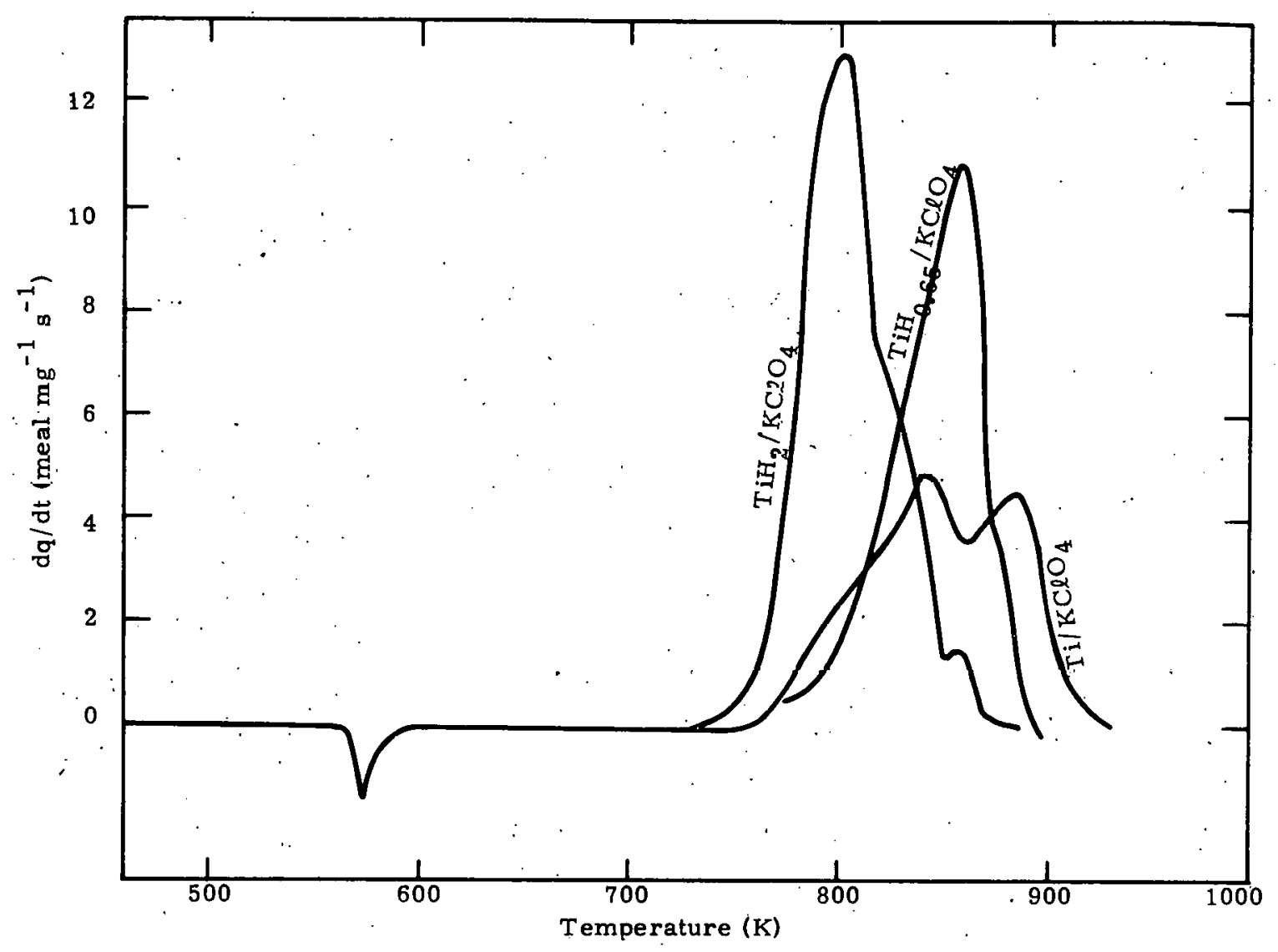

Fig. 57 -

$\mathrm{dq} / \mathrm{dt}=\mathrm{A}(\mathrm{Q})^{\mathrm{n}} \mathrm{e}^{-\mathrm{E} / \mathrm{RT}}$

$Q_{i}=\left[1-\frac{\int_{0}^{\left.T_{L_{(d q} / d t}\right) d t}}{\int^{w\left(d_{4} / d_{L}\right) d t}}\right]$

$\mathrm{dq} / \mathrm{dt}=$ Energy Relcase $\left(\right.$ mcal $\mathrm{mg}^{-1} \mathrm{sec}^{-1}$ )

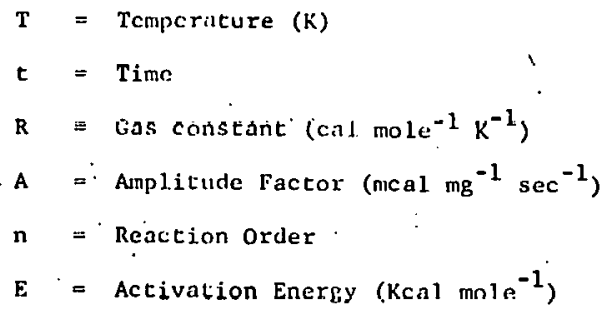


Fig. 58 - DSC Exotherm for $\mathrm{KClO}_{4} / \mathrm{TiH}_{0.65}(67 / 33)$

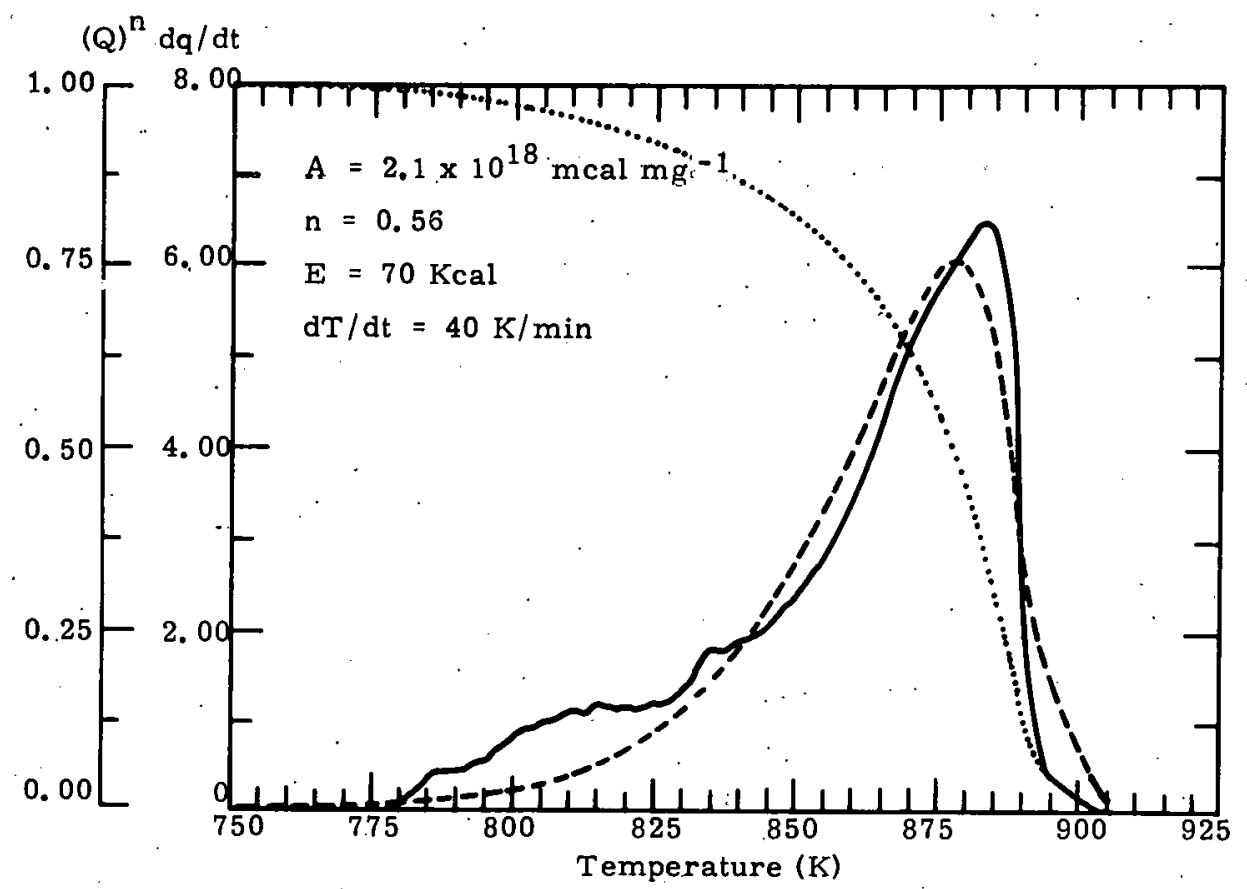

Fig. 59 - DSC Exotherm for $\mathrm{KClO}_{4} / \mathrm{TiH}_{0.65}(67 / 33)$

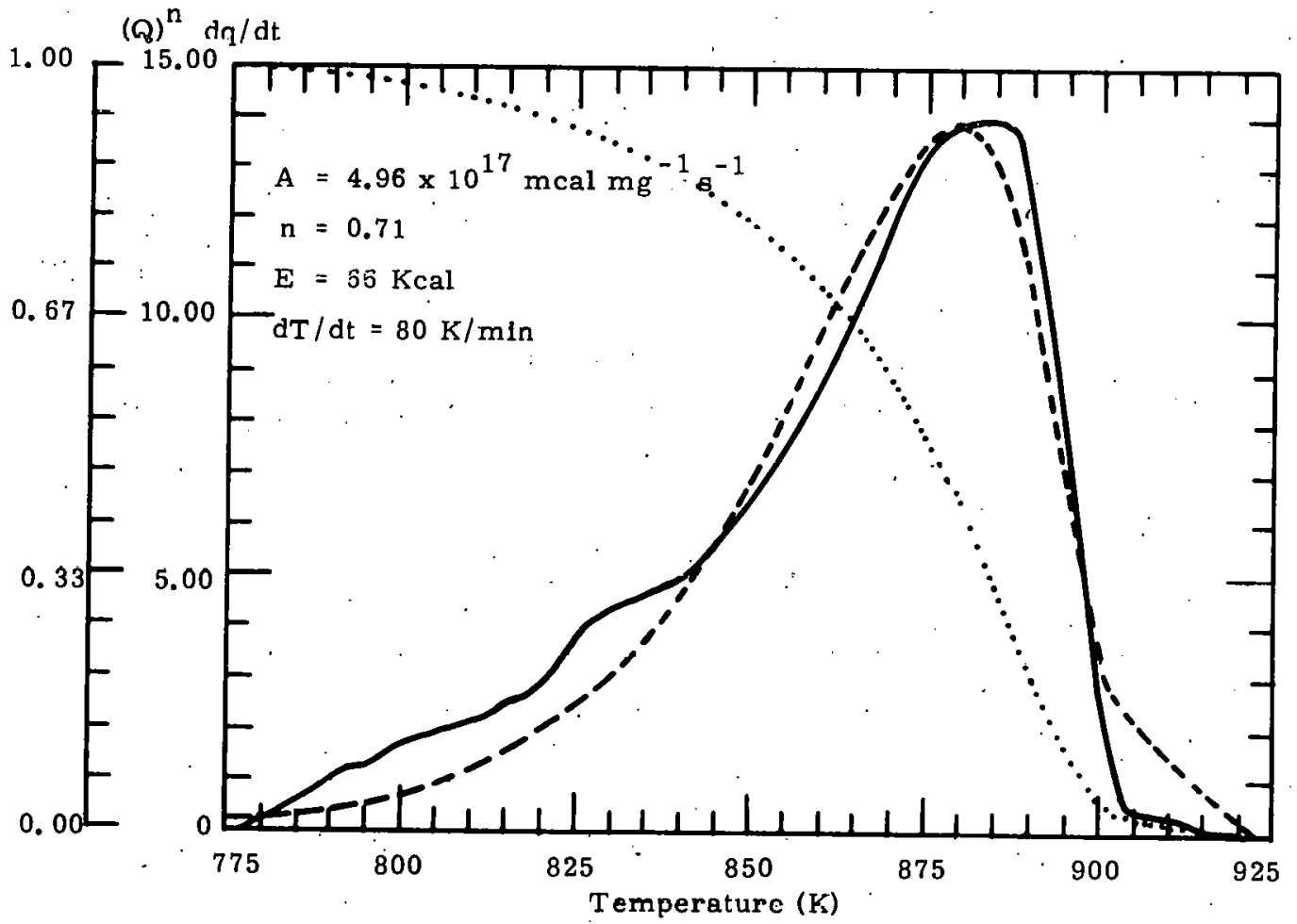


Fig. 60 - DSC Exotherm for $\mathrm{KClO}_{4} / \mathrm{TiH}_{0.65}(67 / 33)$

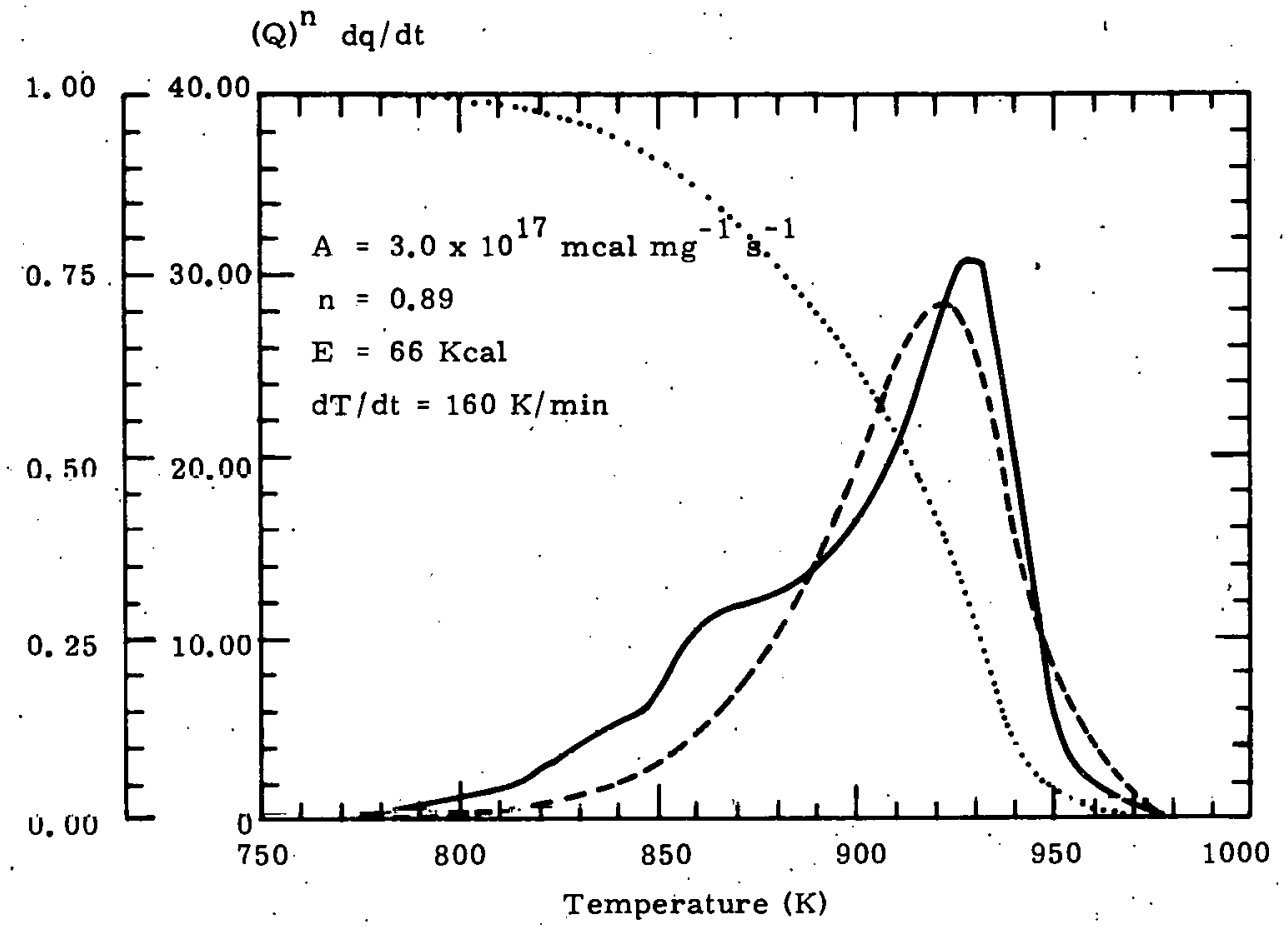

Fig. 61 - DSC Exotherm for $\mathrm{KClO}_{4} / \mathrm{TiH}_{0.65}(67 / 33)$

$(Q)^{12} \mathrm{dq} / \mathrm{dt}$

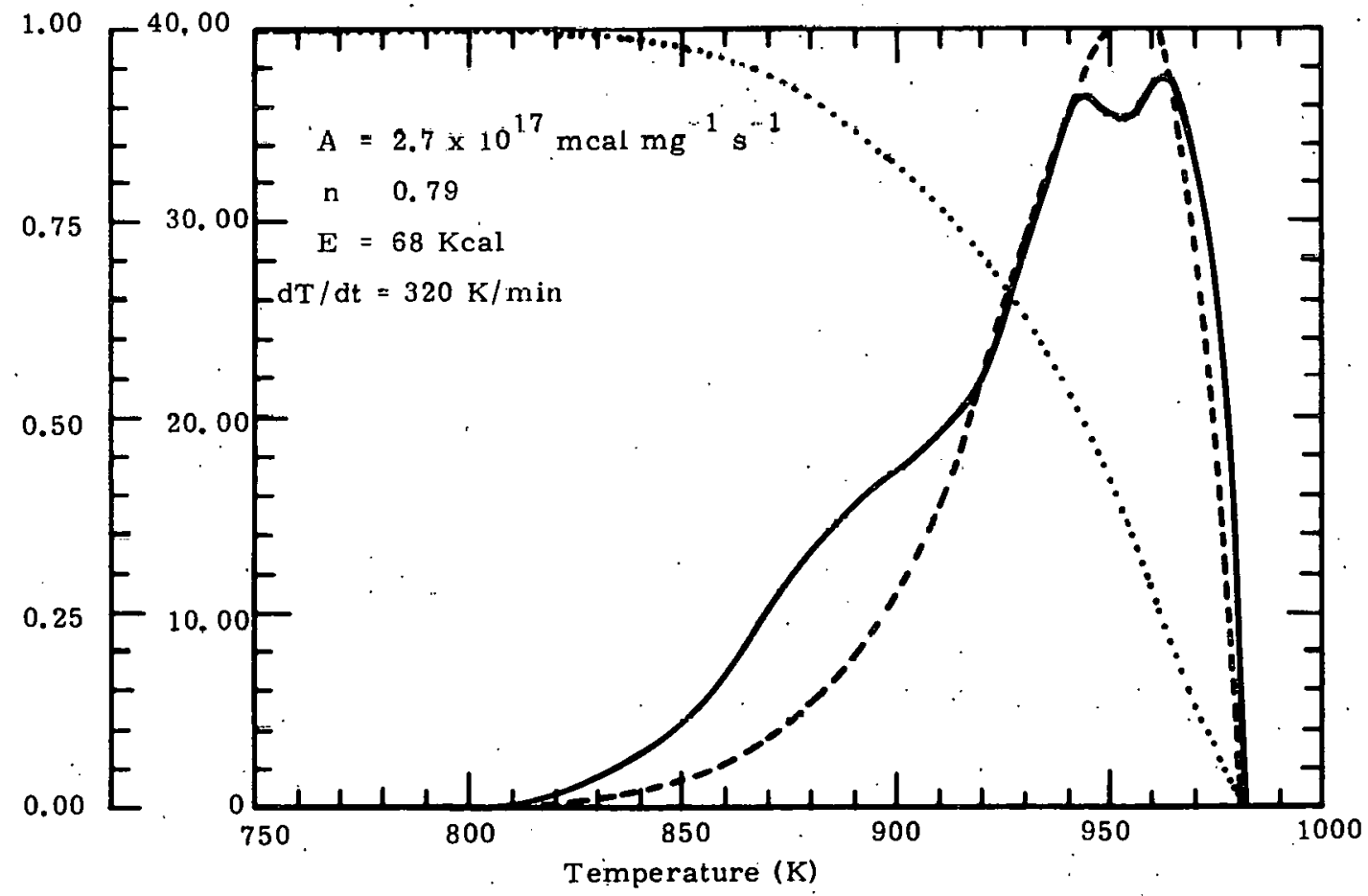


Fig. 62 - DSC Exotherm for $\mathrm{KClO}_{4} / \mathrm{TiH}_{0.65}(67 / 33)$

$(Q)^{\mathrm{n}} \mathrm{dq} / \mathrm{dt}$

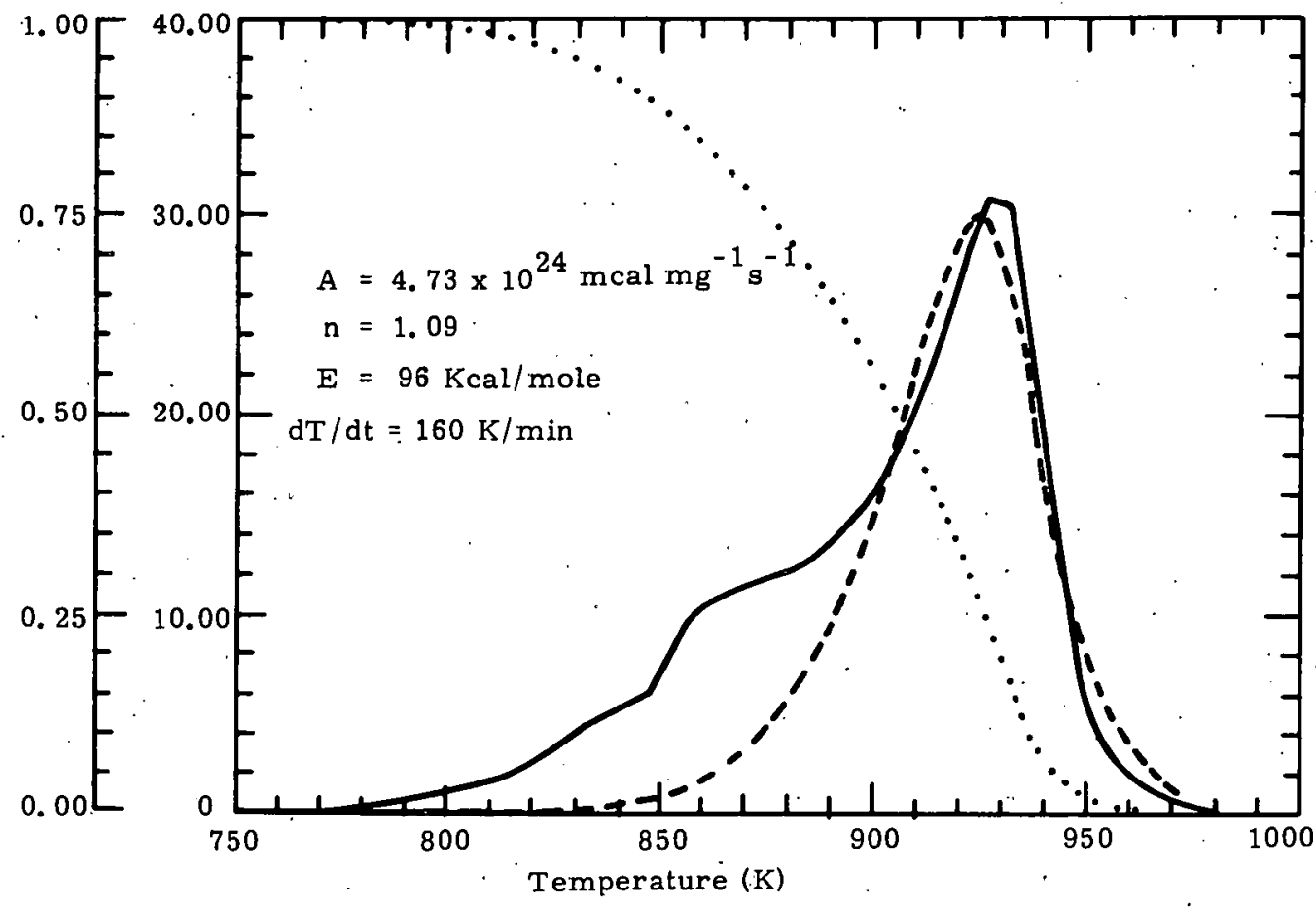

Fig. 63 - DSC Exotherm for $\mathrm{KClO}_{4} / \mathrm{TiH}_{0.65}(67 / 33)$

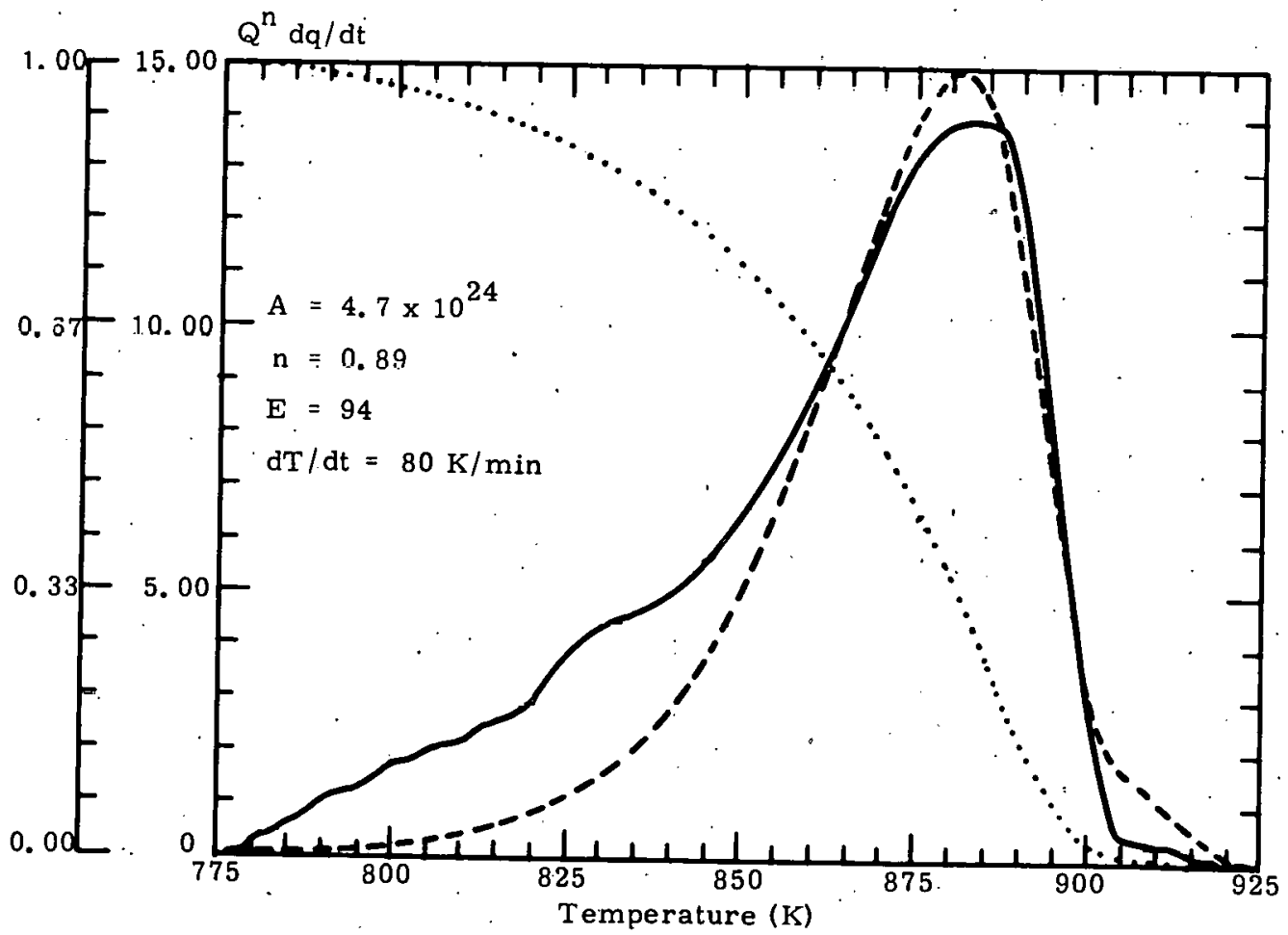


Fig. 64 -

\section{KINETIC PARAMETERS}

$\frac{\text { K/MIN }}{\mathrm{A}}$
$\mathrm{n}$
$\mathrm{E}$

$\frac{40}{2.1 \times 10^{18}}$
0.56
70

$4.9 \times 10^{17}$
0.71
66

160

$3.0 \times 10^{17}$

0.89

66

$\frac{320}{2.7 \times 10^{17}}$

0.79

68

\section{PARTIAL FIT}

$\begin{array}{lcc}\text { A. } & 6.5 \times 10^{24} \\ \text { n } & 0.69 \\ \text { E } & 95\end{array}$

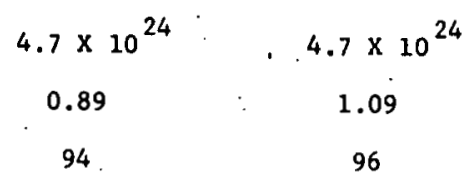

$3.8 \times 10^{2 / 4}$

1.01

94

96

98 
)

FIGS. 65-76 - VIEWGRAPHS FROM PRESENT ATION BY T. M. MASSIS 
Fig. $65-\mathrm{TiH}_{0.65} / \mathrm{KClO}_{4}$ Stability/Compatibility Status

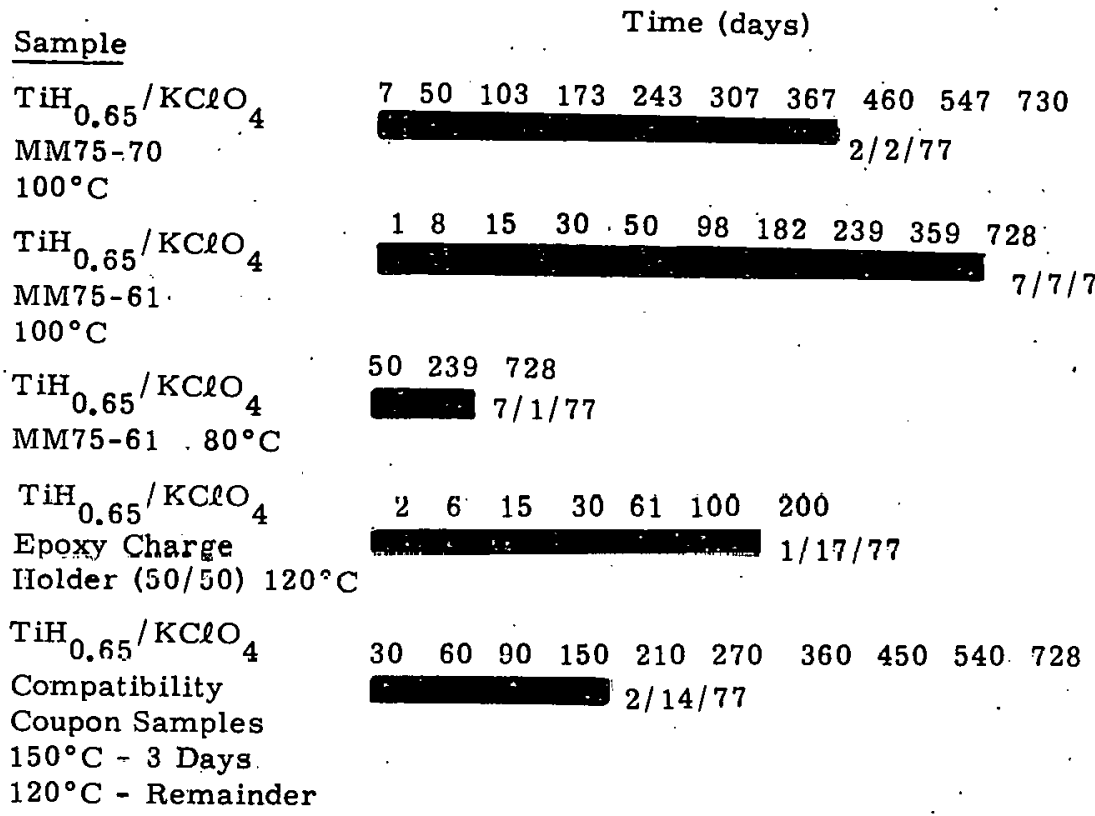

Sample

Time (days)

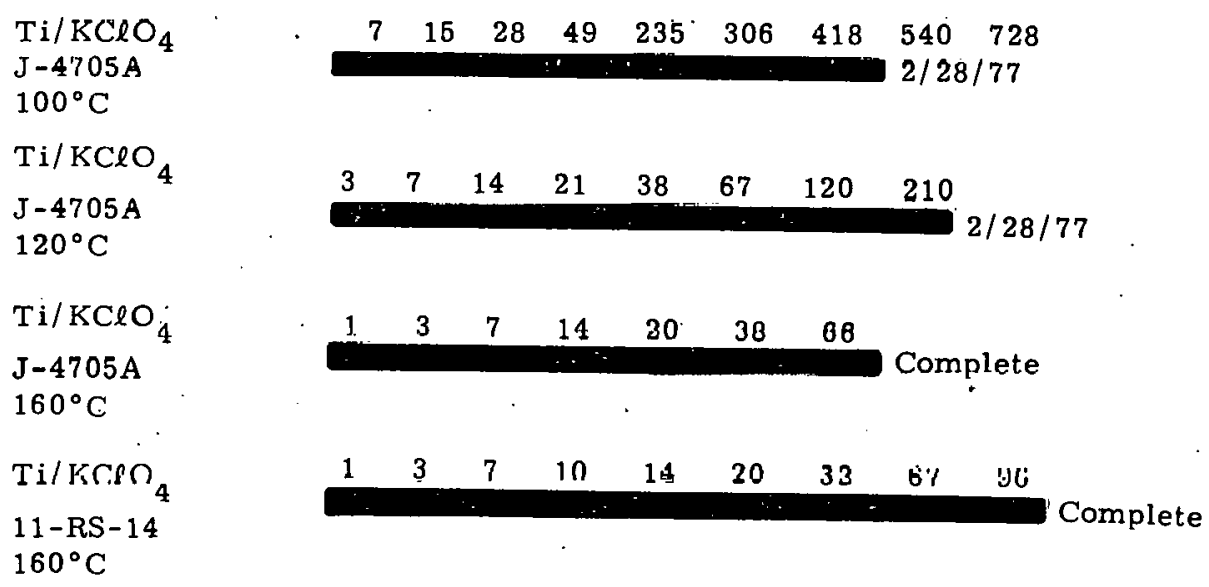


Fig. 67 - Component Aging Status

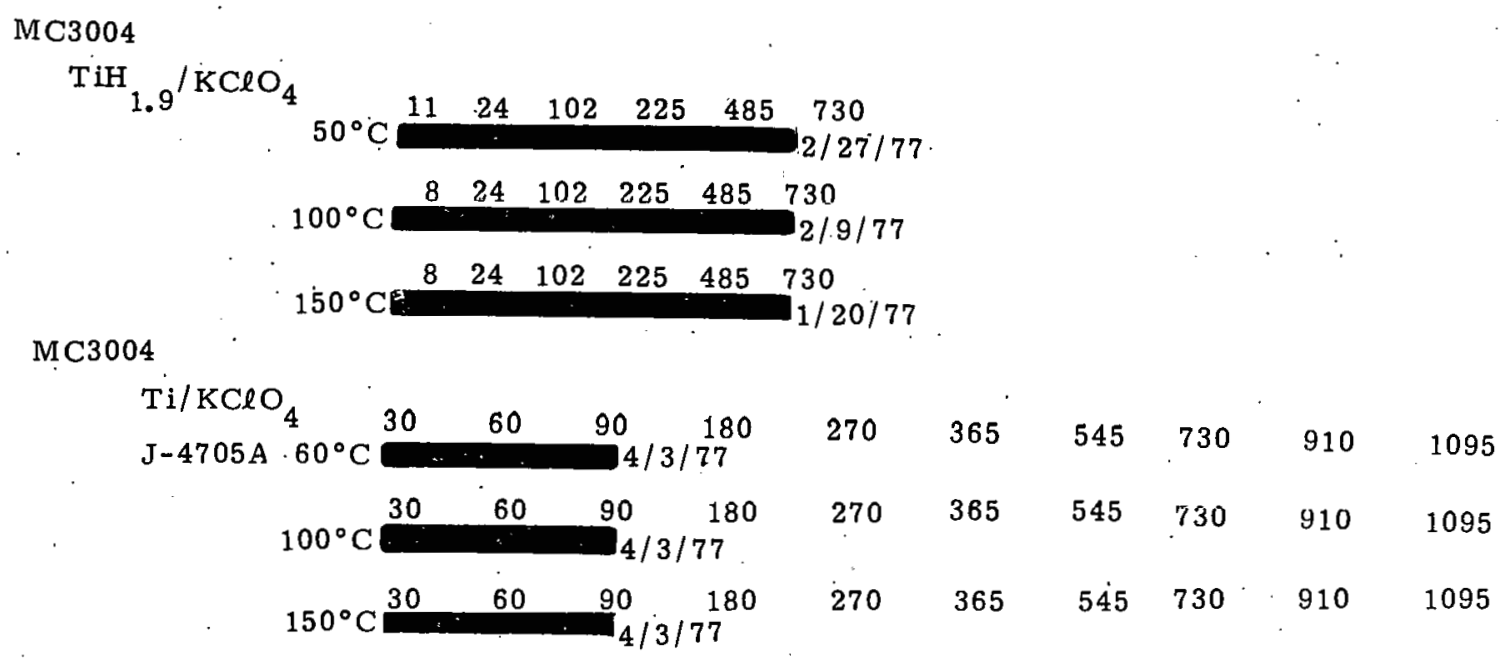

Fig. 68 - Stability of $\mathrm{TiH}_{\mathrm{x}} / \mathrm{KClO}_{4}$ Chloride Formation

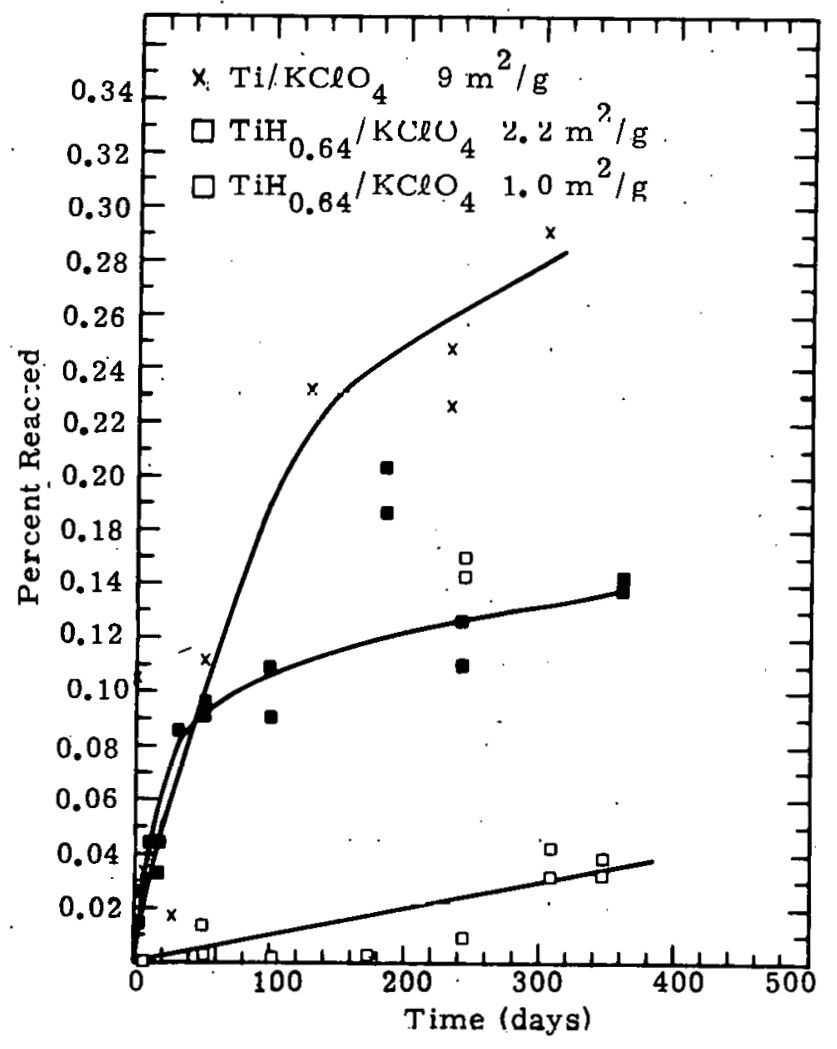


Fig. 69 - Stability of $\mathrm{TiH}_{\mathrm{x}} / \mathrm{KClO}_{4}$ Rate of $\mathrm{C}^{-}$Formation

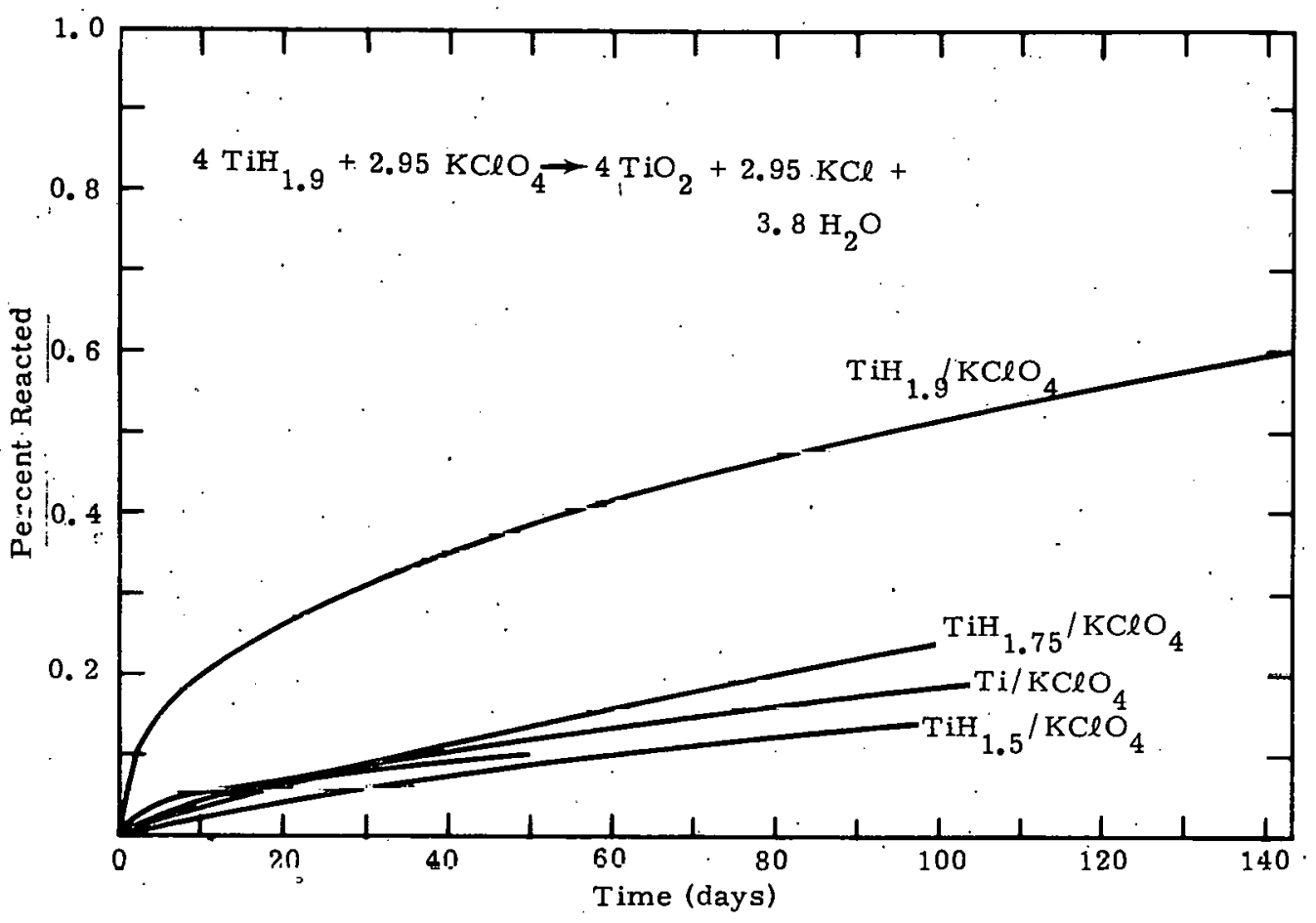

Fig. 70 - Coupon Sample

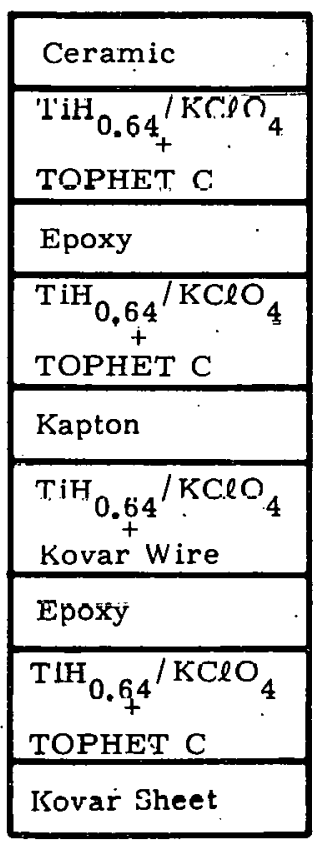

Test Conditions

$120^{\circ} \mathrm{C}-30,60,90,150,210,270,360,450,540,720$ Days 
Fig. 71 - Coupon Sample

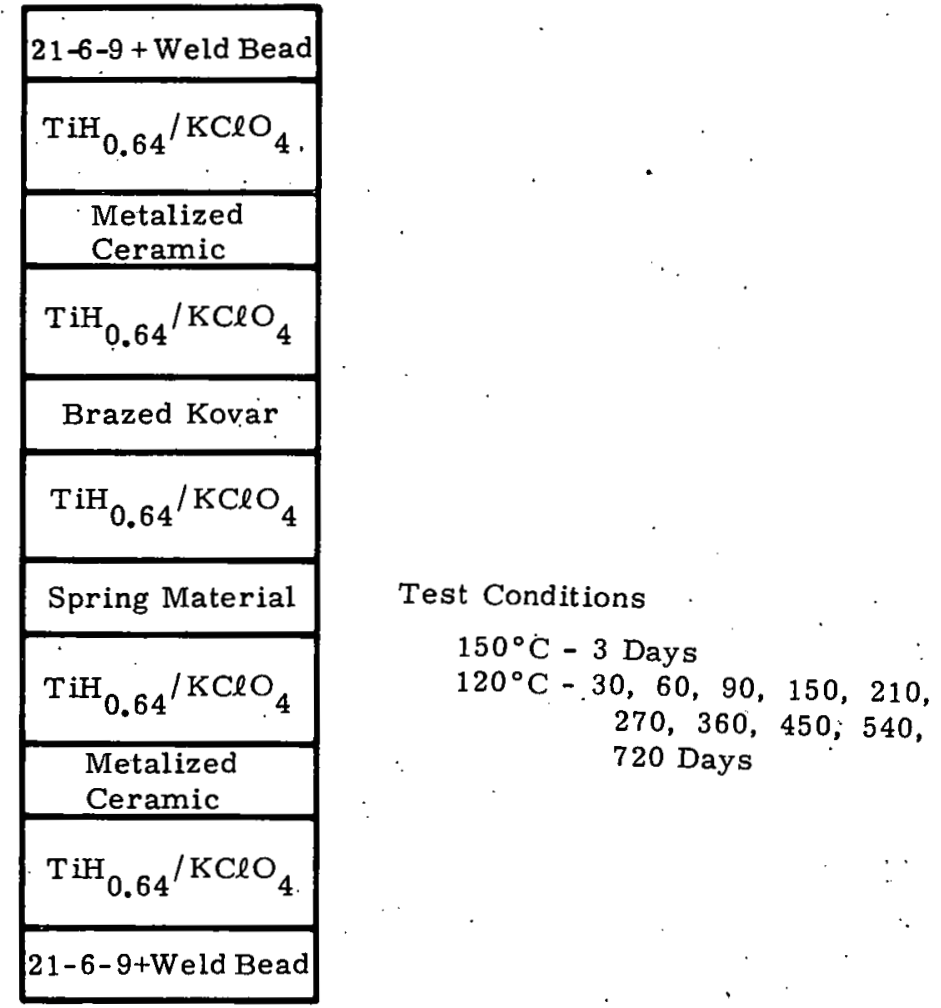

Fig. 72 - Stabllity of $\mathrm{TiH}_{0.65} / \mathrm{KClO}_{4}$ in Coupon

Configuration Chloride Formation

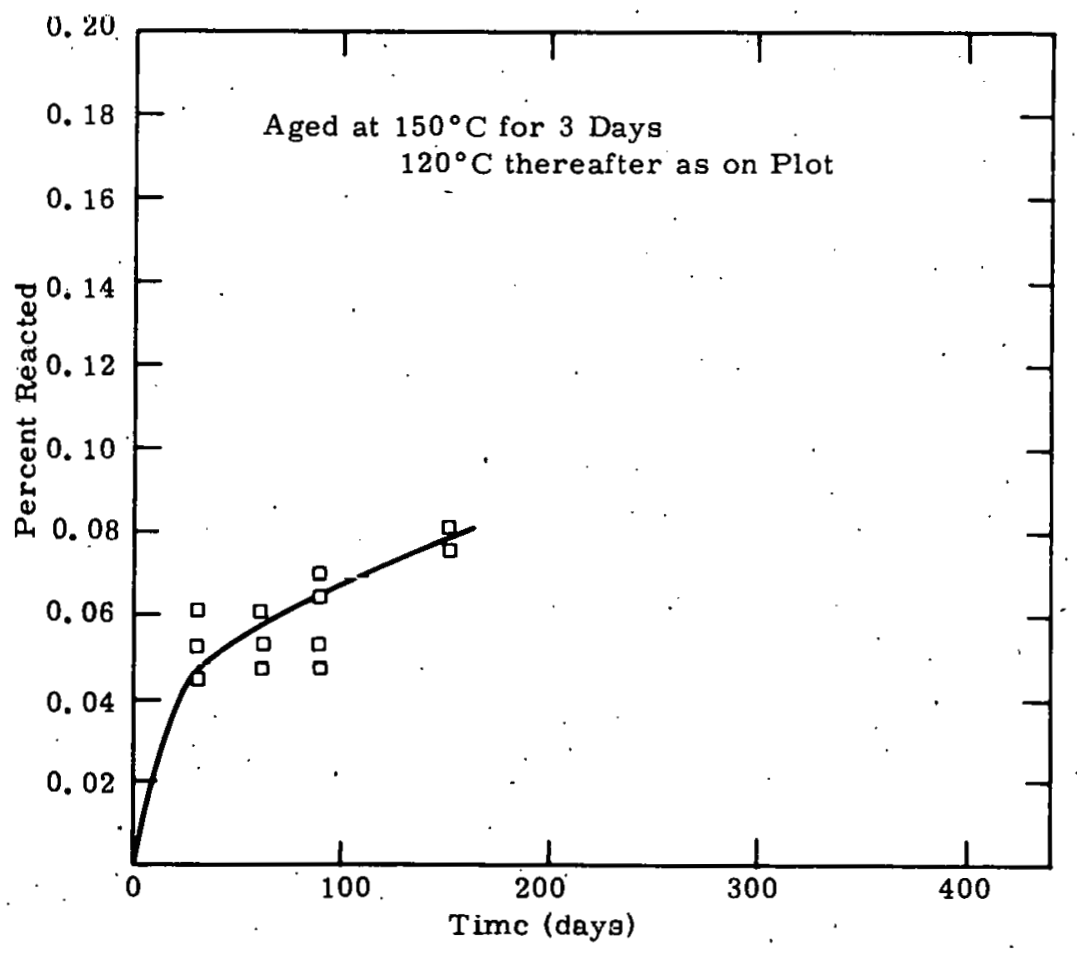


Fig. $7 \grave{3}$ - Compatibility of $\mathrm{TiH}_{0.64} / \mathrm{KClO}_{4}$ and Epoxy Charge Holder Chloride Formation

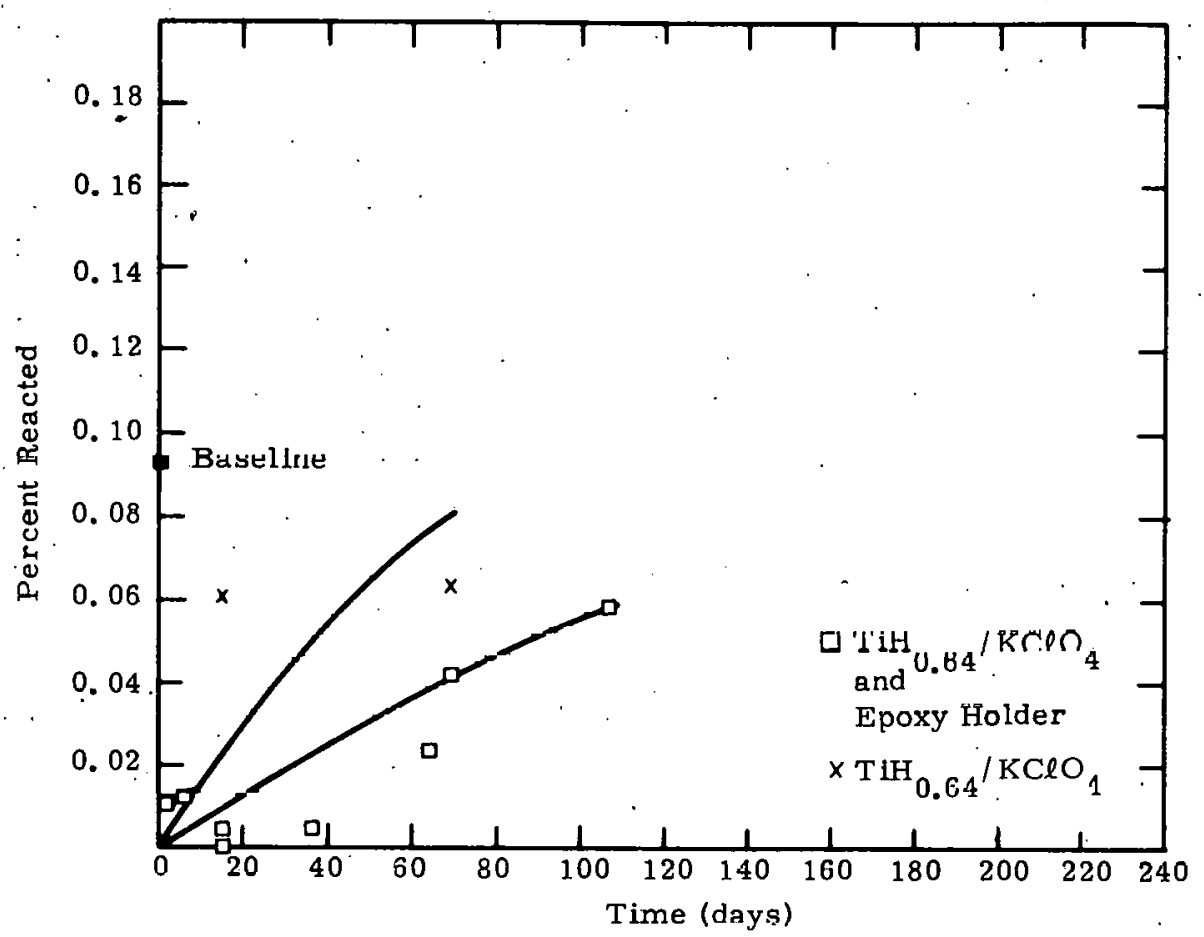

Fig. 74 - Compatibility of $\mathrm{TiH}_{0.64} / \mathrm{KClO}_{4}$ and Epoxy Charge Hniter $\mathrm{CD}, \mathrm{CO}_{2}$ Evolution

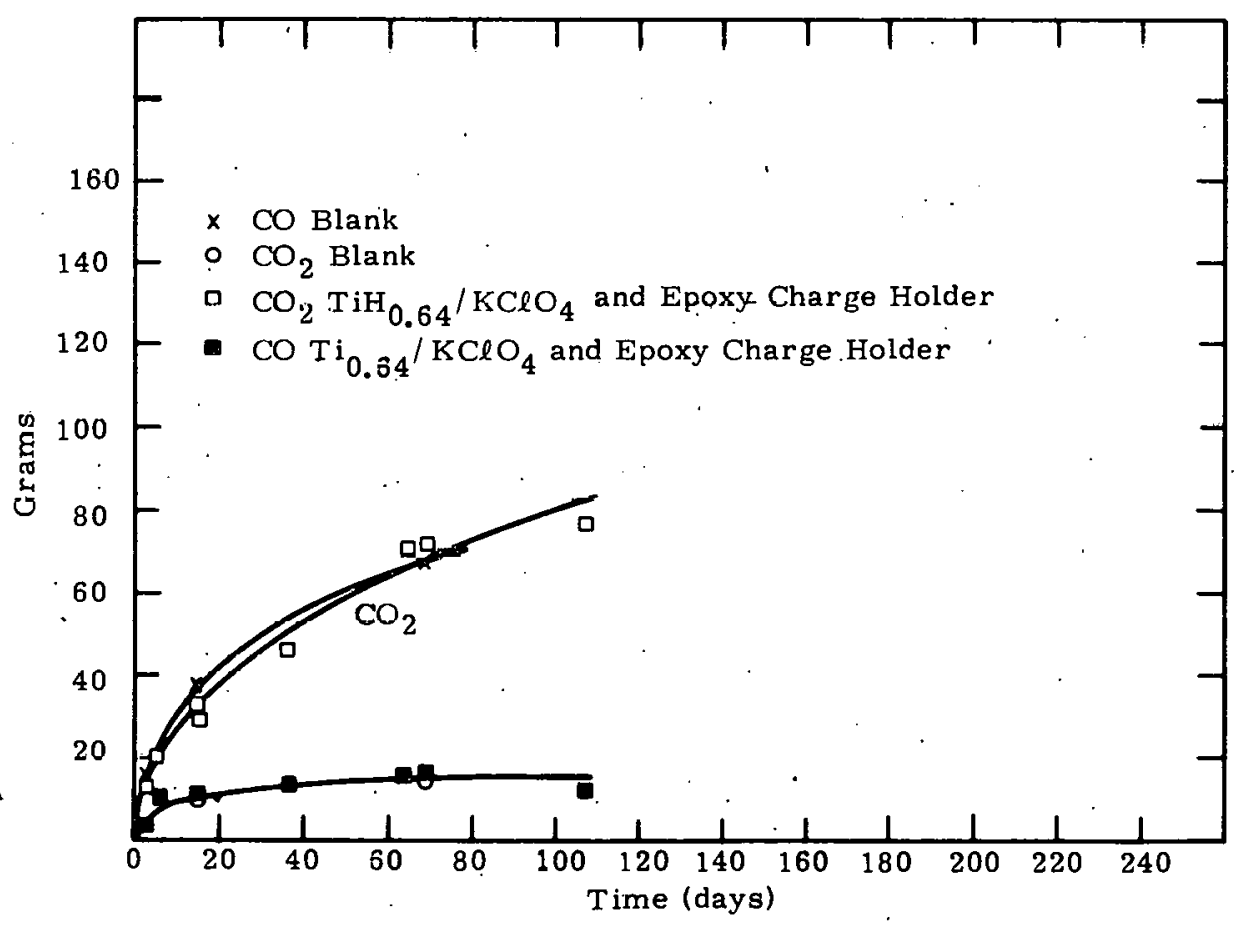


Fig." 75 - Compatibility of $\mathrm{TiH}_{0.64} / \mathrm{KClO}_{4}$ and Epoxy Charge Holder $\mathrm{H}_{2} \mathrm{O}$ Evolution

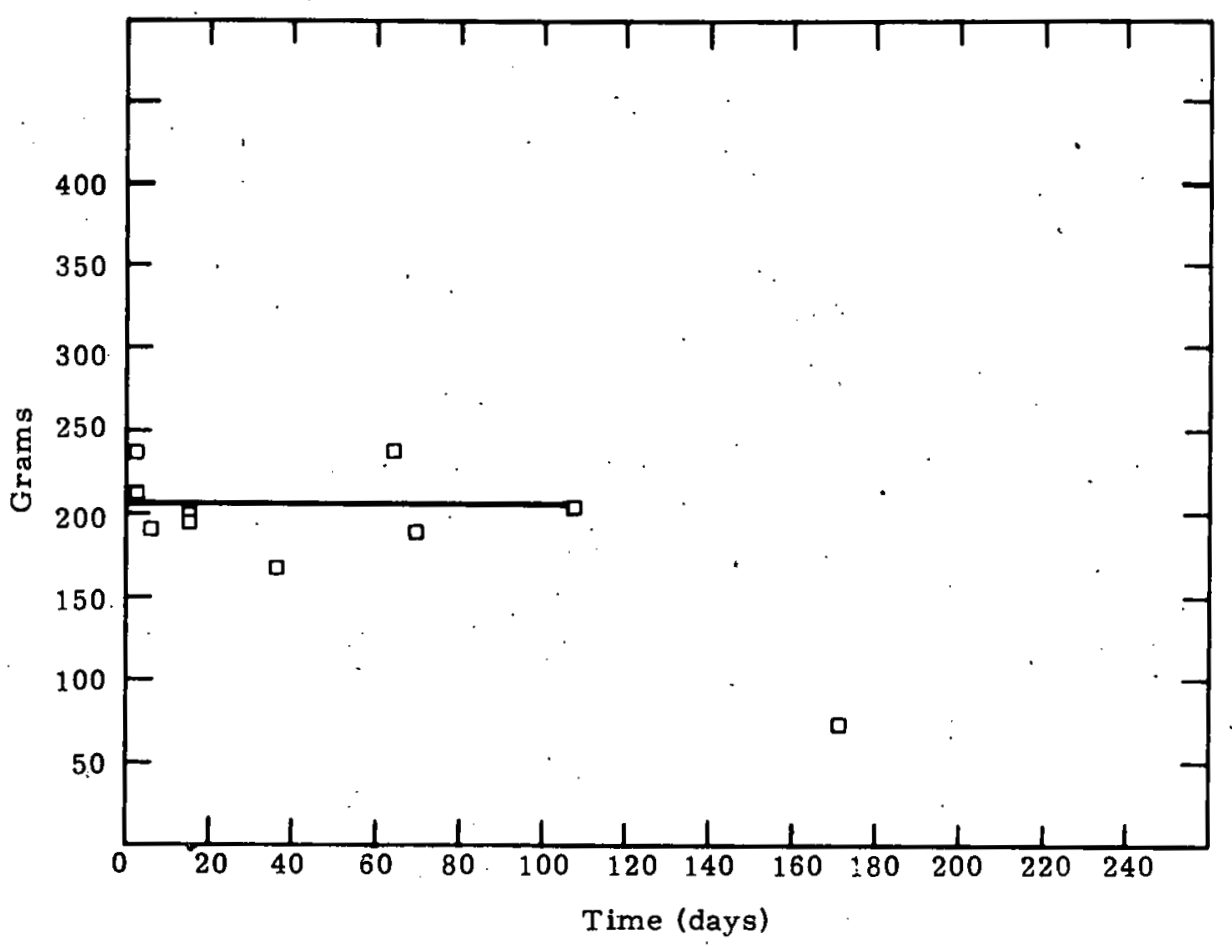

Fig. 76 - Stability of $\mathrm{Ti} / \mathrm{KClO}_{4}$ in $\mathrm{MC}_{\text {Formation }}$. 3004 Chloride

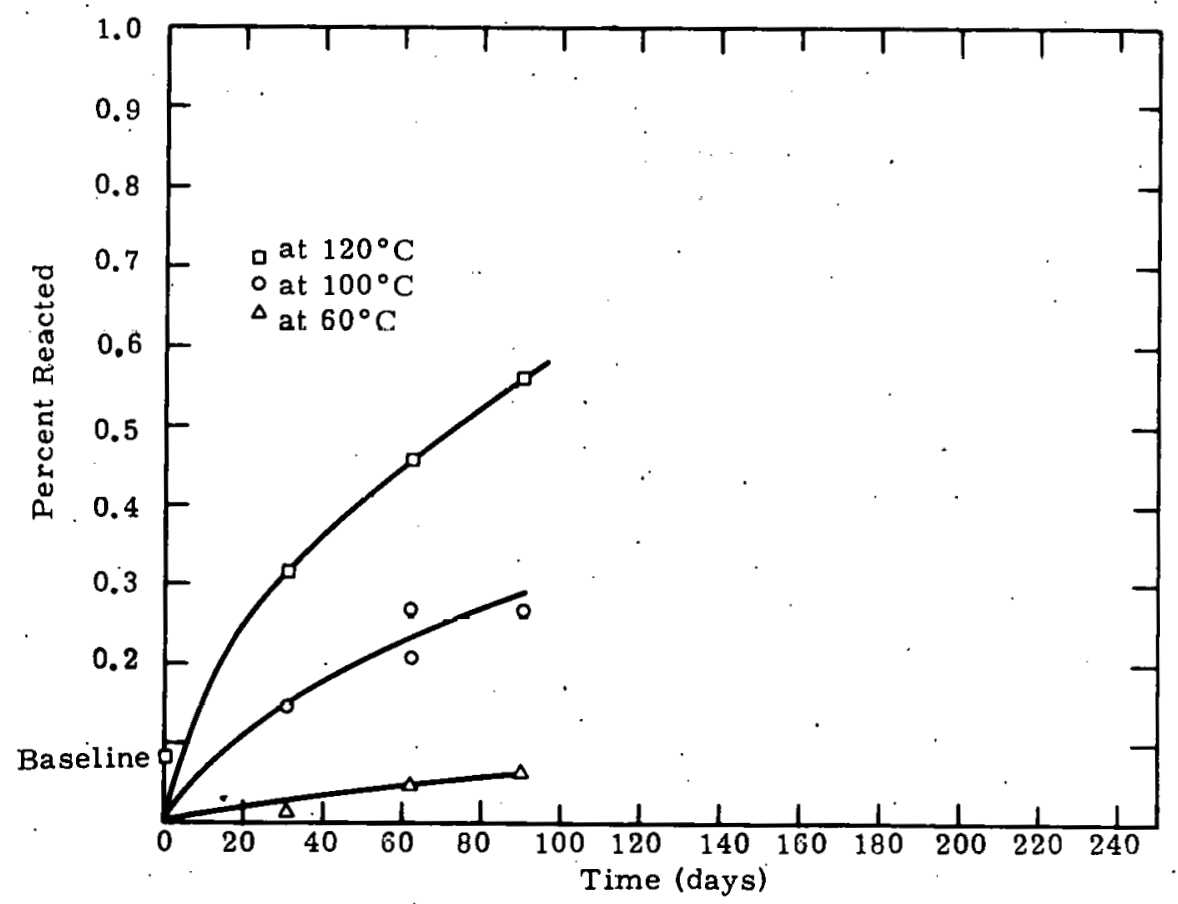


FIGS. 77-87 - VIEWGRAPHS FROM PRESENTATION BY T. M. MASSIS (2) 
Fig. 77 - TMA - Thermomechanical Analysis

- Measurement of Vertical Displacement as a Function of Temperature or Time

- Utilizes a Movable Core Differential Transformer

- Provides a DC Output Proportional to Linear Displacement of the Core

- Sensitivity: $1.5 \times 10^{-4}$ Inches per Inch of Chart Paper

Fig. 78 - System Description
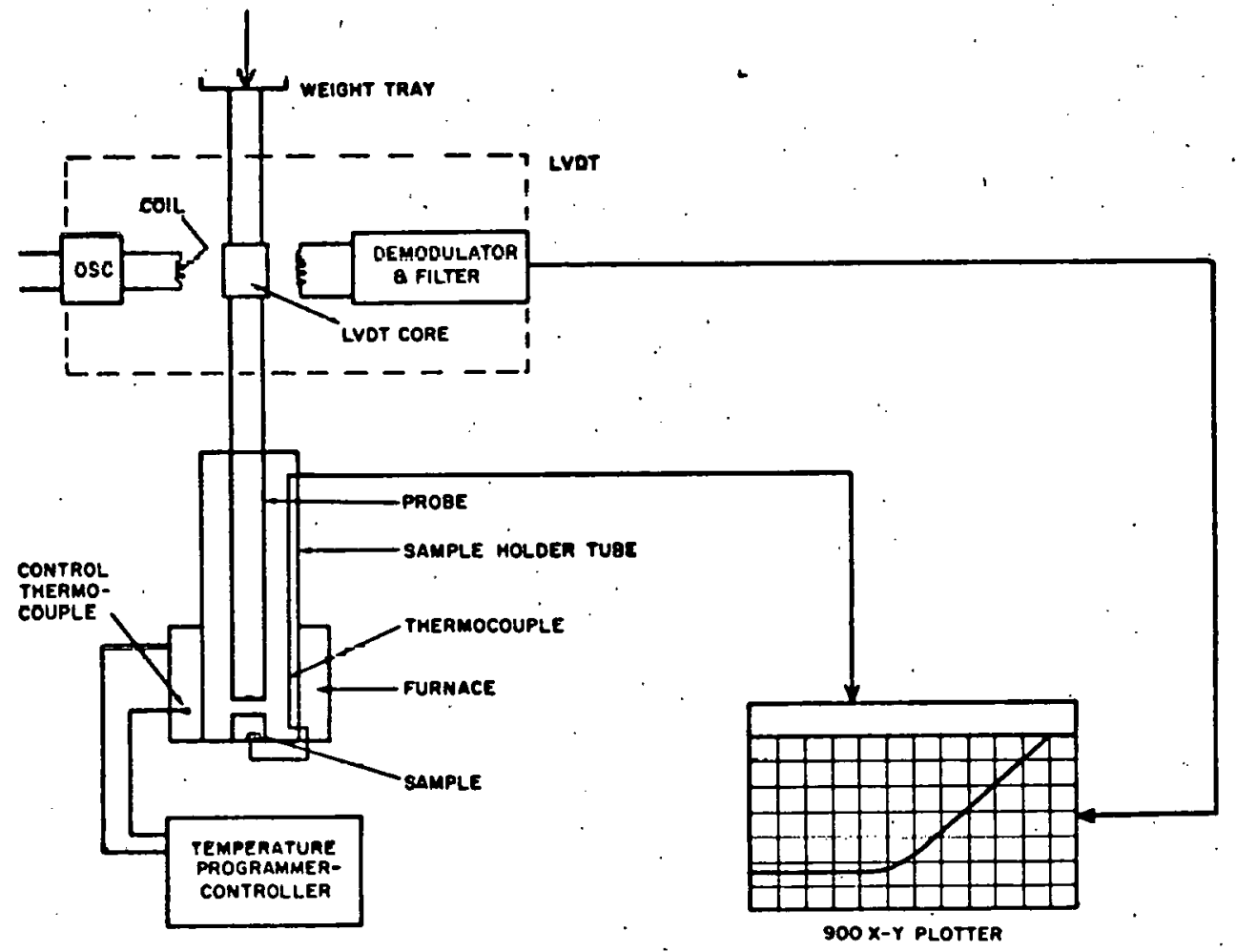
Fig. 79 -

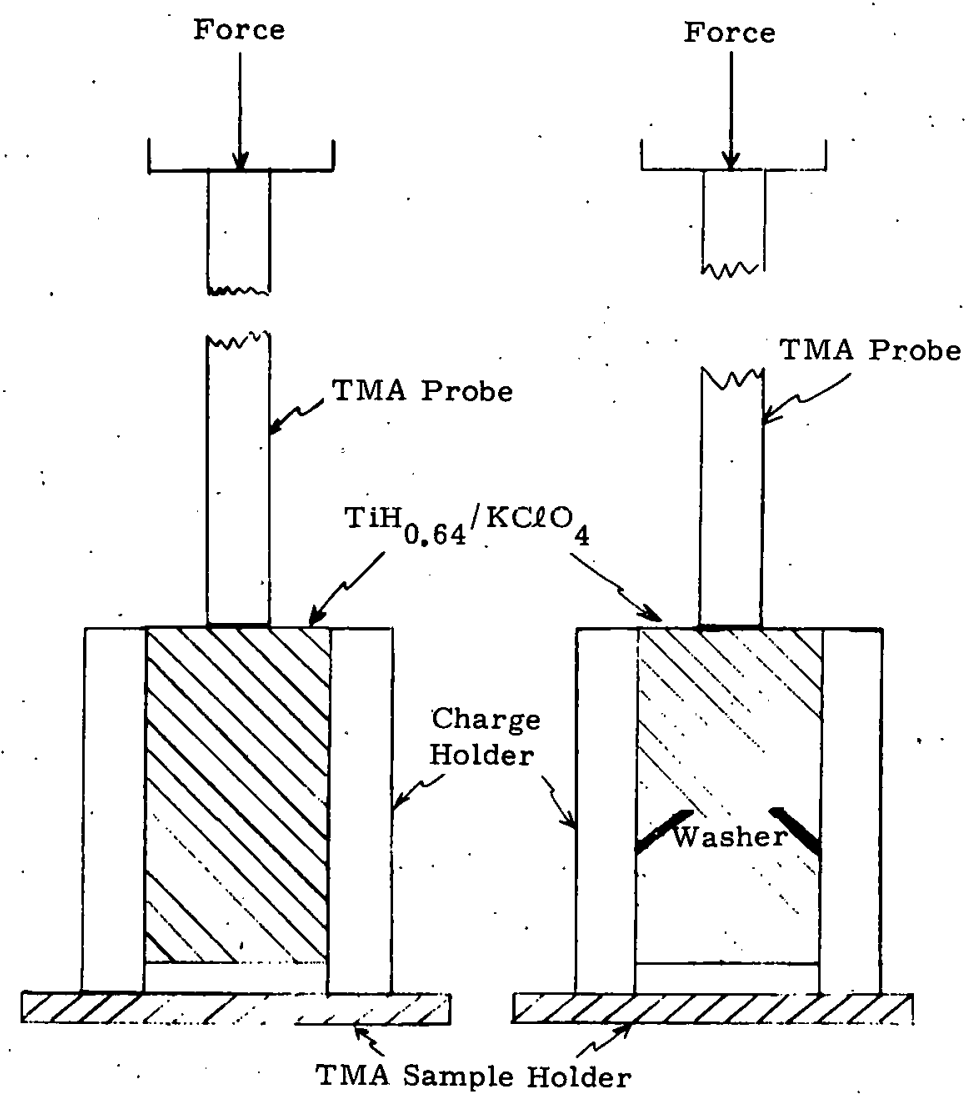

Fig. $80-$ Expansion Coefficient $\times 10^{-6} /{ }^{\circ} \mathrm{C}$

$-50^{\circ} \mathrm{C}$ to $0^{\circ} \mathrm{C} \quad 0^{\circ} \mathrm{C}$ to $50^{\circ} \mathrm{C} \quad 50^{\circ} \mathrm{C}$ to $100^{\circ} \mathrm{C} \quad 100^{\circ} \mathrm{C}$ to $150^{\circ} \mathrm{C}$

$\mathrm{TiH}_{0.65} / \mathrm{KClO}_{4}$ Pellet $\quad 33 \cdots \quad 43 \quad 50 \quad 55$

Pressed at $10 \mathrm{kpsi}$

Epoxy Charge Holder Length Expanxion

21

20

21

24

Epoxy Charge Holder

21

20

21

22 


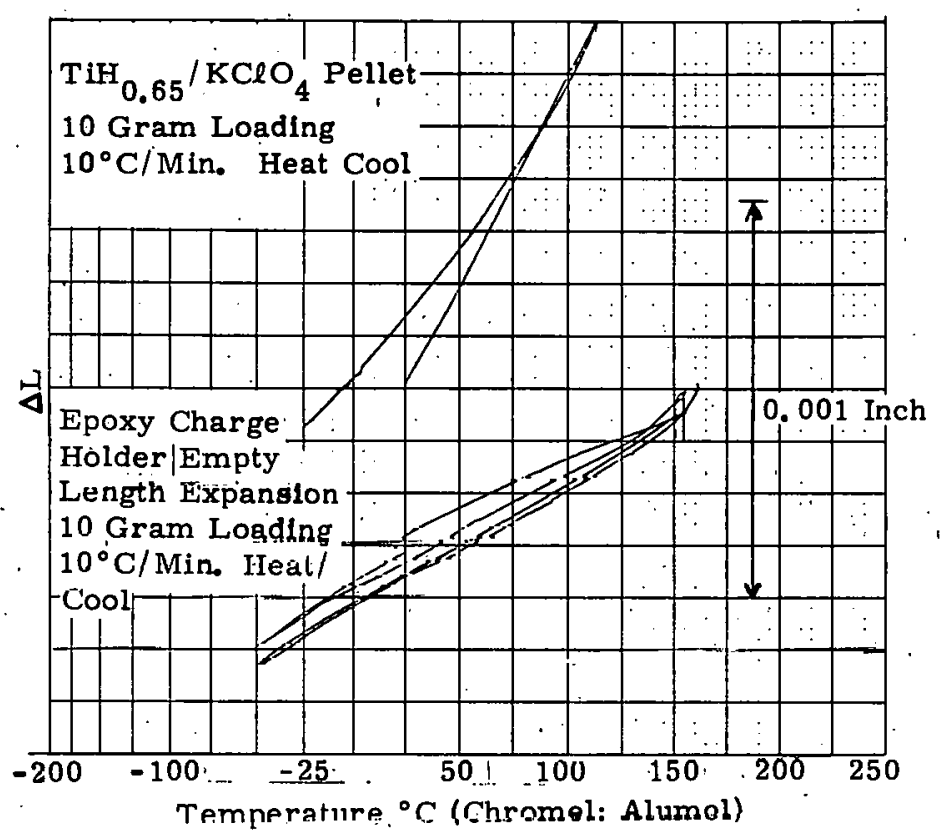

Fig. 82 -

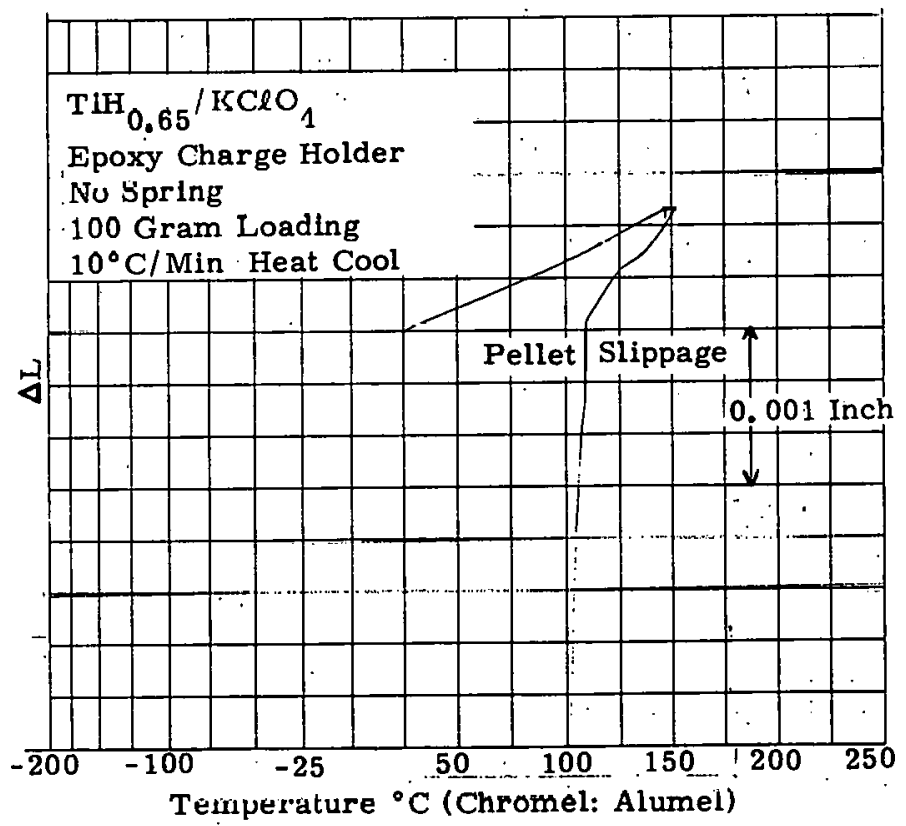


Fig. 83 -

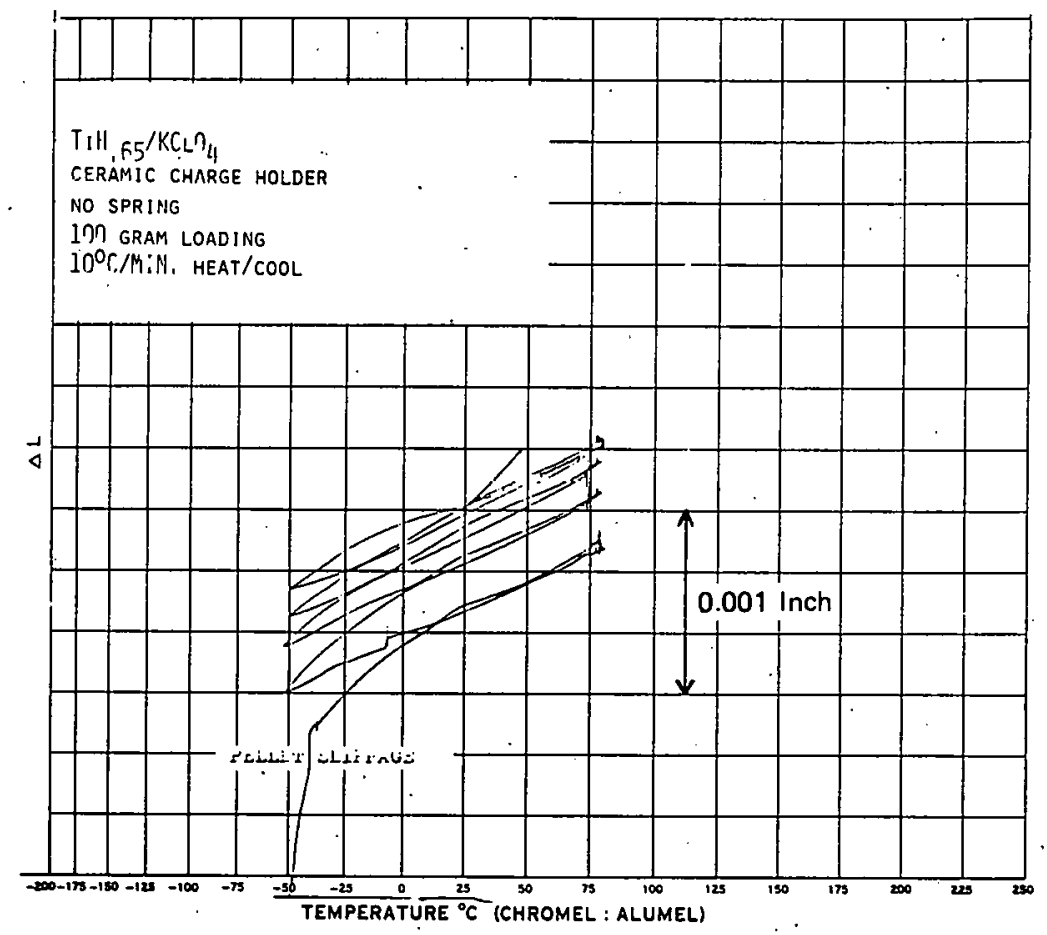

Fig 84 -

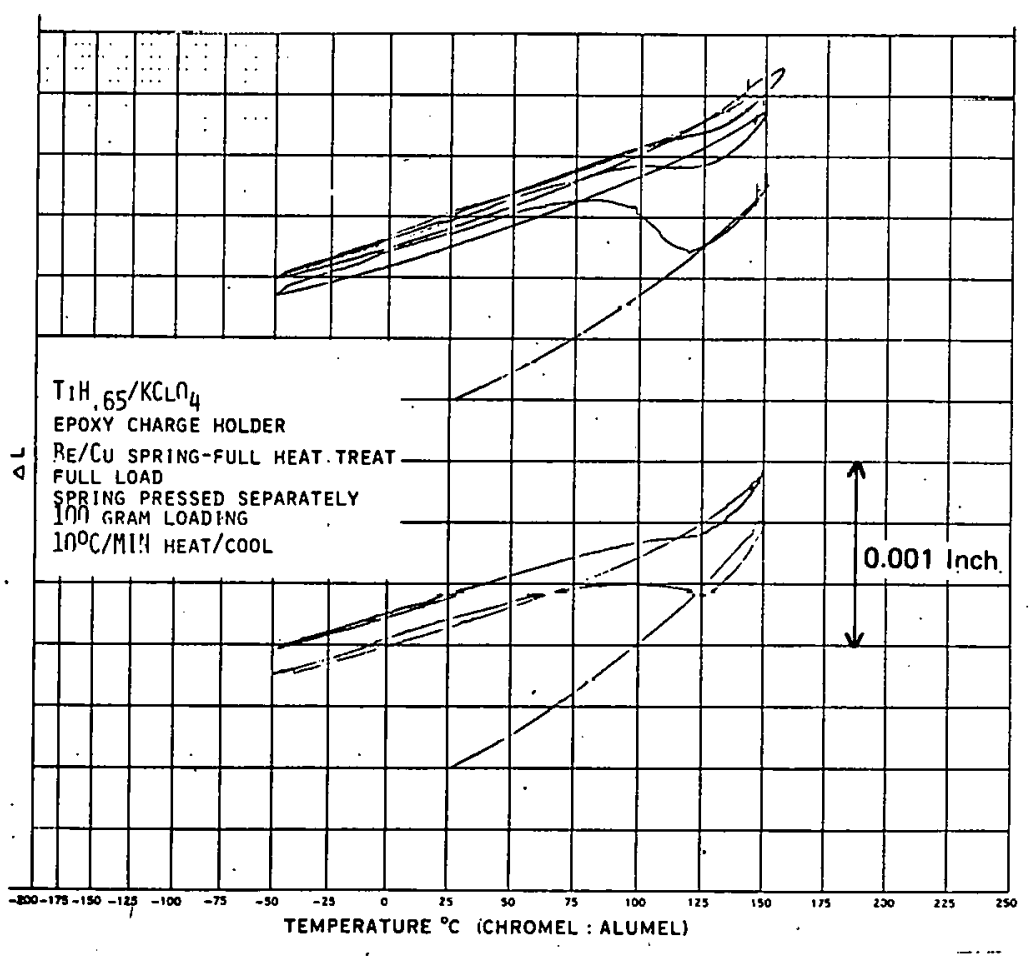


Fig. 85 -

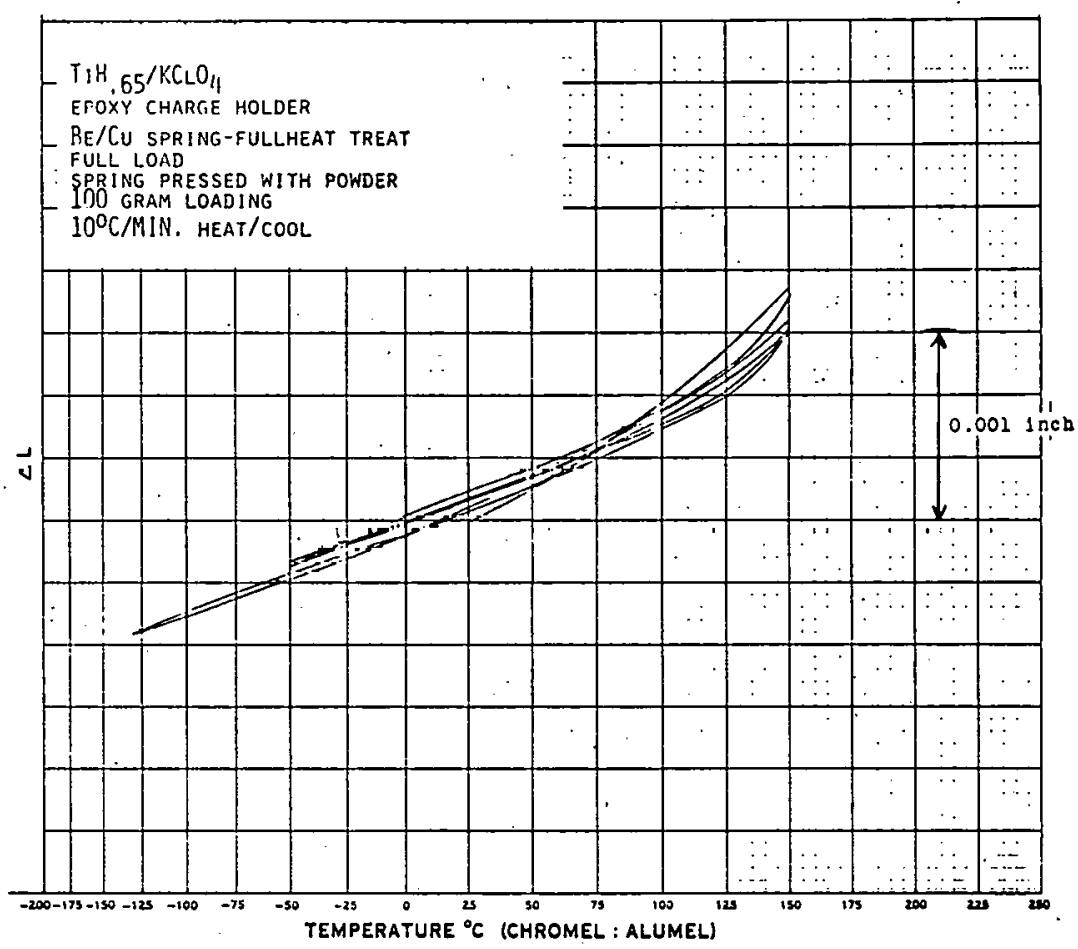

Fig. 86 -

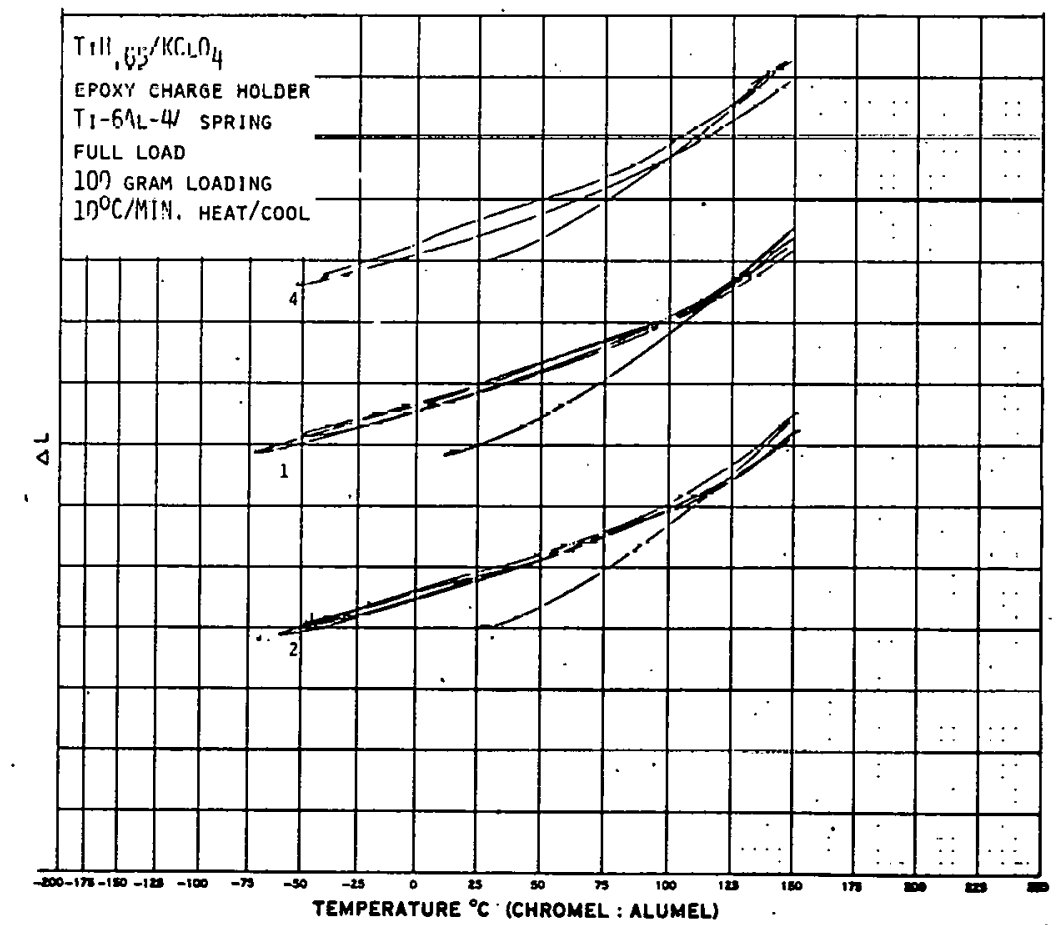


Fig. 87 -

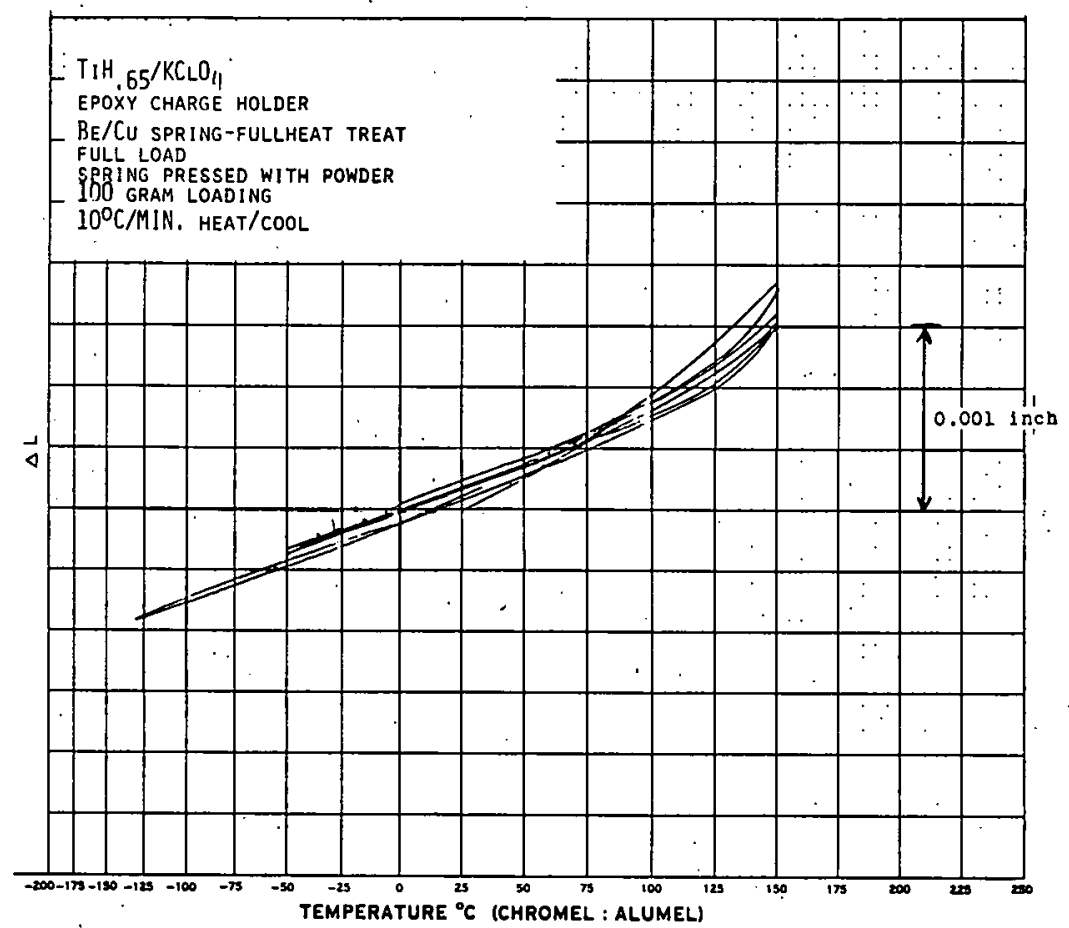


FIGS. 88-101 - VIEWGRAPHS FROM PRESENTATION BY L. W. COLLINS 
Fig. 88 - Moisture Content of $\mathrm{Ti} / \mathrm{KClO}_{4}$

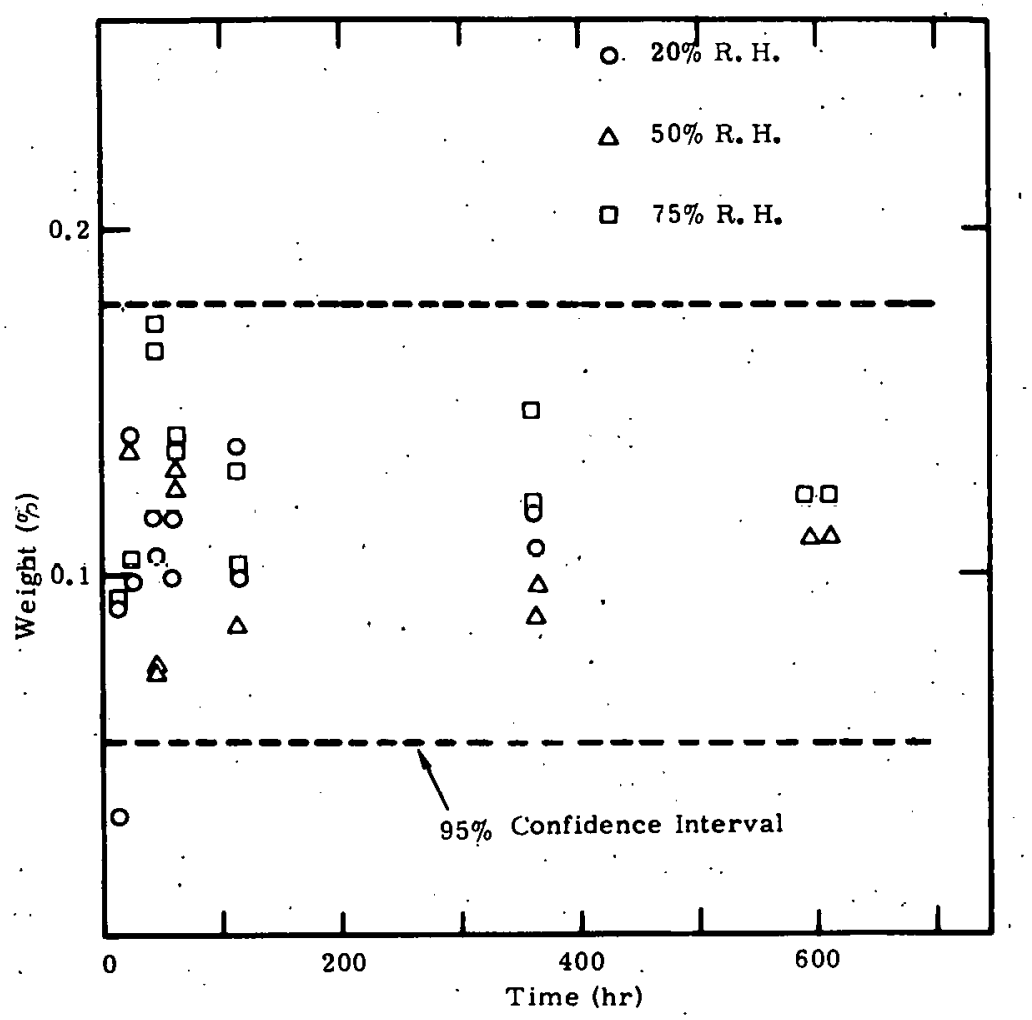

Fig. 89 - Moisture Content of $\mathrm{TiH}_{0.65} / \mathrm{KClO}_{4}$

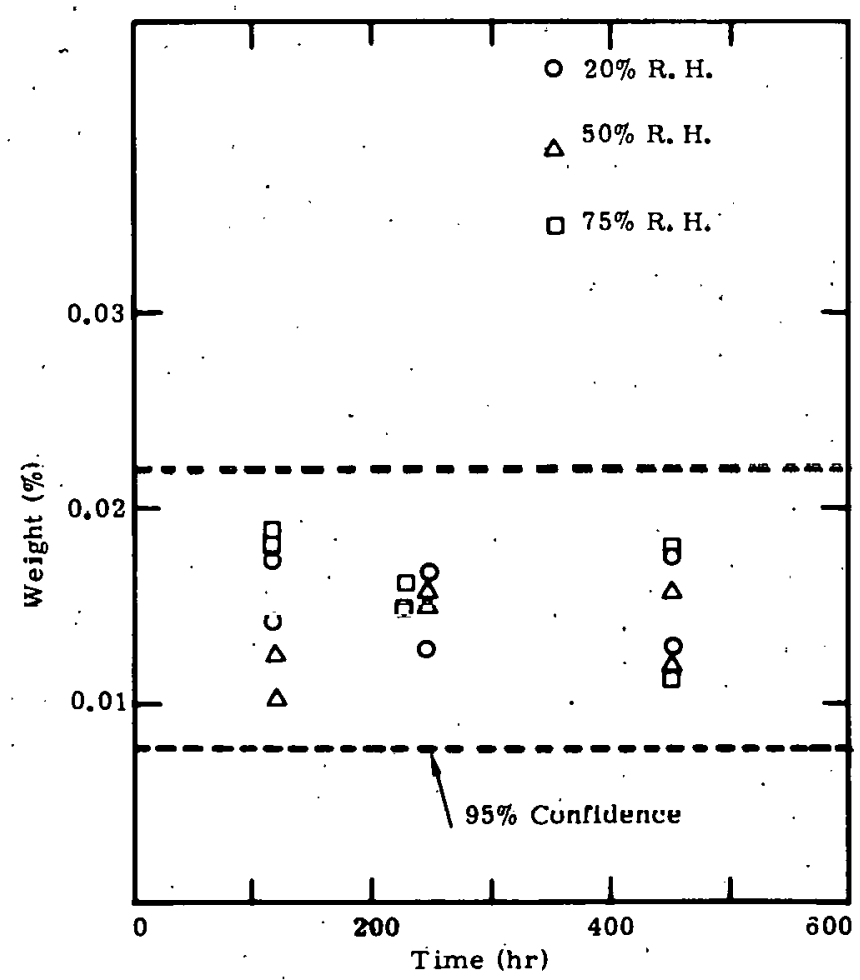


Fig. 90 - Chloride Content of $\mathrm{Ti} / \mathrm{KClO}_{4}$

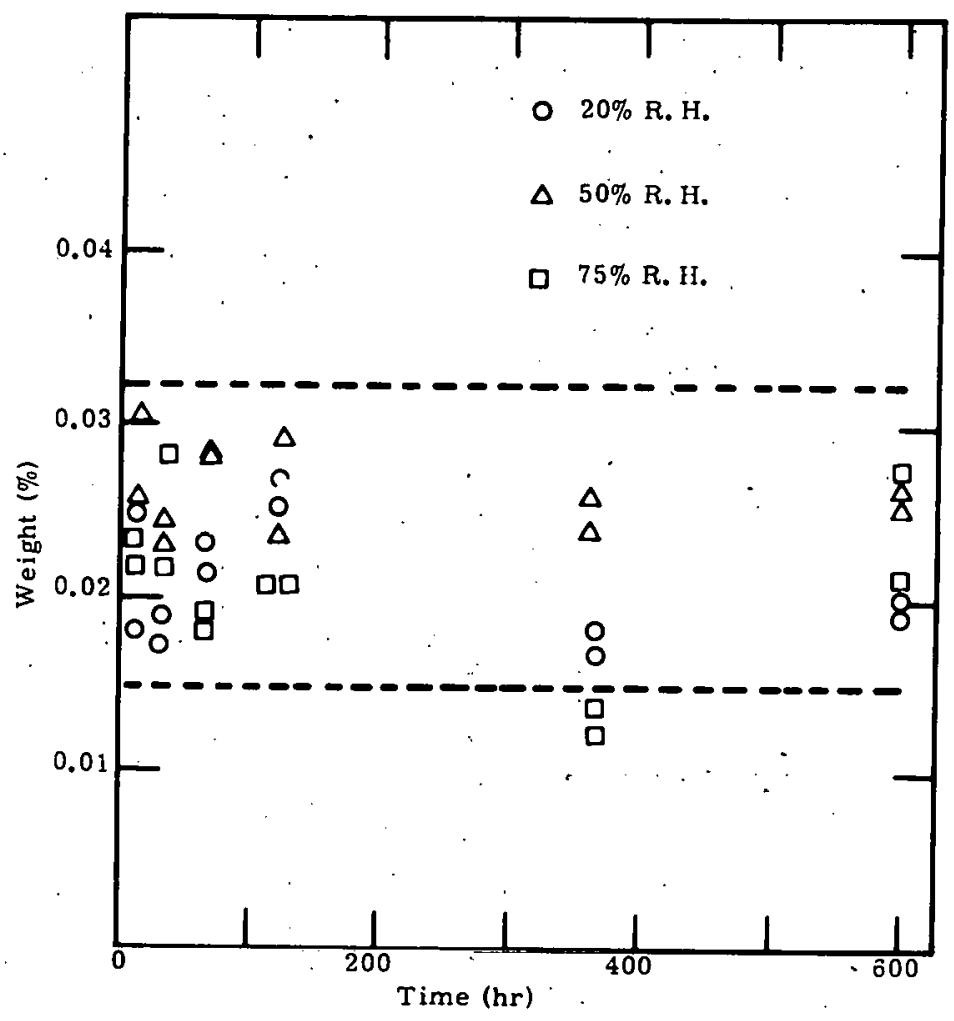

Fig. 91 - Chloride Content of $\mathrm{TiH}_{0.65} / \mathrm{KClO}_{4}$

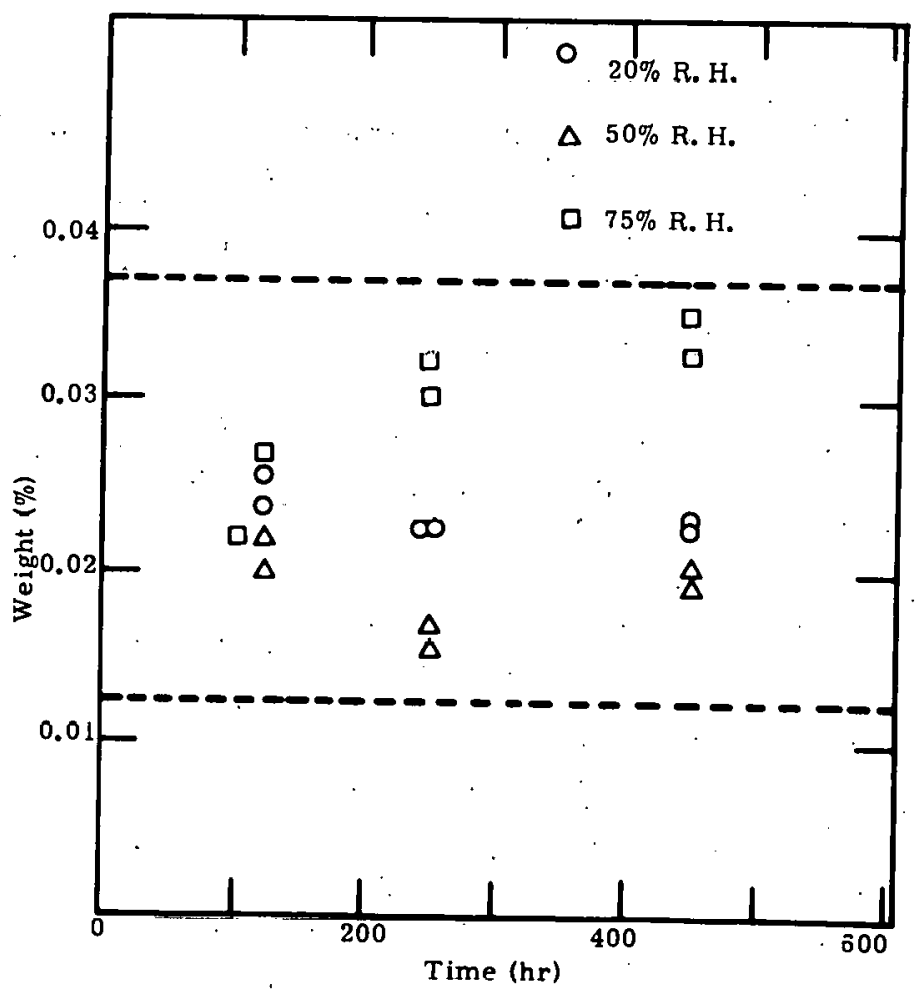


- No Statistically Significant Increase in the Moisture or Chloride Content of $\mathrm{Ti} / \mathrm{KClO}_{4}$ or $\mathrm{TiH}_{0.65} / \mathrm{KClO}_{4}$.

- Blends Exposed to Relative Humidities from $25 \%$ to $75 \%$ for Periods Up to 1 Month.

Fig. 93 -

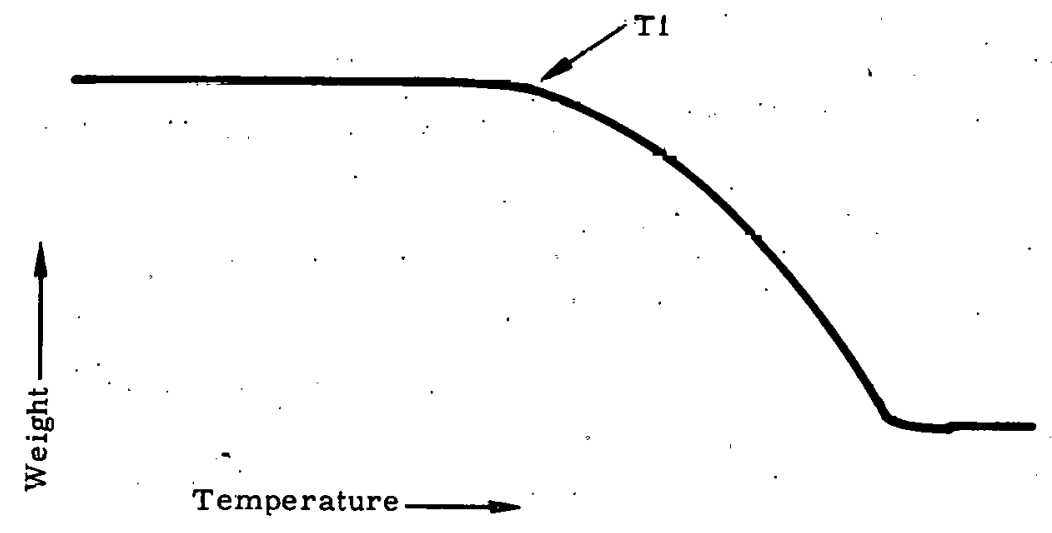

- "Decomposition temperature" was determined from the temperature of initial deflection of TG curves.

- T'i values were extrapolated to a zero heating rate by nonlinear La Grangian extrapolation.

- $\Delta \mathrm{Ti}=\mathrm{TiKClO}_{4}-\mathrm{TIKClO}_{4}+$ IVİetál Uxide 


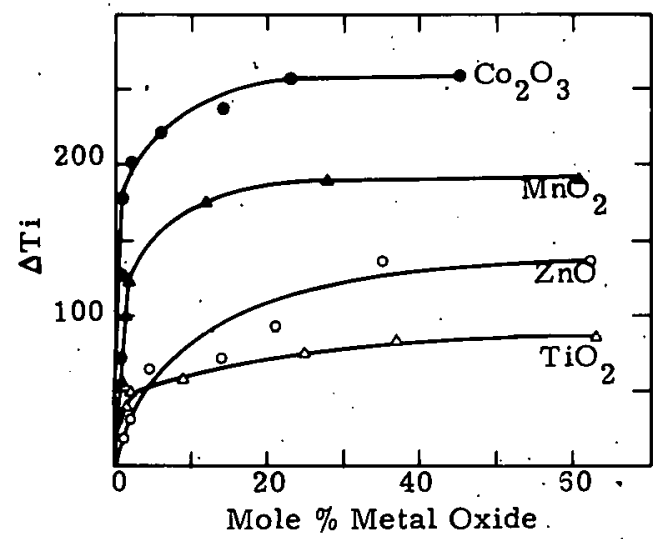

- The catalytic efficiency varies with the oxide used.

- Less than $0.001 \%$ of metal oxides such as $\mathrm{Co}_{2} \mathrm{O}_{3}$ can perceptibly alter the decomposition temperature of $\mathrm{KClO}_{4}$ by more than $25^{\circ} \mathrm{C}$.

Fig. 95 -

Kinetics Calculations Based Upon the Following Assumptions:

- Decomposition reaction can be characterized by $\mathrm{KClO}_{4} \rightarrow \mathrm{KCl}+2 \mathrm{O}_{2}$

Decomposition rate is slow enough that self heating is negligible.

Decomposition : reaction obeys first-order kinetics law.

Fig. $96-$

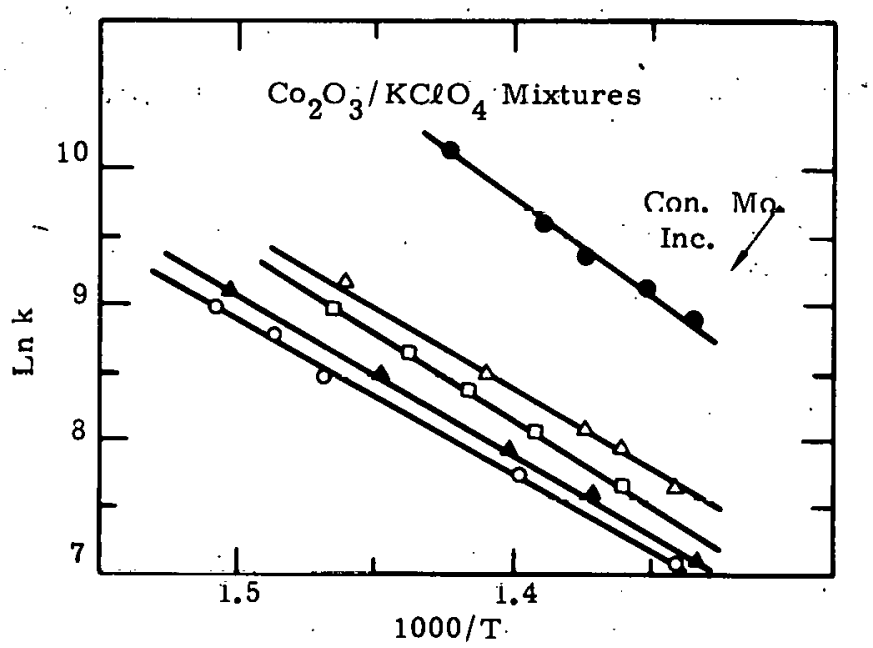

- Variation in the quantity of metal oxide shifts the preexponential factor.

- A correlation coefficient of 0.99 was obtained for the least-squares fit of the data. 
Fig. 97 -

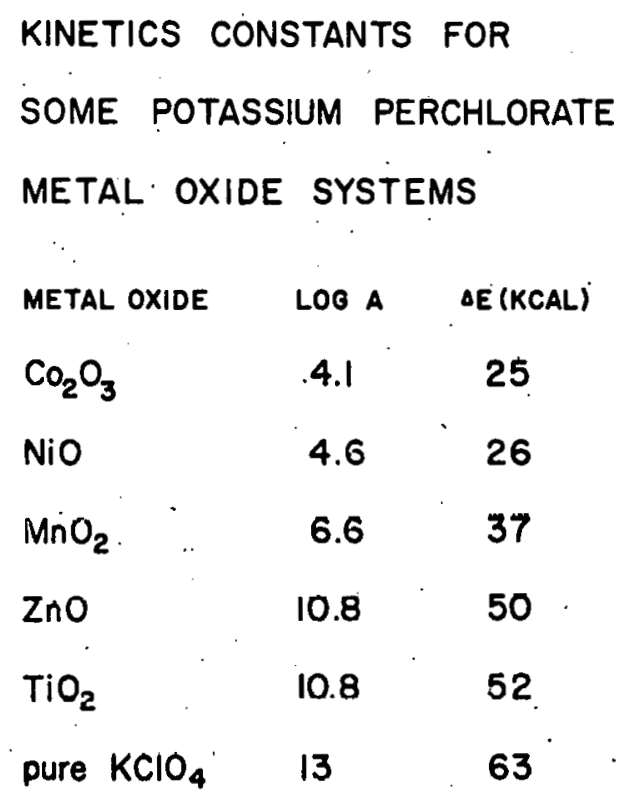

Fig. 98 -

Conclusions:

1. Trace quantities of metal oxides produce large decreases in the activation energy of decomposition of not.assinm perchlorate.

a. Extrapolation to room temperature gives a negligible rate.

b. $P$-lype bemlconductors are generally better catailysts than Na:type.

2. $\mathrm{TiO}_{2}$ has a relatively small effect on the decomposition of $\mathrm{KClO}_{4}$

3. Catalytic effects might influence performance more than longterm stability. 
Fig. $" 99-\mathrm{TiH}_{0.65} / \mathrm{KClO}_{4}$ Stability Study Extends From January to November 1977

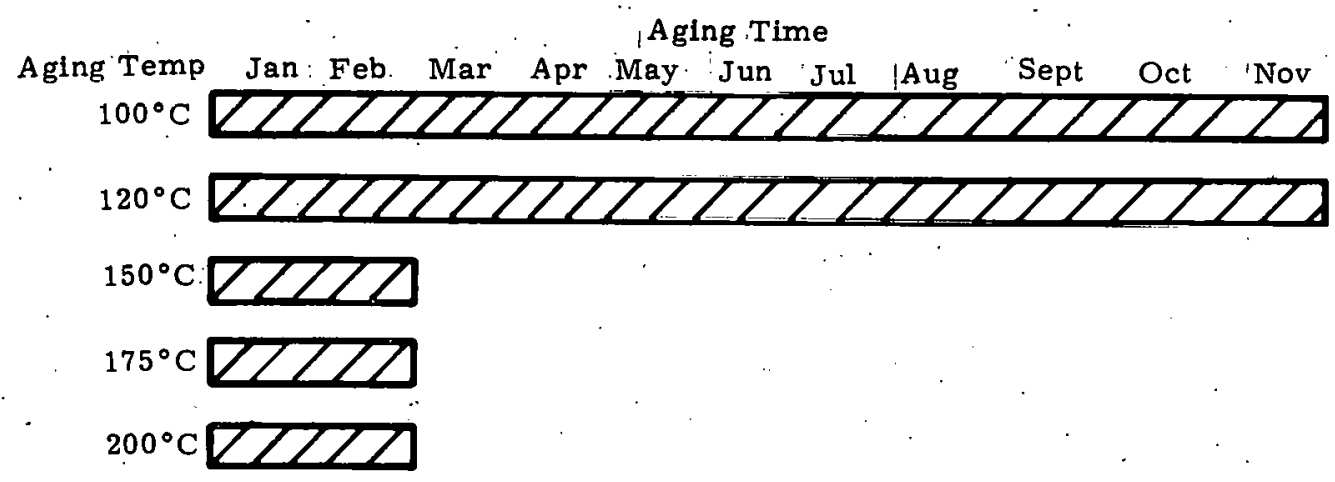

Fig. 100 -

The feasibility of using Chemiluminescence for compatibility/stability studies is being investigated
$A+B \rightarrow C+h v$
$D \rightarrow$ pdts + hv

Chemiluminescence, light emitted during some chemical reactions; can be used to infer the nature of the reaction.

Fig. 101 -

Possible advantages of using Chemiluminescence for compatibility/ stability studies

1. Very slow reaction rates can be measured -- rates as low as $10^{-14}$ moles/year reported

2. Measurements made inhours vs. years required for present techniques

3. Measurements made at room temperature rather than at elevated temperature

4. Low cost equipment -- $\$ 5 \mathrm{~K}$ to $\$ 10 \mathrm{~K}$ 
FIGS. 102-109 - VIEWGRAPHS FROM PRESENTATION BY A. C. MUNGER 
- Compared 150 va: $170 \mathrm{mll}$ I. D. charge holders

- Compared ceramlc vä. epoxy charge holders

- Evaluated effects of surface finlah on compaction

- Evaluated pushout forces for loaded charge holders.

Fig. 103 -

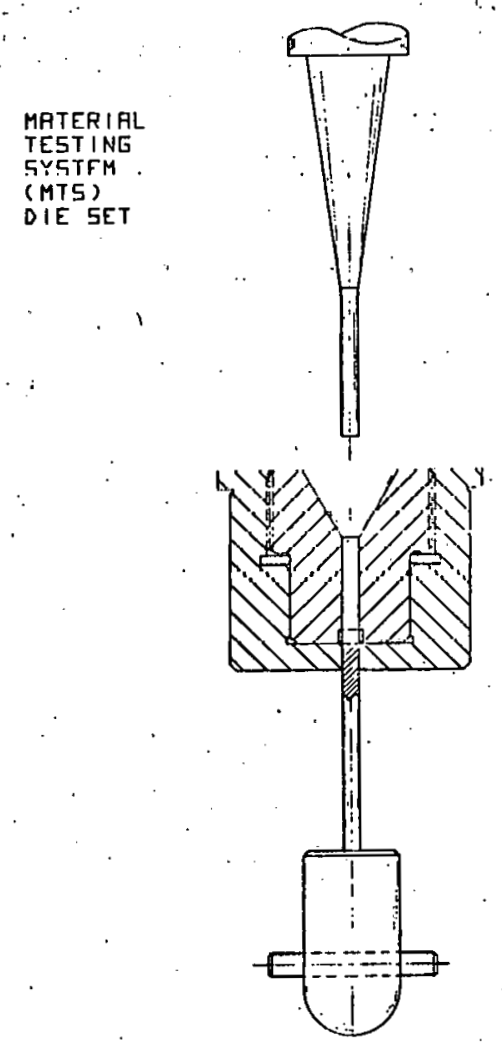


Fig. 104 -

Typical MTS Force Analog

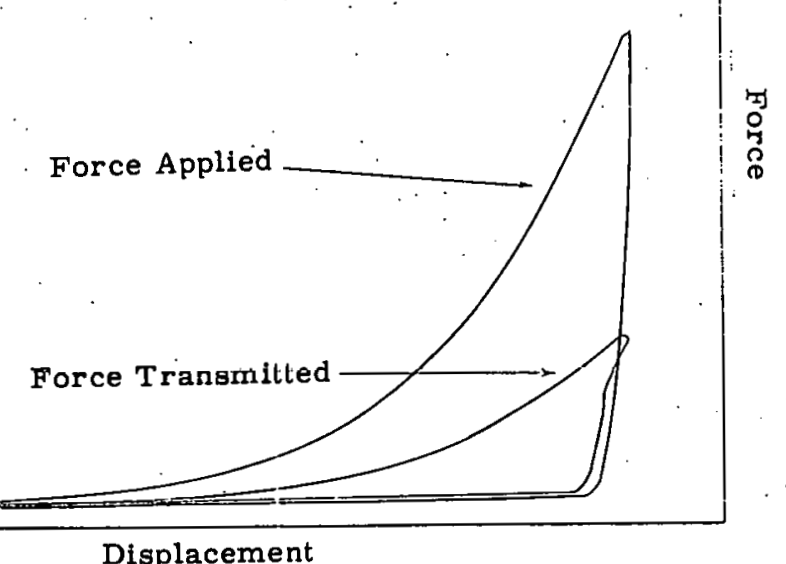

Fig. 105 - Compaction in Various Charge Holders

\begin{tabular}{|c|c|c|c|}
\hline $\begin{array}{c}\text { Charge } \\
\text { Holder } \\
\text { Diameter } \\
\text { (mil) } \\
\end{array}$ & $\begin{array}{c}\text { Force } \\
\text { Transmitted } \\
\text { Ratio } \\
(\%) \\
\end{array}$ & $\begin{array}{l}\text { Surface } \\
\text { Finish } \\
\mu \text { in. (RMS) }\end{array}$ & Charge Holder \\
\hline 150 & 50 & 4 & Molded Plastic \\
\hline 170 & 60 & 4 & Molded Plastic \\
\hline 150 & 28 & 64 & Ceramic \\
\hline 170 & 30 & 64 & Ceramic \\
\hline 170 & 33 & 64 & Molded Plastic \\
\hline
\end{tabular}

Fig. 106 - Comparison of Compaction

\begin{tabular}{lcccl} 
Batch & $\begin{array}{c}\text { Force Trans. } \\
\text { Ratio } \\
(\%)\end{array}$ & & $\begin{array}{c}\text { Density } \\
\left(\mathrm{mg} / \mathrm{m}^{3}\right)\end{array}$ & Charge Holder \\
\cline { 2 - 2 } & 29 & & & \\
P03094 & 31 & & 1.82 & Ceramic \\
P02040 & 28 & & 2.02 & Ceramic \\
P03094 & 33 & 1.83 & Molded Plastic \\
& & & 2.15 & Molded Plastic
\end{tabular}




\section{PO3094}

$33 / 67$ blend of $1787 \mathrm{ET}$ and $1759 \mathrm{ET}$

1787ET particle size $\left(C^{3}\right)$

$0.9 \mu$

particle size zeiss

3. $7 \mu$

BET surface area

$1.1 \mathrm{~m}^{2} / \mathrm{gm}$

1759ET particle size zeiss

$7.6 \mu$

BET surface area

$0.2 \mathrm{~m} 2 \% \mathrm{~g}$

\section{PUZO40}

$33 / 37$ blend of $1675 \mathrm{ET}$ and $1759 \mathrm{ET}$

$1675 \mathrm{ET}$ particle size $\left(\mathrm{C}^{3}\right)$

$0.9 \mu$

BET surface area

$8.1 \mathrm{~m}^{2} / \mathrm{g}$

Fig. 108 - Planned Material Analysis

- Characterize effect of particle size on compaction

- Characterize effects of surface area/topography on compaction

- Evaluate particle size ratios between fuel and oxidizer

- Necord force relaxation after compaction

- Kecơd lórces généráted during temperature changes.

Fig. 109 - Future Plans

- Temperature control of die

- More accurate measurement of displacement

- Bridgewire resistance monitoring during compaction

- HP-9825 data acquisition system

- HP-9825 process control 


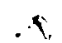

FIGS. 110-115 - VIEWGRAPHS FROM PRESENTATION BY W. E. SWARTZ 
Fig. 110 - Initial Rates of Sulfur Segregation for Lot 16 Iron

\begin{tabular}{|c|c|c|}
\hline $\mathrm{T}\left({ }^{\circ} \mathrm{C}\right)$ & $1000 / \mathrm{T}\left(\mathrm{K}^{-1}\right)$ & $\mathrm{Vi}$ \\
\hline 200 & 1.486 & $8.2 \times 10^{-4}$ \\
\hline 500 & 1.294 & $2.0 \times 10^{-3}$ \\
\hline 600 & 1. 145 & $9.28 \times 10^{-3}$ \\
\hline 700 & 1.028 & $4.93 \times 10^{-2}$ \\
\hline
\end{tabular}

Fig. 111 -

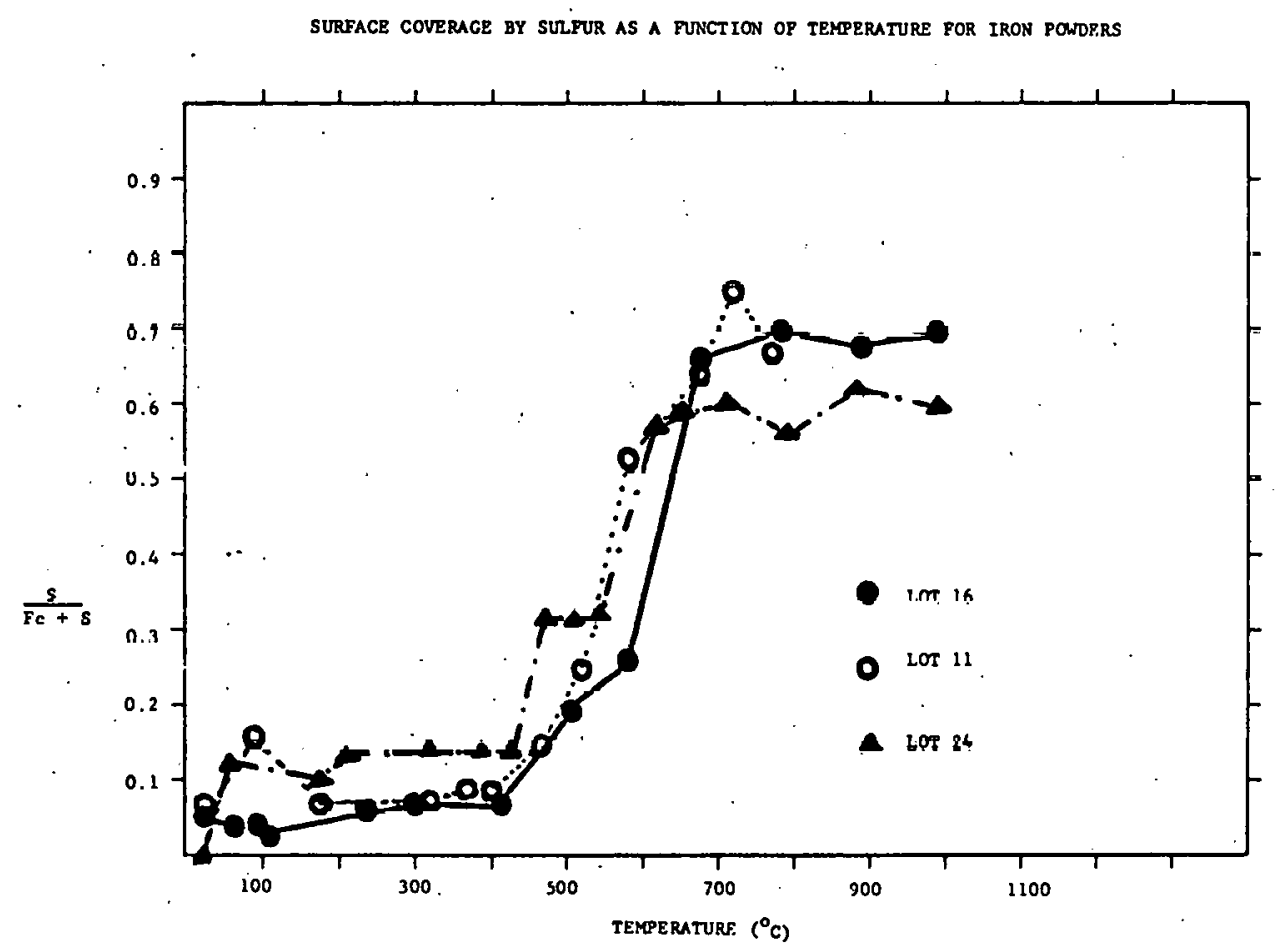


Fig. 112 -

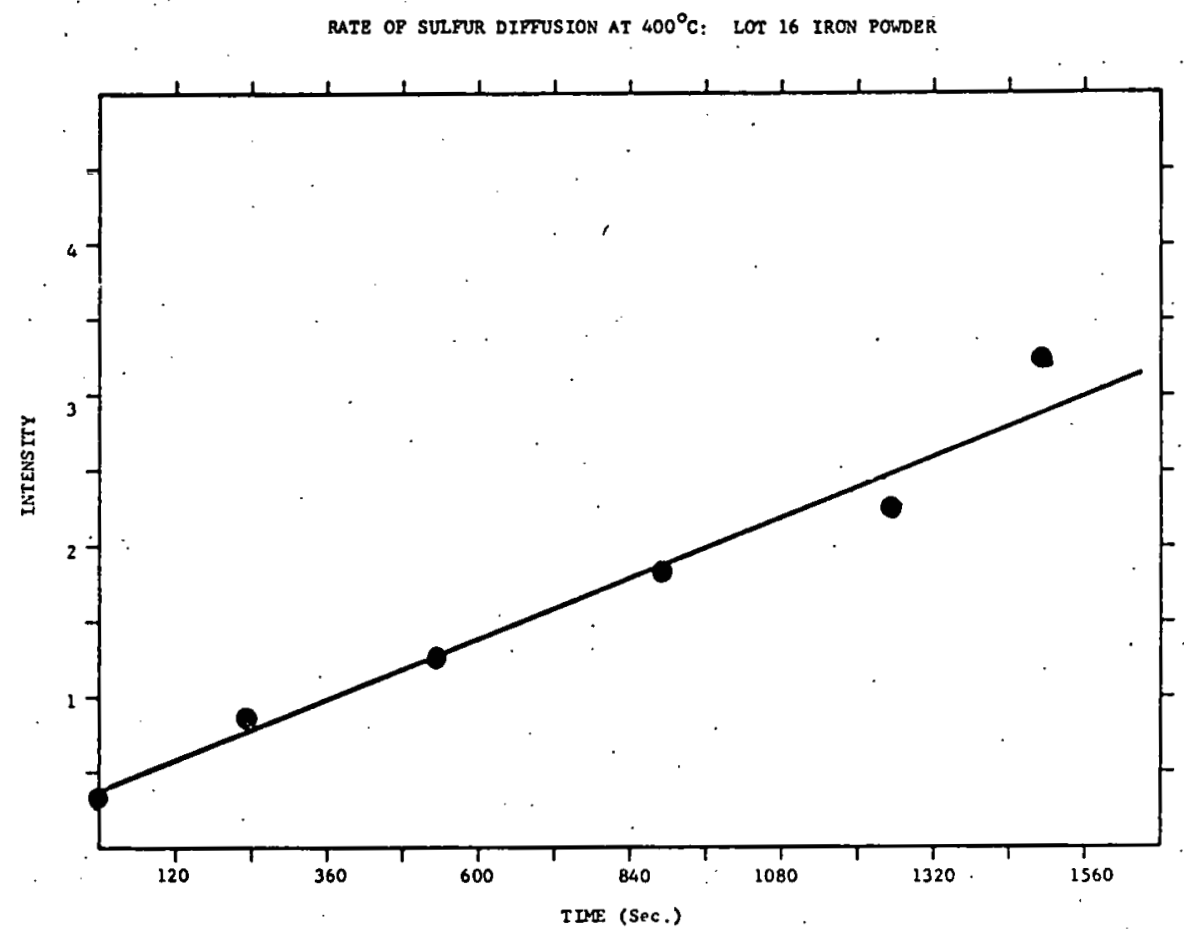

Fig. 113 -

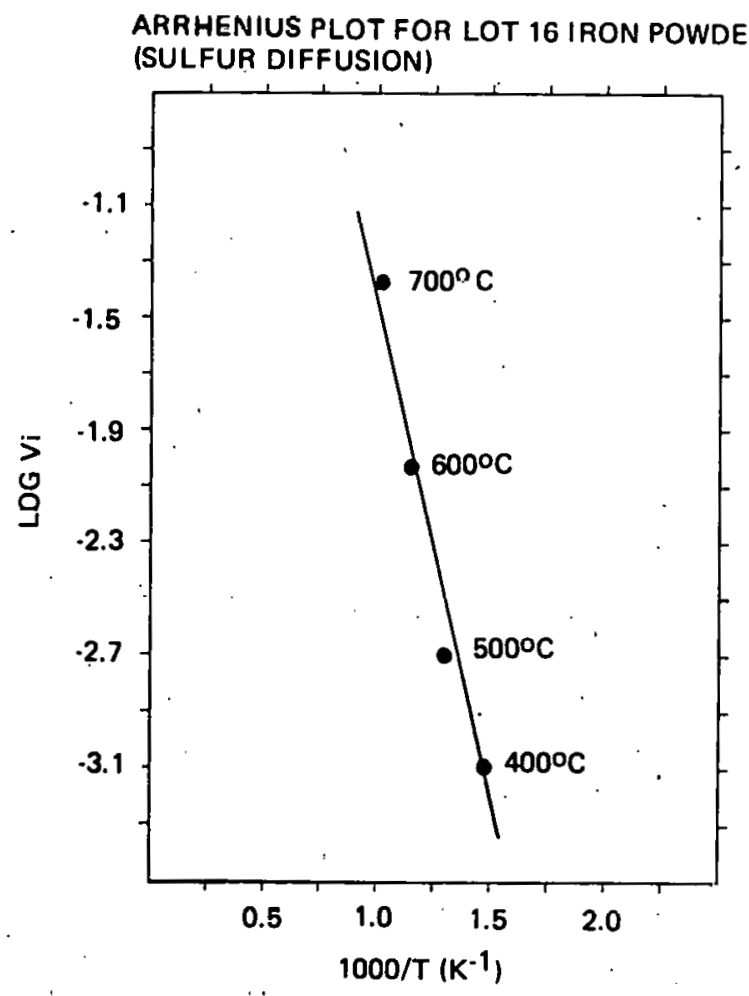


Fig. 114 -

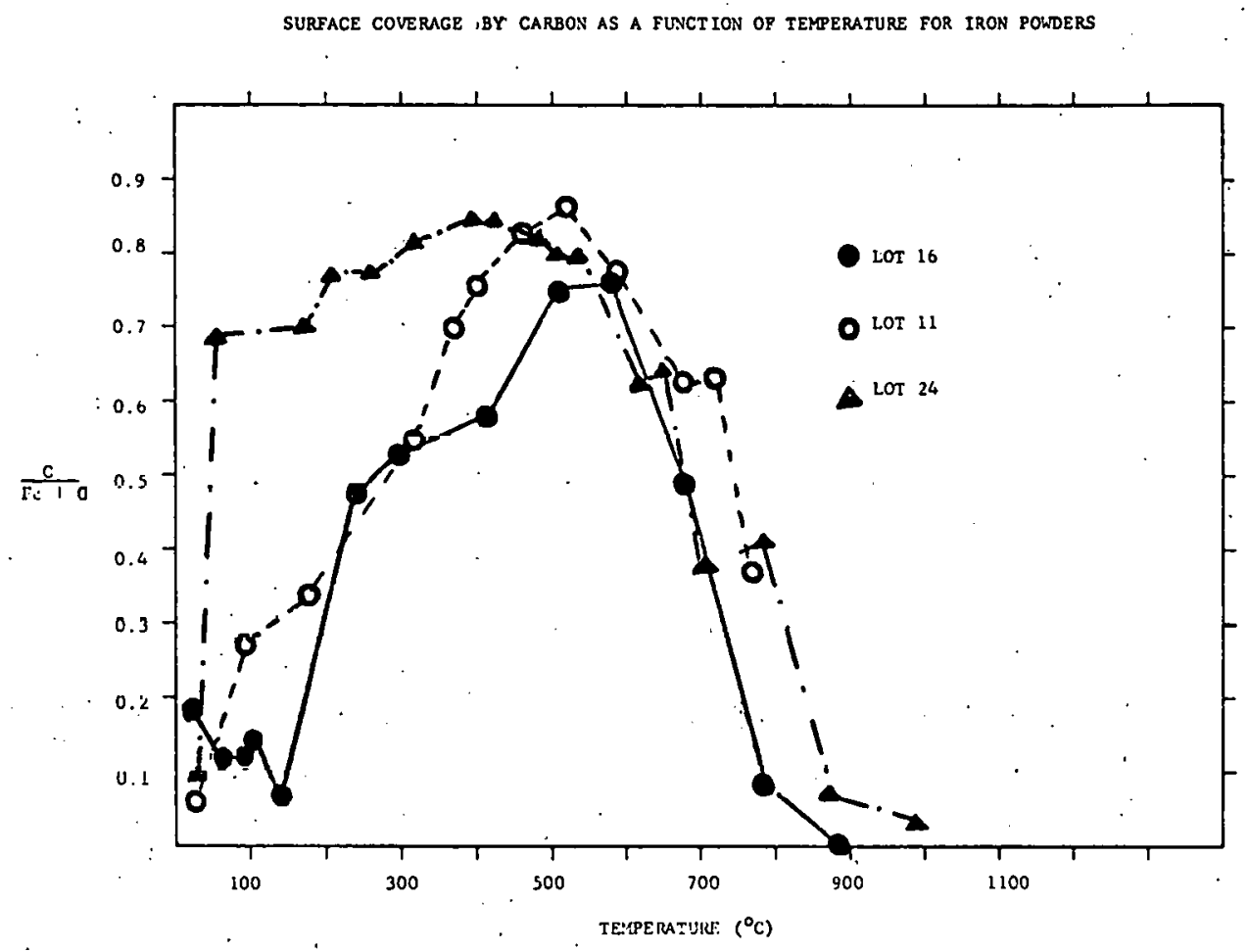

Fig. 115 -

RGA DATA POR LOT 16 IRON PONDER

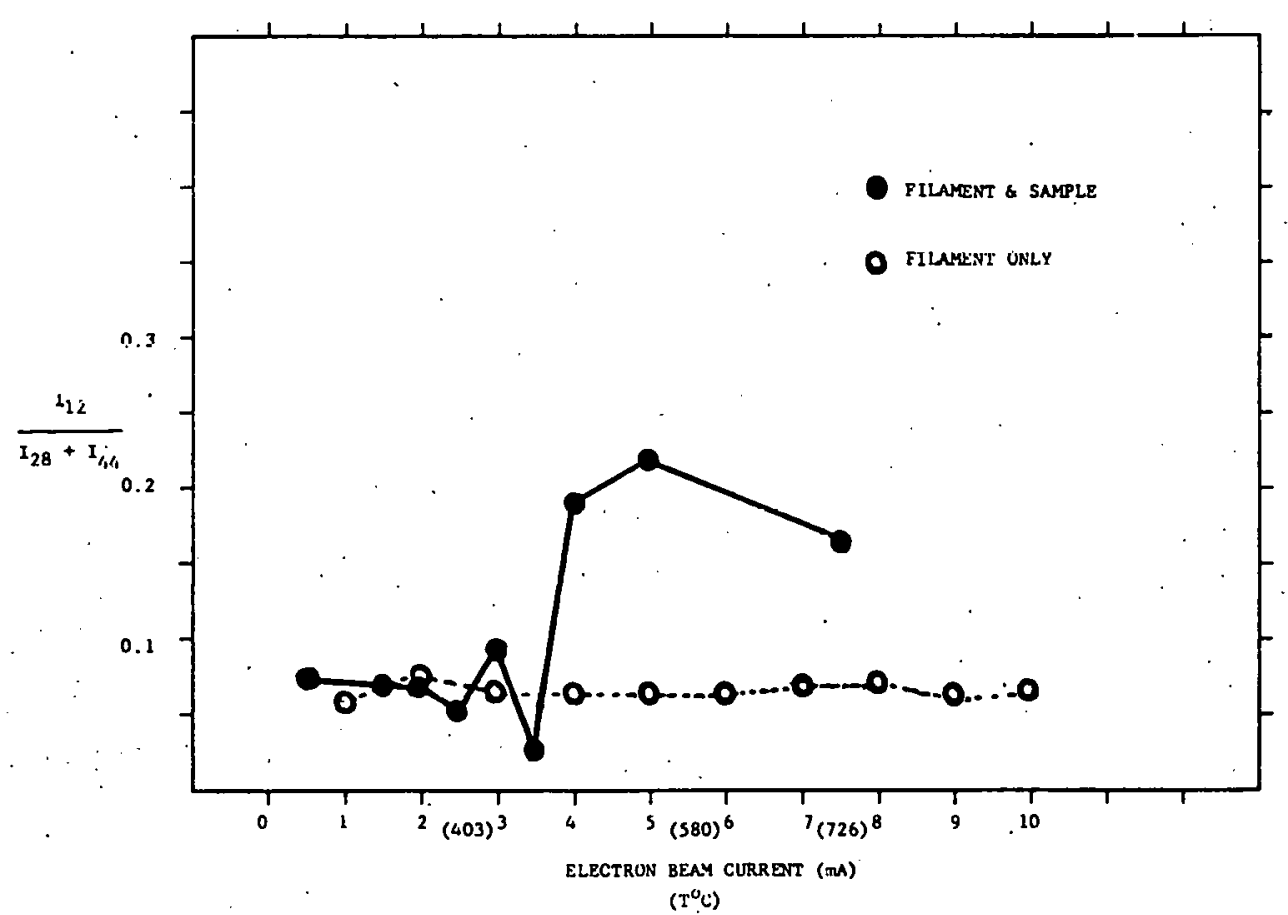

$\left(T^{\circ}, C^{\circ}\right)$ 
FIGS. 116-122 - VIEWGRAPHS FROM PRESENTATION BY A. B. DONALDSON

$\cdot($

?

$\therefore$

$\cdots$ 
Flg. 116 -
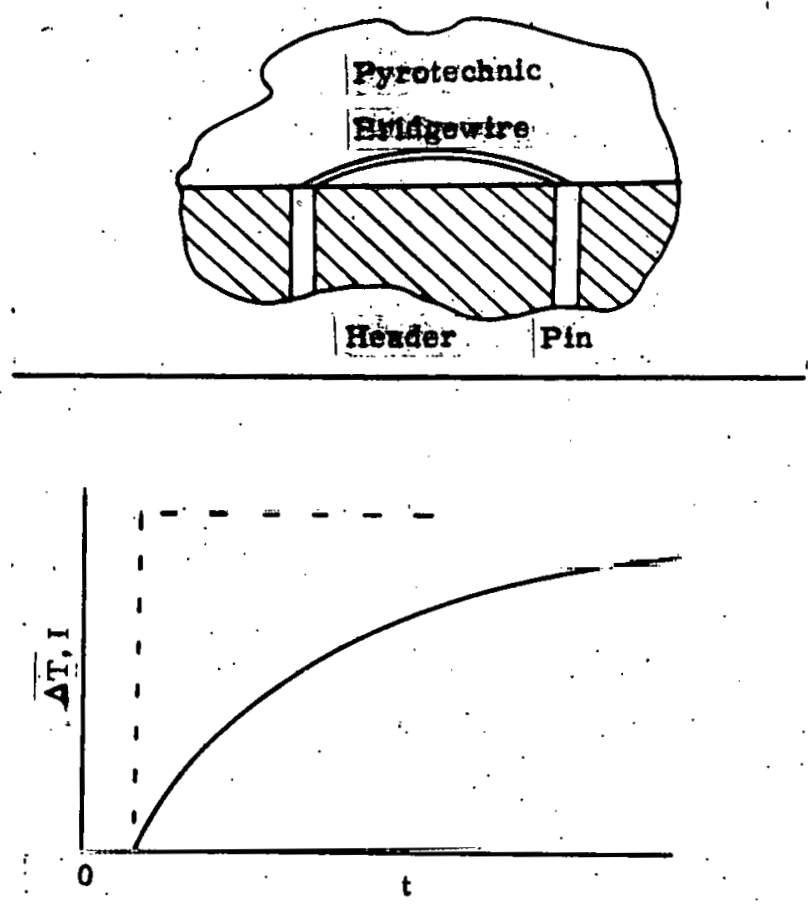

Fig. 117 -

Differential Equation

$$
\frac{1}{r} \cdot \frac{\partial}{\partial r}\left(r \frac{\partial T}{\partial r}\right)+\frac{\rho q z}{k} e^{-E a / R T}=\frac{1}{\alpha} \frac{\partial T}{\partial t} \cdot\left\{\begin{array}{l}
a<r<\infty \\
t>0
\end{array}\right.
$$

Boundary Conditions

$$
\begin{aligned}
& \pi \alpha^{2} \hat{\rho} \hat{c} \frac{d \hat{T}}{d t}=\frac{I^{2} R}{\Pi g^{2}}-\left.2 \Pi a k \frac{\partial T}{\partial r}\right|_{a} \quad\left\{\begin{array}{l}
r=a \\
t>0
\end{array}\right. \\
& \mathbf{T}=\left.\mathbf{T}\right|_{\mathbf{r}=\mathbf{a}} \\
& \left\{\begin{array}{l}
r=a \\
t>0
\end{array}\right. \\
& \left\{\begin{array}{l}
r+\infty \\
t>0
\end{array}\right.
\end{aligned}
$$

\section{Initial Conditiong}

$$
T=\hat{T}=T i
$$


Fig. 118 -

$$
\begin{gathered}
\quad t \rightarrow t_{i n g},\left.\frac{\partial^{2} T}{\partial r^{2}}\right|_{a},\left.\frac{\partial T}{\partial r}\right|_{a} \rightarrow 0 \\
\therefore \frac{d \hat{T}}{d t}=\left.\frac{\partial T}{\partial t}\right|_{a} \text { at } t=t_{i g n .} \\
\Rightarrow \quad \frac{q z}{c} e^{-E a / R T^{*}}=\frac{I^{2} R}{\Pi^{2} a^{4} \hat{p} \hat{c}} \\
\left.\Rightarrow T^{*}\right|_{a}=\frac{E a / R}{\left(\ln \frac{\Pi^{2} a^{4} \hat{\rho} \hat{c} q z}{I^{2} R}\right)} .
\end{gathered}
$$

Fig. 119 -

$$
\begin{aligned}
t_{\text {ign }}= & t_{\text {inert }}+t_{\text {ad. expl. }} \\
\simeq & t_{\text {inert }} \\
t_{\text {inert }}= & f^{-1}\left(T^{*}\right) \\
T^{*}= & T i+\frac{2 Q \sigma}{\Pi^{3} k} \int_{0}^{\infty} \frac{\left(1-e^{-u^{2} T}\right) d u}{u^{3} \Delta(u)} \\
\Delta(u)= & {\left[u J_{0}(u)-\sigma J_{1}(u)\right]^{2} } \\
& +\left[u Y_{0}(u)-\sigma Y_{1}(u)\right]^{2}
\end{aligned}
$$

Short Time Approximation

$$
T^{*} \cong T i+\frac{\sigma Q}{z \Pi k}\left\{\tau-\frac{4 \sigma}{3 \sqrt{\pi}} \tau^{3 / 2}\right\}
$$

\section{Long Time Approximation}

$$
T^{*} \equiv T i+\frac{Q}{4 \pi k}\{\ln (4 \tau)-\gamma\}
$$


Fig. 120 -

$$
\dot{0}=1.0
$$

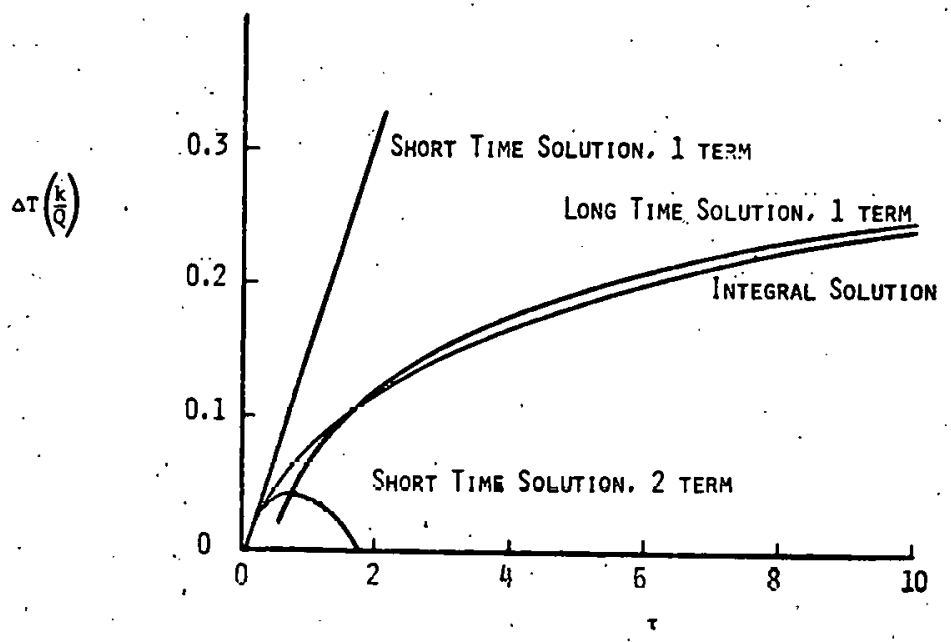

Fig. 121 -

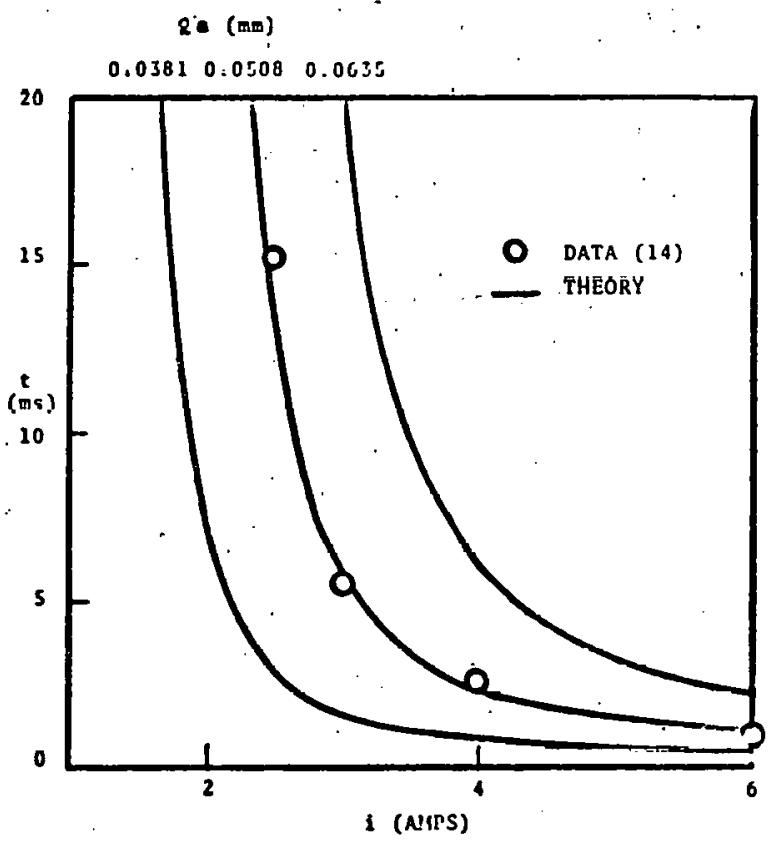


Fig. 122 -

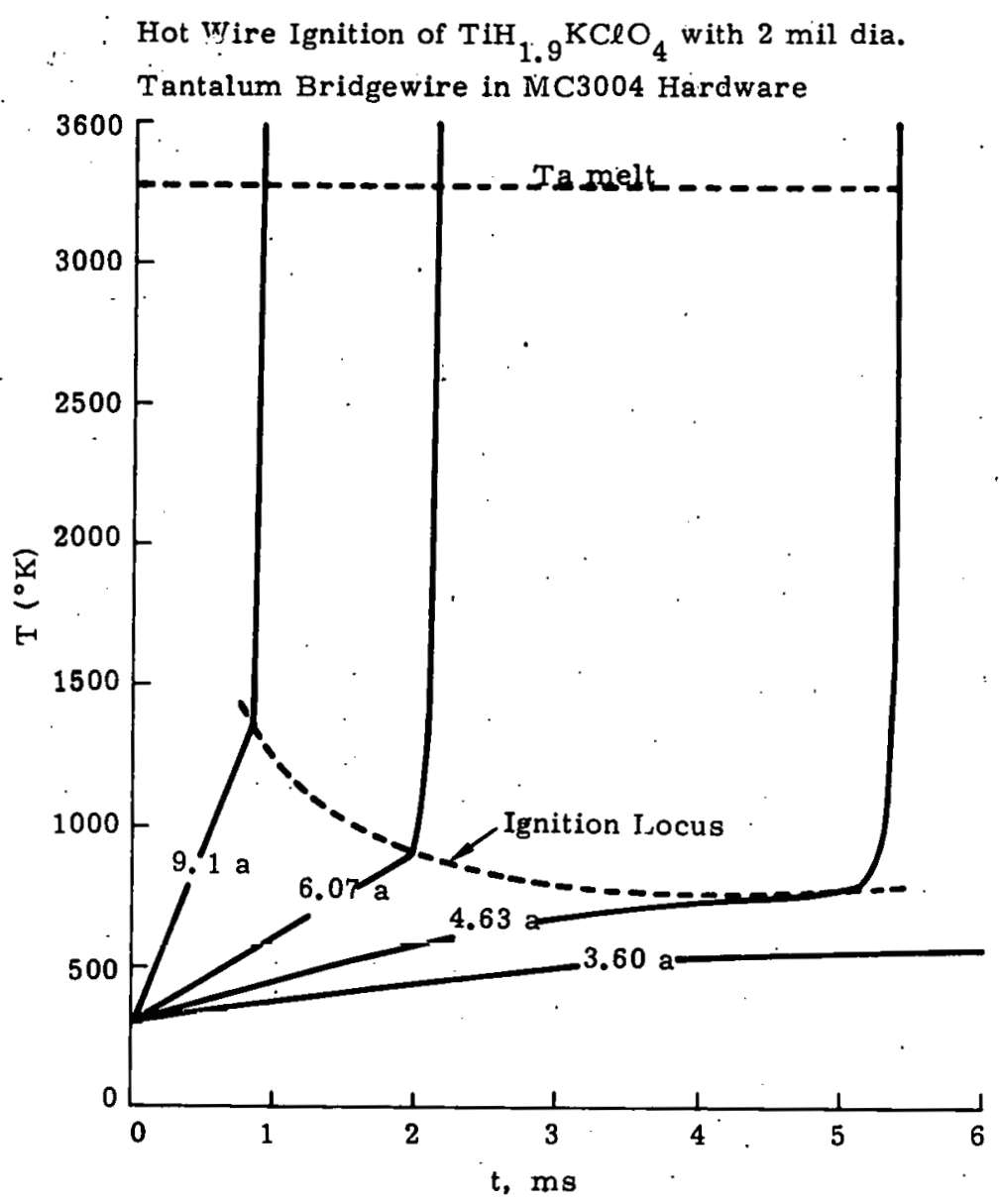


Monsanto Research Corporation (18)

Mound Laboratory

P. O. Box 32

Miamisburg, $\mathrm{OH} 45342$

Attn: R. E. Bowman

-R. J. Braun

J. R. Brinkman

R. S. Carlson

W. J. Cave

L. W. Collins

R. J. DeSando

C. S. Friedman

G. Kettling

C. D. King, Jr.

C. M. Love

A. C. Munger

J. W. ReQd

W. H. Smith

D. B. Sullenger

H. L. Turner

R, E, Vallee

W. G. Yates

$2500 \cdot$ J. C. King

2510 D: H. Anderson

2513. D. B. Hayes, Attn: A. K. Jacobson, 2513

2513 J. G. Harlan

2513 J. E. Kennedy

2514 R. A. Damerow

2515 E. A. Kjeldgaard

2515 M. L. Lieberman

2515 B. R. Steele

2516 N. E. Brown

2516 'I'. M. Massis

2516 P. K. Morenus

2516 P. G. Neiswander

2516 R. K. Quinn

254i G. W. Gobell

Attn: M, M, Robertion, 2511

E. A. Igel, 2541

5150 J. E. Schirber

5800 R. S. Claassen, Attn: R. L: Schwoebel, 5820

5821 R. M. Merrill

5822 R. E. Whan

5825 A. W. Mullendore

Attn: D. M. Haaland, 5825

r. H. Holloway, 5825

G. C. Nelson, 5825

5830 M. J. Davis, Attn: J. L. Jellison, 5833

5840 H. J. Saxton, Attn: R. J. Eagan, 5845

8393 R. $\mathrm{Ng}$

3141 C. A. Pepmueller (Actg) (5)

8266 E. A. Aas (2)

3151 W. L. Garner (3)

For: ERDA/TIC (Unlimited Release)

ERDA/TIC (25)

(R. P. Campbell, 3171-1) 